NBER WORKING PAPER SERIES

\title{
THE GEOGRAPHY OF UNEMPLOYMENT
}

\author{
Adrien Bilal \\ Working Paper 29269 \\ http://www.nber.org/papers/w29269
NATIONAL BUREAU OF ECONOMIC RESEARCH
1050 Massachusetts Avenue \\ Cambridge, MA 02138 \\ September 2021, Revised September 2022
}

This paper is a revised version of the first chapter of my Ph.D. dissertation at Princeton University. I thank my advisors Gregor Jarosch, Richard Rogerson, Esteban Rossi-Hansberg and Gianluca Violante for invaluable guidance and support. I would like to express my gratitude to the editors Robert Barro and Larry Katz, and three anonymous referees, for improving the paper. This paper has benefited from discussions with Mark Aguiar, Lorenzo Caliendo, Damien Capelle, Fabian Eckert, Nik Engbom, Pablo Fajgelbaum, Cécile Gaubert, Gene Grossman, Greg Kaplan, Sam Kortum, Hugo Lhuillier, Adrien Matray, Simon Mongey, Charly Porcher, Xavier Ragot, Steve Redding, Chris Tonetti and Owen Zidar, as well as numerous discussants, seminar and conference participants. I gratefully acknowledge financial support from the Simpson Center for Macroeconomics, the International Economics Section, and the Industrial Relations Section at Princeton University. This work is supported by a public grant overseen by the French National Research Agency (ANR) as part of the "Investissements d'Avenir" program (reference: ANR-10EQPX-17-Centre d'accès sécurisé aux données-CASD). Special thanks to Xavier Ragot and the Observatoire Français des Conjonctures 'Economiques at Sciences Po Paris for offering physical access to the data. The views expressed herein are those of the author and do not necessarily reflect the views of the National Bureau of Economic Research.

NBER working papers are circulated for discussion and comment purposes. They have not been peer-reviewed or been subject to the review by the NBER Board of Directors that accompanies official NBER publications.

(C) 2021 by Adrien Bilal. All rights reserved. Short sections of text, not to exceed two paragraphs, may be quoted without explicit permission provided that full credit, including $(\subseteq$ notice, is given to the source. 
The Geography of Unemployment

Adrien Bilal

NBER Working Paper No. 29269

September 2021, Revised September 2022

JEL No. E20,E24,E60,F16,H21,J42,J61,J63,J64,R13,R23

\begin{abstract}
$\underline{\text { ABSTRACT }}$
Unemployment rates differ widely across local labor markets. I offer new empirical evidence that high local unemployment emerges because of elevated local job losing rates. Local employers, rather than local workers or location-specific factors, account for most of spatial gaps in job stability. I then propose a theory in which spatial differences in job loss emerge in equilibrium because of systematic differences between employers across local labor markets. The spatial allocation of heterogeneous employers in turn follows from their spatial sorting decisions. Labor market frictions induce productive employers to over-value locating close to each other. The optimal policy incentivizes them to relocate towards areas with high job losing rates, providing a rationale for commonly used place-based policies. I estimate the model using French administrative data. The estimated model accounts for over three fourths of the cross-sectional dispersion in unemployment rates and for the respective contributions of job losing and job finding rates. Inefficient location choices by employers amplify spatial unemployment differentials five-fold. Both real-world and optimal place-based policies can yield sizable local and aggregate welfare gains.
\end{abstract}

Adrien Bilal

Department of Economics

Harvard University

1805 Cambridge Street

Cambridge, MA 02138

and NBER

adrienbilal@fas.harvard.edu

Supplemental Material is available at http://www.nber.org/data-appendix/w29269 


\section{Introduction}

Unemployment rates vary enormously across local labor markets. In 2017 in Versailles, an affluent French city close to Paris, 5\% of workers were unemployed. In southern Marseille, the unemployment rate exceeded $12 \%$. Comparable differences arise in the United States and in most other developed countries. ${ }^{1}$ Despite their magnitude, these spatial gaps persist over decades. While local governments devote billions of dollars every year to attract jobs, the determinants of spatial unemployment differentials remain elusive. Why is the unemployment rate persistently high in some places and low in others? What are the welfare implications of this spatial dispersion for workers? Can place-based policies improve the prospects of local residents and the aggregate economy?

This paper proposes answers to these questions with four contributions. First, I offer new empirical evidence showing that spatial unemployment differentials result from spatial gaps in the rate of job loss, which are in turn shaped by local employers rather than local workers. Second, I propose a theory of the location choice of employers with labor market frictions that accounts for spatial differences in job stability. Third, I estimate the framework on French administrative data. Fourth, I quantify the local and aggregate welfare gains from place-based policies in general equilibrium.

Specifically, in the first part of the paper, I examine how local labor market flows differ between locations. I assess whether differences in unemployment rates across commuting zones reflect differences between job losing (inflow) versus job finding (outflow) rates using French matched employer-employee data. Differences in job losing rates emerge as the primary source of spatial unemployment differentials, accounting for $77 \%$ of the variation. By contrast, job finding rates are nearly constant across locations. Using a two-way fixed effect approach, I then establish that employer-specific heterogeneity accounts for two thirds of spatial job loss differences, while worker-specific heterogeneity accounts for only one third. The contribution of employers is robust to controlling for location-specific factors. Similar patterns also hold in the Current Population Survey in the United States.

The dominant role of the job losing rate indicates that locations have high unemployment because workers repeatedly lose their job there, not because finding a job is particularly hard. This result contrasts with aggregate unemployment fluctuations, as well as with existing models of spatial unemployment that have focused on the job finding rate. ${ }^{2}$ The composition analysis reveals that spatial gaps in the rate of job loss arise because of systematic differences in job stability between employers.

In the second part of the paper, I propose an analytical theory to account for spatial gaps in job losing rates and the key role of employer heterogeneity. Workers choose freely where to live and work, and employers choose where to open jobs. ${ }^{3}$ They meet in local labor markets subject to standard search frictions. Housing is in limited supply. Employers offer jobs that differ in initial productivity, which subsequently fluctuates due to idiosyncratic shocks. As a result, endogenous job loss arises, and initially more productive jobs are more stable.

Local labor market flows reflect spatial differences in employer productivity, regardless of whether employer productivity is given or determined in equilibrium. The job losing rate is high where employers

\footnotetext{
${ }^{1}$ In 2017, the unemployment rate was $5 \%$ in Boston, Massachusetts. It was $13 \%$ in Flint, Michigan. See the OECD (2005) report for more countries.

${ }^{2}$ Changes in the job finding rate have been found to be the dominant force in aggregate unemployment fluctuations over the business cycle. See Shimer (2005), Hall (2005), Fujita and Ramey (2009), Krusell et al. (2017).

${ }^{3} \mathrm{As}$ is common in the search literature, there is no difference between employers, firms and jobs in my framework.
} 
are unproductive and jobs have low surplus. Job finding rates depend on two components: the meeting rate of workers and the probability that a meeting sucessfully results in a viable match. Whether job losing rates vary strongly across locations while job finding rates remain largely flat thus depends on cross-sectional patterns of employer productivity and labor market tightness.

The location decisions of employers shape spatial heterogeneity in productivity. Employers value two types of location characteristics. First, they value exogenous location fundamentals. Standard production complementarities imply that more productive employers are willing to pay more for locations that are inherently better suited for production. There, less productive employers are priced out by high wages and thus self-select into locations with poor fundamentals but low wages.

Second, employers value endogenous recruiting conditions. The location choice of employers then interacts with labor market frictions to uncover labor market pooling complementarities. Productive employers make high profits. Thus, they forego relatively more than unproductive employers while waiting for a worker: productive employers have a higher opportunity cost of time. At the margin, they are willing to pay more for slack labor markets where they recruit rapidly. By contrast, unproductive employers are priced out by high wages and self-select into low wage areas where they fill vacancies slowly.

Sorting emerges in spatial equilibrium as a result of the differential valuation of both exogenous and endogenous local characteristics by different employers. Of course, when differences in local fundamentals are large, cross-sectional sorting patterns based on vacancy filling rates alone hold only conditionally. Unconditional sorting patterns are more complex.

The spatial sorting of employers has strong predictions for local labor market flows. Spatial gaps in job losing rates are large because different employers locate in different places. Job finding rates vary less in the cross-section because workers make offsetting decisions that stablize both components of job finding rates. At the margin, productive employers are drawn towards slack labor markets. If the labor market was too slack however, workers would out-migrate. In addition, higher sucess probabilities of meetings in locations with productive employers are partially balanced by workers being more selective there.

Reduced-form evidence using administrative establishment-level productivity and vacancy data supports these implications. Labor productivity correlates negatively with job losing rates across French establishments and commuting zones. Local labor market tightness rises at most modestly with local unemployment.

I then show that the spatial equilibrium features misallocation because of a labor market pooling externality. Labor market frictions enable unproductive employers to attract more workers than would be socially optimal, should they enter in a location with more productive competitors. Hence, employers privately co-locate too much with more productive competitors that attract a larger pool of workers and ease recruiting. A utilitarian planner thus chooses an optimal policy that incentivizes productive employers to relocate towards high job loss areas. A corporate tax credit whose generosity rises with local job losing rates implements the optimal allocation, providing a rationale for commonly used place-based policies that subsidize employers in high unemployment locations.

The third part of the paper develops and structurally estimates a quantitative version of the framework with three main additions. First, locations also differ in residential amenities that capture non-monetary compensating differentials such as pleasant weather. Second, migration frictions introduce empirically plausible migration elasticities. Third, workers differ in human capital that depreciates while they are unemployed. In equilibrium, localized scarring effects in high unemployment areas produce clusters of 
workers with low human capital. There, productive stable jobs are less likely to open, further worsening local labor market conditions and magnifying spatial disparities.

Despite its richness, the quantitative model retains the tractability of the analytical framework. As a result, it produces estimating equations that allow for transparent identification by leveraging the many dimensions of the French administrative data. A recursive scheme delivers a sequence of regression equations that identify all but one of the 19 parameters without requiring to simulate from the model. The model can match a number of non-targeted moments such as the tenure profile of job loss within and across locations. The estimation directly targets neither the cross-sectional variance of local unemployment rates nor its breakdown into job losing and job finding rates.

The fourth part of the paper reveals that the estimated model accounts for the primary margins of spatial unemployment differentials. It generates over $75 \%$ of the cross-sectional variance of local unemployment rates in the data. It also closely replicates the respective contributions of job losing and job finding rates. $77 \%$ stem from the job losing rate in the data, against $73 \%$ in the model. The model matches the empirical relationship between local labor market flows on the one hand, and local wages, population and labor market tightness on the other hand. Pooling externalities are crucial to rationalize the location choice of employers, and hence job losing rate differences. Shutting down pooling externalities diminishes the incentives of employers to sort, and strongly reduces gaps in job losing rates. As a result, the spatial variation in unemployment rates shrinks by $84 \%$.

Two counterfactuals then explore the impact of place-based policies in general equilibrium. I start with the optimal policy. It takes the form of a corporate tax credit that is more generous in high unemployment locations. The optimal policy thus offsets the labor market pooling externality, and incentivizes more productive employers to relocate towards high unemployment locations. The optimal policy cuts the local unemployment rate by 5 to 10 percentage points and achieves 5 to $10 \%$ local welfare gains in cities such as Marseille. Long-run scarring effects of unemployment are central to these welfare gains, accounting for three fourths of the total. Aggregate welfare gains are just under 1\%. They are more modest than local gains in high unemployment locations because they average over a sizeable redistribution of resources across locations. As the most productive and stable jobs leave the lowest unemployment locations, residents experience welfare losses there.

I contrast the optimal policy with the French Enterprise Zones (EZ) program- the "Zone Franches Urbaines." The French EZ program was rolled out in 1996 and consisted in heavy subsidies for businesses opening jobs in high unemployment areas. Qualitatively, the French EZ policy resembles the optimal policy and should deliver positive welfare gains. Quantitatively however, the French EZ program is much smaller than the optimal policy in scale and scope. I find that the French EZ program reduces unemployment in treated areas by 2 to 3 percentage points, consistent with existing difference-in-difference estimates. Local welfare gains do not exceed a few percent. In the aggregate, the EZ program raised welfare by $0.1 \%$. Albeit modest, the impact of the EZ program is six times higher per dollar spent than the optimal policy, due to decreasing returns to redistribution. This comparison suggests that smallscale place-based policies are likely to be more efficient than large-scale ones in the presence of fiscal optimization or political economy constraints.

This paper adds to four strands of literature. First and most closely related is the body of work that 
examines persistent spatial unemployment differentials. ${ }^{4}$ Kline and Moretti (2013), Şahin et al. (2014), Marinescu and Rathelot (2018) and Schmutz and Sidibé (2018) study spatial variants of the Diamond (1982), Mortensen (1982), and Pissarides (1985) model. All of these papers focus on job finding rates. By contrast, I stress that job losing rates are the key drivers of spatial unemployment differentials. ${ }^{5}$ As a result, a different theory is required. It brings about that subsidies to high unemployment areas raise welfare, reconciling theory with real-world place-based policies.

Second, this paper adds to the literature that studies the location decisions of agents. A first subset focuses on workers' location decisions based on income prospects (Roback, 1982, Kennan and Walker, 2011, Desmet and Rossi-Hansberg, 2013, Bilal and Rossi-Hansberg, 2021). ${ }^{6}$ A second set of papers studies firms' location choices (Combes et al., 2012, Gaubert, 2018). Both literatures abstract from unemployment, while I show that including it leads to distinct policy implications. A final strand of literature proposes theoretical assignment models to study sorting between workers and employers (Sattinger, 1993, Shimer and Smith, 2000, Eeckhout and Kircher, 2018, Davis and Dingel, 2020), which I build on.

Third, this paper adds to the body of work that studies the efficiency properties of search models (Hosios, 1990, Mortensen and Pissarides, 1994). ${ }^{7}$ The labor market pooling externality is a spatial analogue of Acemoglu (2001): when heterogeneous jobs coexist, too many low productivity jobs open because they fail to internalize that they divert workers away from productive jobs. In my model, similar forces push unproductive jobs to inefficiently locate in places that are too productive for them. In contemporaneous work, Brancaccio et al. (2020) emphasize a related mechanism in transport markets.

Finally, this paper is closely tied to the large literature on agglomeration and congestion externalities. Going back to at least Marshall (1920) who coined labor market pooling as a key agglomeration force, local externalities have formed the basis for place-based policies. ${ }^{8}$ Empirical analyses of the latter have found mixed employment effects (Glaeser and Gottlieb, 2008, Hanson, 2009, Neumark and Simpson, 2014, Busso et al., 2013, Mayer et al., 2015, Slattery and Zidar, 2020). Several papers propose spatial models to analyze place-based policies, but all abstract from unemployment (Ossa, 2017, Fajgelbaum et al., 2018, Slattery, 2019, Fajgelbaum and Gaubert, 2020). Agglomeration economies often imply subsidies to high income locations. I emphasize instead a particular mechanism whereby labor market pooling externalities favor subsidies to low income locations, consistently with many real-world place-based policies. The idea that redistributing a given set of jobs across locations can improve aggregate outcomes goes back at least to Bartik (1991), and has been recently revived by Austin et al. (2018). This paper proposes a theory of frictional local labor markets that makes this idea precise.

The remainder of the paper is structured as follows. Section 1 presents the data and empirical analysis. Section 2 builds and empirically validates a simple model of spatial unemployment differentials with endogenous job loss. Section 3 lays out the quantitative extensions and estimation. Section 4 discusses spatial unemployment gaps and policy counterfactuals. The last section concludes. An Appendix and Online Supplemental Material collect proofs and additional details.

\footnotetext{
${ }^{4}$ Blanchard and Katz (1992)'s seminal work found little evidence of state-level unemployment persistence between 1975 and 1985. Kline and Moretti (2013) and Amior and Manning (2018) show that unemployment and labor force participation differentials between US commuting zones are highly persistent after 1980, but abstract from variation in job losing rates.

${ }^{5}$ See Hall (1972) for a study of 12 U.S. cities, and Topel (1984) for an analysis across U.S. states.

${ }^{6}$ See also Diamond (2016), Giannone (2017) Caliendo et al. (2021), Glaeser et al. (2018), and Couture et al. (2019).

${ }^{7}$ See Jarosch (2021) and Mangin and Julien (2021) for recent contributions.

${ }^{8}$ See Krugman (1991) and Amiti and Pissarides (2005) for a study of labor pooling without search frictions.
} 


\section{Descriptive evidence}

This section first describes the data. Next, I highlight that spatial unemployment gaps are large and persistent. Then, I show that spatial unemployment gaps are primarily driven by spatial differences in job losing rates, in turn tied to employers rather than workers or location-specific factors. My main analysis focuses on France where I can exploit the richness of administrative data, but I also confirm the main findings in the United States.

\subsection{Data}

Worker flows in and out of unemployment are central components of labor market studies. Aggregate time series exercises typically break down the contribution of job losing and job finding rates in accounting for the unemployment rate. While they are jointly determined equilibrium variables, separating their contributions is a useful diagnostic device that informs the underlying economic mechanisms.

Adapting this approach to a geographic setting is challenging. On the one hand, large repeated cross-sections like the Census or the American Community Survey are ill-suited for measuring worker flows. On the other hand, surveys with a short panel dimension such as the Current Population Survey (CPS) typically have a much smaller cross-section. ${ }^{9}$ This limitation leads to measurement error concerns, particularly for the outflow from unemployment, and prevents any compositional split. In addition, panel surveys often stop tracking movers who change location.

To circumvent these difficulties, I turn to administrative matched employer-employee data from France. I use a combination of the DADS and of the French Labor Force Suvey (LFS) between 1997 and $2007 .{ }^{10}$ The DADS have two advantages. First, they are a representative dataset containing almost one million individuals in any cross-section. Second, the DADS are a panel covering the entire work history of individuals, with rich demographic, geographic and firm-level information. The sample size lets me break down the analysis by city and finely disaggregated employer and worker groups to control for composition.

The DADS are well-suited to study individual-level employment and non-employment across space. ${ }^{11}$ To further separate non-employment into unemployment and non-participation, I first restrict my sample to males between 30 and 52 years old. This group has a high and stable labor force participation rate, thereby limiting concerns related to life-cyle changes therein. Second, I complement the DADS with the LFS. I compute conditional transition probabilities between employment, unemployment and non-participation in the LFS, by broad city and worker group. I then use those conditional transition probabilities from the LFS to probabilistically discriminate between non-participation and unemployment in the DADS. ${ }^{12}$ In practice, this imputation has a limited impact on the results. I aggregate the resulting sample at the quarterly frequency. Table 11 in Supplemental Material D.1 compares aggregate statistics in this sample and in the LFS.

\footnotetext{
${ }^{9}$ The CPS has about five unemployed individuals per metropolitan area on average in any cross-section.

${ }^{10}$ DADS: "Déclarations Annuelles de Données Sociales." The LFS is the "Enquête Emploi."

${ }^{11}$ Consistent with the International Labour Office's definition, I define an employed individual as one who has a job. A non-employed individual is one who is not working for a wage. An unemployed individual is one who is not working but is actively looking for a job and available to start work within two weeks.

${ }^{12}$ This imputation exercise resembles Blundell et al. (2008) who use the Panel Study of Income Dynamics to complement consumption categories in the Consumption Expenditure Survey. For instance, if an individual goes through an employment to non-employment transition in the DADS, I define her employment status after the transition (unemployment or noemployment) based on the LFS transition probabilities.
} 
I complement these datasets with several other data sources. I compute city-level and establishmentlevel variables with a repeated cross-section version of the DADS that covers the universe of French workers. For over-identifying exercises in Section 2.6, I use firm-level balance sheet data covering the near universe of French businesses for the same period, as well as establishment-level vacancy data from a largescale survey. I also use a single cross-section of housing prices from an online realtor, MeilleursAgents.com.

I define a location as a commuting zone as defined by the French statistical institute INSEE. ${ }^{13} \mathrm{~A}$ commuting zone is an area where most of the residents work at jobs located in that same area. There are 328 commuting zones that partition the French territory. This definition is most natural as a spatial notion of a local labor market. In what follows, location, commuting zone and city are used interchangeably. I construct a measure of skill from occupation and age data because the main DADS panel dataset does not have education data. Skill is defined as the average age and occupation wage premium for a worker, derived from a Mincer regression. Supplemental Material D.1 provides more details.

For the United States, I use the CPS. I define a location as a metropolitain statistical area, and use a similar definition of skill as in France. ${ }^{14}$ I focus on white males between 30 and 52 years old that are household heads, and use the CPS's definition of unemployment.

\subsection{Dispersion and persistence of spatial unemployment differentials}

I start by showing that local unemployment rates are widely dispersed and highly persistent across locations in France. Figure 1(a) maps commuting-zone level unemployment rates in mainland France. Darker shades of blue encode higher unemployment rates. Figure 1(a) highlights that commuting zones with unemployment rates above $12 \%$ or below $6 \%$ can be found throughout the country. The crosssectional standard deviation is 2.5 percentage points, twice as much as the time-series standard deviation of the aggregate unemployment rate, 1.3 percentage points.

To assess the persistence of spatial unemployment differentials, I split the sample in two subperiods, 1997-2001 and 2002-2007. Figure 1(b) plots the local unemployment rate in the second subperiod against the unemployment rate in the first subperiod for every city. Local unemployment rates are highly persistent, as they line up closely around the orange 45 degree line. The 5 -year autocorrelation is $0.91 .^{15}$

Figure 1 confirms earlier findings from Kline and Moretti (2013) and Amior and Manning (2018) for the United States. I now turn to the main empirical contribution of this paper: unpacking how worker flows in and out of unemployment differ between commuting zones.

\subsection{Worker flows in and out of unemployment}

Inflows from local employment, from non-participation and in-migration from other locations all contribute to local unemployment. Similarly, outflows into local employment, into non-participation and out-migration reduce the number of unemployed workers. In what follows, I use standard terminology from the literature and call the rate at which employed workers flow into unemployment the job losing rate. Similarly, I call the rate at which unemployed workers flow into employment the job finding rate.

\footnotetext{
13 "Institut National de la Statistique et des Etudes Economiques."

${ }^{14}$ I also check that using education to define skill in the CPS leaves the results unchanged.

${ }^{15}$ In Supplemental Material D.2, I show that controlling for economy-wide industry business cycles increases local persistence, with a conditional autocorrelation of 1.05 .
} 
Figure 1: Unemployment rates in France, by commuting zone and over time

(a) Local unemployment rates, 1997-2007 averages

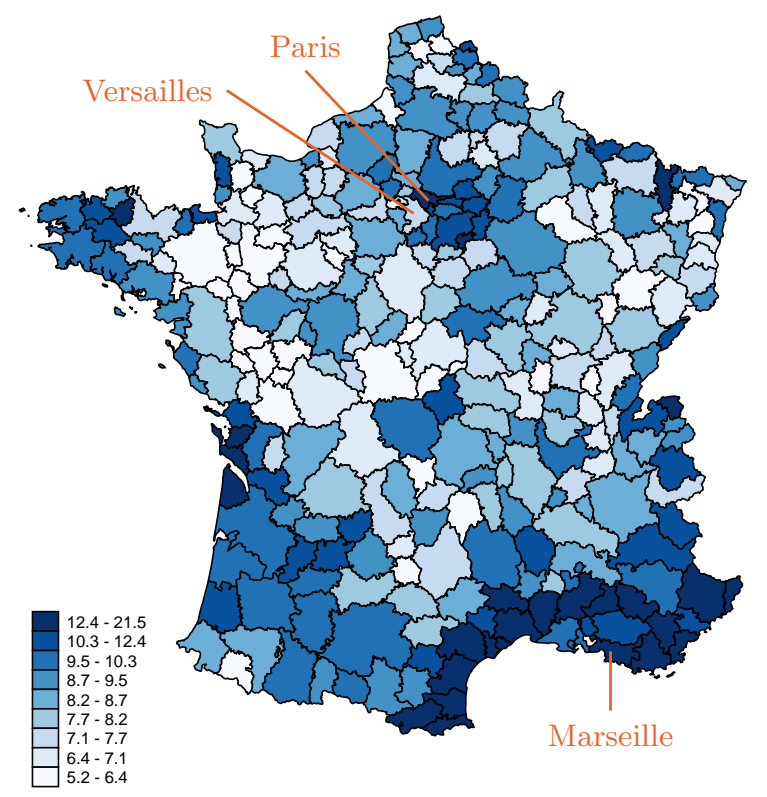

(b) Persistence of local unemployment rates

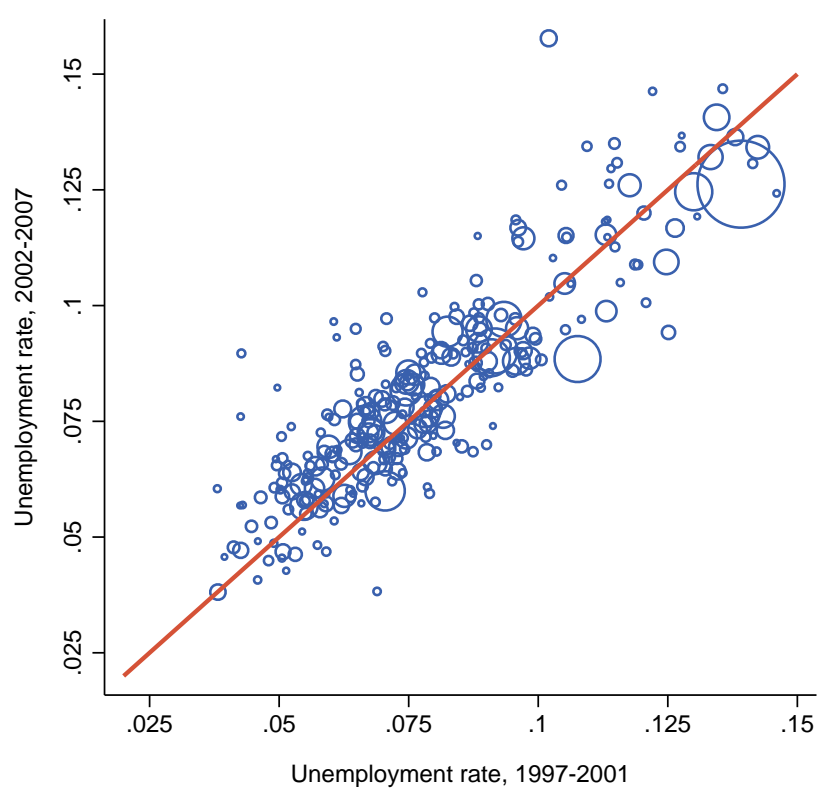

Note: Figure 1(a) maps commuting zone unemployment rates from the DADS panel. Corsica and overseas territories omitted for exposition. Figure 1(b) plots commuting zone unemployment in two subperiods of the sample. Blue circles represent a commuting zone. Size is proportional to population.

To guide the analysis, start with a simple two-state accounting model. Suppose that employed workers in city $c$ face a constant job losing rate $s_{c}$ per unit of time (separation rate to unemployment), and that unemployed workers face a constant job finding rate $f_{c}$ per unit of time. Abstract from movements in and out of the labor force and migration. In steady state, the local unemployment rate $u_{c}$ satisfies

$$
\log \frac{u_{c}}{1-u_{c}}=\log s_{c}-\log f_{c}
$$

Both $s_{c}$ and $f_{c}$ map to transition probabilities between employment and unemployment in the data.

I depict the contribution of job losing and job finding rates to local unemployment using equation (1). Figure 2 plots the logarithm of job losing rates $s_{c}$ and finding rates $f_{c}$ against the logarithm of the unemployment-employment ratio $\frac{u_{c}}{1-u_{c}}$ across commuting zones, for France and the United States.

Job losing rates emerge graphically as the main driver of spatial unemployment differentials. The data align closely with the 45 degree line in orange for both countries in Figure 2(a). In contrast to job losing rates, job finding rates appear nearly flat across locations in Figure $2(\mathrm{~b}){ }^{16}$

I confirm quantitatively the key role of job losing rates. I use equation (1) for an exact variance decomposition by constructing a predicted unemployment rate from job losing and finding rates using equation (1). I find that the job losing rate accounts for $77 \%$ of the cross-sectional variation of the spatial unemployment rate in France. The job finding rate accounts for the remaining 23\%. In the US, the job losing rate accounts for $73 \%$ of the cross-sectional variation in spatial unemployment rate.

I establish the robustness of these results with several additional exercises. First, the central role of job

\footnotetext{
${ }^{16}$ Similarly, job-to-job mobility co-varies little with local unemployment in Figure 17(b), Supplemental Material D.2.
} 
Figure 2: Local labor market flows and unemployment in France and in the United States.

(a) Job losing rate

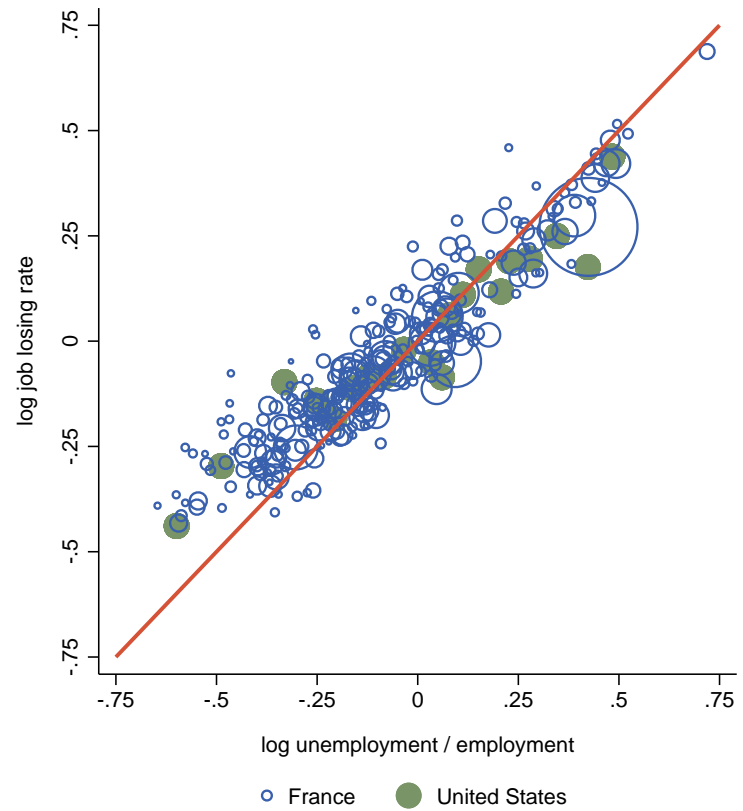

(b) Job finding rate

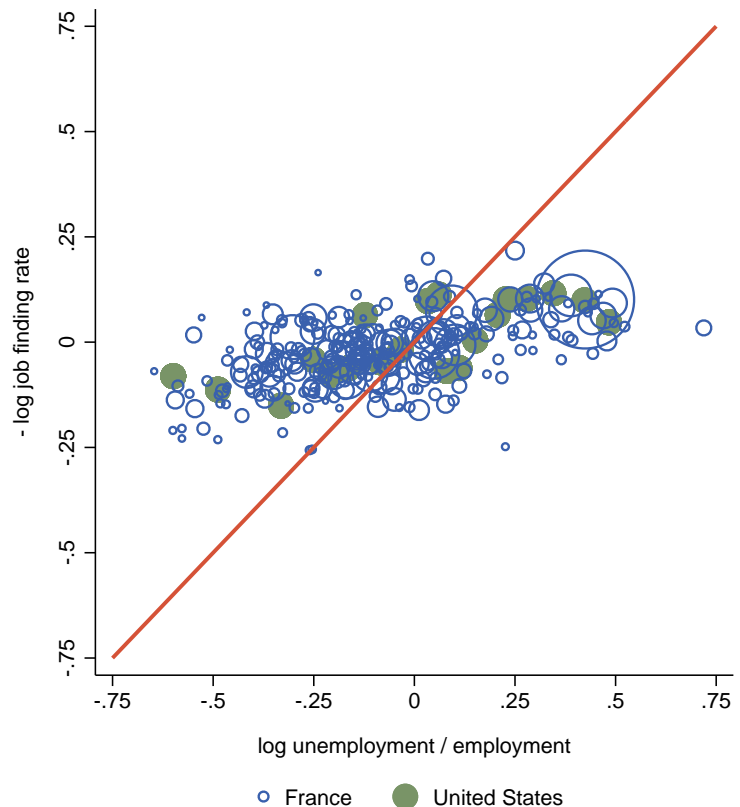

Note: Figure 2(a) scatterplots the log of the job losing rate against the log of the unemployment-employment ratio, across commuting zones in France (DADS panel) and in the United States (CPS). Blue circles represent commuting zones in France, with size proportional to population. Green dots represent metro area groups in the US. US metro areas are grouped into 20 equally populated bins to reduce measurement error due to the smaller cross-sectional size of the CPS. 45 degree line in orange. Figure 2(b) scatterplots minus the log of the job finding rate against the log of the unemployment-employment ratio, across commuting zones in France and in the US.

loss is robust to deviations from the exact variance decomposition. Table 4 in Appendix A.1 shows that neither movements in and out of the labor force, migration, local transitional dynamics, time aggregation of quarterly probabilities into instantaneous rates, using the LFS only, nor other residual mechanisms, introduce a significant wedge between the left and right sides of equation (1).

Second, I verify that mechanical correlates of job loss such as temporary contracts, seasonality, firm exit or job reallocation cannot provide a systematic explanation for spatial differences in job losing rates. Supplemental Material D.3 establishes that these phenomena account for at most 8 to $23 \%$ of spatial gaps in job loss. By contrast, Table 2 in Section 4.1 shows that job losing rates are strongly negatively associated with local wages, but only weakly with local population. Job finding rates do not correlate strongly with either variable.

Third, I relate long-run differences across locations to changes over time. I split the sample into two subperiods and use equation (1) in changes over time. Consistently with the business cycle literature, Figure 10 in Appendix A.1 finds that job finding rates play a larger role for spatial unemployment differentials at shorter frequencies. Thus, variation in job losing rates is key in the long run rather than in the short run even at the city level. ${ }^{17}$

\footnotetext{
${ }^{17}$ Elsby et al. (2013) document that the role of the job finding rate for aggregate business cycles is strongest in Anglo-Saxon economies. Albeit somewhat less pronounced, the job finding rate remains dominant in other OECD economies. Figure 2 indicates that the job losing rate is equally important for spatial differences in both the United States and France.
} 


\subsection{Employer and worker composition}

Three main reasons may lead to spatial differences in job losing rates. First, workers who reside in some locations may separate into unemployment more frequently. Second, employers in these same locations may offer jobs that are particularly unstable. Third, city-specific factors may affect local job stability.

To disentangle these explanations, I estimate a three-way fixed effect model (Abowd et al., 1999):

$$
\mathrm{EU}_{i, t}=\alpha_{i}+\beta_{J(i, t)}+\gamma_{C(i, t)}+\varepsilon_{i, t}
$$

where $i$ indexes workers and $\alpha_{i}$ denotes a worker fixed effect. $J(i, t)$ denotes worker $i$ 's employer in quarter $t$, and $\beta_{J(i, t)}$ denotes an employer fixed effect. $C(i, t)$ denotes worker $i$ 's city in quarter $t$, and

$\gamma_{C(i, t)}$ denotes a city fixed effect. $\mathrm{EU}_{i, t}$ is an indicator variable taking the value one if worker $i$ separates into unemployment in quarter $t$, and zero otherwise.

I use two main specifications. First, I define an employer as a firm-by-4-digit-occupation. This definition captures spatial heterogeneity in the type of jobs to the extent that different firms operate in different locations. This definition also captures heterogeneity in the type of jobs across occupations within the same firms. Identification follows from the well-known conditional random mobility assumption (Card et al., 2013). Worker mobility across firm-occupations identifies employer effects separately from worker effects. Worker mobility across locations separates city effects from worker effects. In this spatial context, I also exploit multi-establishment firms to separately identify firm-occupation effects from city effects. To alleviate concerns associated to limited mobility bias, I follow Bonhomme et al. (2019) and cluster worker, employers and commuting zones into groups before estimating (2). I provide more details in Appendix A.2.

In the second main specification, I define an employer as an establishment-by-4-digit-occupation. This definition captures both spatial heterogeneity in the type of jobs across establishments within the same firm, as well as heterogeneity in the type of jobs across occupations within the same establishment. Since establishments do not move by definition, I do not include a city fixed effect in this specification.

After estimating (2), I retrieve the estimated fixed effects, and average them within every commuting zone group $c$ to obtain a sample analogue of

$$
\mathrm{EU}_{c}=\mathbb{E}_{c}\left[\alpha_{i}\right]+\mathbb{E}_{c}\left[\beta_{J(i, t)}\right]+\gamma_{c}
$$

Equation (3) breaks down the commuting zone quarterly job losing rate $\mathrm{EU}_{c}$ into an average worker component $\mathbb{E}_{c}\left[\alpha_{i}\right]$, an average employer component $\mathbb{E}_{c}\left[\beta_{J(i, t)}\right]$, and, in the first specification, a city component $\gamma_{c}$. I use this decomposition to assess whether worker composition, employer composition or city-specific factors contribute most to spatial job loss differentials.

I find that systematic differences in the type of employers operating across cities are the primary reason why job losing rates differ across space. To reach this conclusion, Figure 3(a) plots the contributions of the average employer (firm-by-occupation), worker and city components to the unconditional local job losing rate. Employer effects account for $52 \%$ of the cross-sectional variation in job losing rates, while city effects account only for $22 \%$ and worker effects account for $28 \%$.

Of course, different establishments are likely to offer jobs with different attributes, even within the same firm. Figure 3(b) plots the same decomposition as in Figure 3(a) when employers are defined as an 
Figure 3: Contribution of employer, city and worker effects to local job losing rates in France.

(a) Firm, city and worker effects

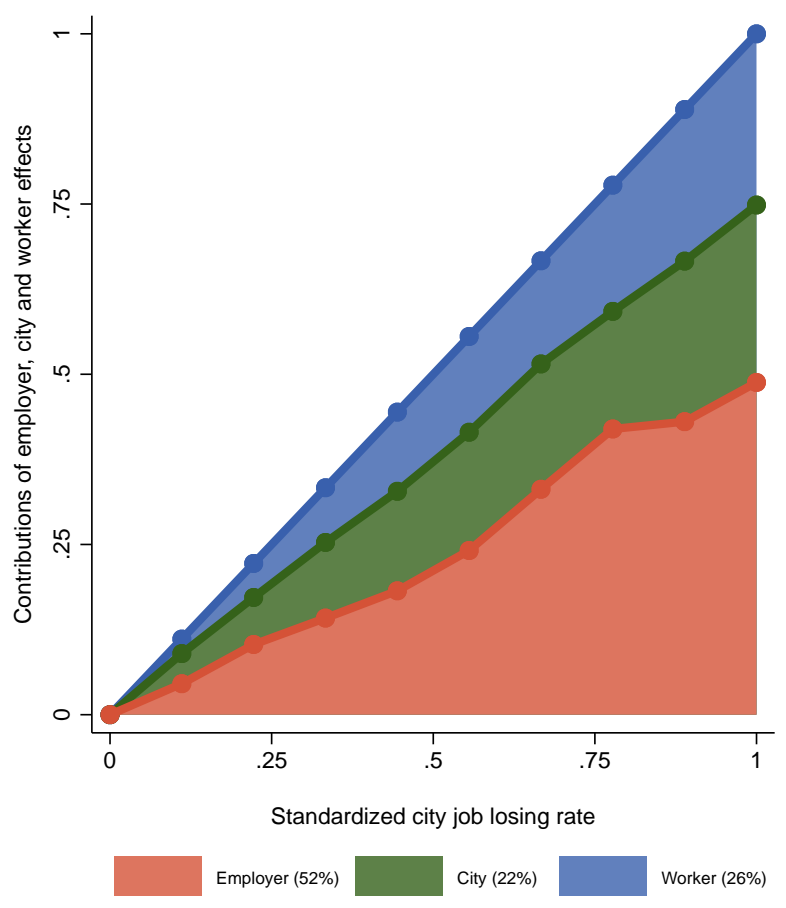

(b) Establishment and worker effects

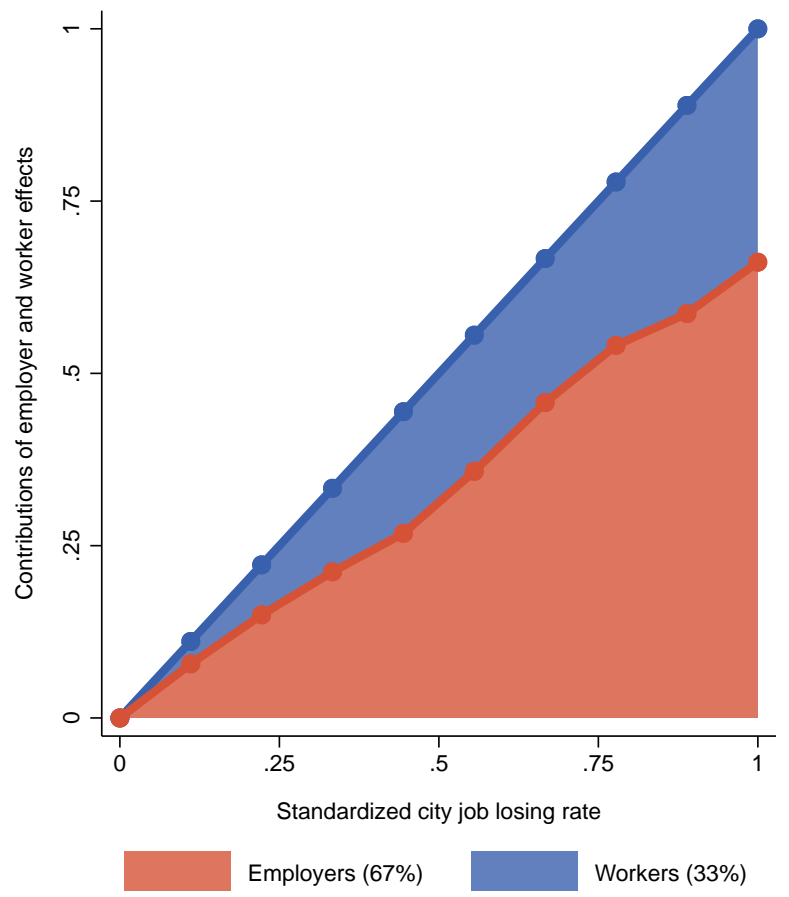

Note: Panel 3(a), left: firm-by-4-digit-occupation, city and worker fixed effects. Panel 3(b), right: establishment-by-4-digit-occupation and worker fixed effects. Orange: average employer effect. Green: average city effect. Blue: average worker effect. DADS panel, France. Workers, employers and commuting zones clustered into 10 population-weighted groups based on their unconditional job losing probability. X-axis represents the sum of employer, city and worker effects, standardized between 0 and 1.

establishment-by-occupation rather than a firm-by-occupation. In this case, employer effects account for $67 \%$ of the cross-sectional variation in job losing rates, while worker effects account for only $33 \%$.

Comparing both specifications confirms that employer heterogeneity is the dominant source of variation in local job losing rates. Its contribution lies between $52 \%$ and $67 \%$. The exact proportion depends on how much within-firm cross-establishment variation stems from within-firm sorting of establishments as opposed to truly location-specific factors. Yet, location-specific factors can account for no more than $22 \%$ of the overall variation, and worker composition accounts for no more than $33 \%$.

What are the characteristics of employers with high job losing rates? I correlate employer fixed effects with a number of firm-level observables in Figure 11 in Appendix A.2. Firms with unstable jobs sell less than but employ a comparable workforce to firms with stable jobs. Firms with unstable jobs have low labor productivity, are less capital-intensive and less profitable. They pay low wages but their labor share is high. They are largely present in both tradable and non-tradable industries. Together, these observations indicate that employers with unstable jobs have high labor costs relative to revenues and are found throughout the economy.

A number of additional exercises confirm the dominant role of employer composition. First, I demonstrate that industry heterogeneity plays only a limited role. Figure 12 in Appendix A.2 shows that the co-movement between unemployment, job losing and job finding rates holds for tradable and non-tradable industries. I then residualize local job losing rates from industry and skill heterogeneity similarly to the specification in (2), and plot the estimated city fixed effects in Figure 13, Appendix A.2. While there is 
heterogeneity in job losing rates across industries, the mix of industries in cities does not co-vary enough with industry-specific job losing rates to account for a sizeable share of spatial variation in job losing rates. Instead, the key heterogeneity driving job loss differentials arises within 3-digit industries rather than between industries, as well as within worker skills.

Second, I verify that my findings are robust to alternative econometric specifications. Table 5 in Appendix A.2 shows that results remain similar when using alternative definitions of employers, such as establishments or firms without interacting with occupation, or when varying the number of clusters.

Third, I assess whether the conditional random mobility assumption that underpins identification in equation (2) is likely to hold. I correlate changes in individual-level job losing rates with changes in city-level and firm-level job losing rates for movers, and split the results for movers towards cities or firms with systematically higher or lower job losing rates. Violations of the conditional random mobility assumption should manifest as larger coefficients on city and firm-level job losing rates after splitting the sample. Table 6 in Appendix A.2 finds no evidence against the conditional random mobility assumption.

Overall, the results in this section indicate that spatial differences in job losing rates are by far the largest contributor to spatial unemployment rate differentials in France and in the United States. These spatial differences are not explained by the local industry mix or the composition of the workforce. Instead, spatial gaps in job loss primarily reflect systematic differences in the type of jobs offered by employers. These findings are, to the best of my knowledge, new to the literature. They elude existing models of local unemployment that focus on job finding rates and abstract from the role of employers. By contrast, job losing rates and employer heterogeneity lie at the heart of the theory I propose below.

\section{$2 \quad$ A model of spatial unemployment differentials}

This section develops a theory of spatial unemployment differentials. I build on the spatial equilibrium model of frictional unemployment in Kline and Moretti (2013). I add two key ingredients. First, job loss is endogenous and tied to employers. Second, heterogeneous employers decide where to locate.

\subsection{Setup}

Time is continuous. There is a single final good used as the numeraire and freely traded across locations.

Geography. There is a continuum of ex-ante heterogeneous locations endowed with one unit of housing. Locations differ in productivity $\ell$ with cumulative distribution function $F_{\ell}$ on a connected support $[\underline{\ell}, \bar{\ell}]$, with density $F_{\ell}^{\prime}$. Thus, a location is characterized by its productivity $\ell$ rather than its particular name. ${ }^{18}$

Workers. There is a unit measure of infinitely-lived homogeneous workers. Their preferences over streams of consumption of the final good $c_{t}$ and housing services $h_{t}$ are

$$
\mathbb{E}_{0}\left[\int_{0}^{\infty} e^{-\rho t}\left(\frac{c_{t}}{1-\omega}\right)^{1-\omega}\left(\frac{h_{t}}{\omega}\right)^{\omega} d t\right],
$$

\footnotetext{
${ }^{18}$ Revenue productivity $\ell$ captures factors that determine whether a location is well-suited for production. For instance, a location with high quality transportation infrastructure has high $\ell$. Productivity can also encode that local demand for non-tradables may be particulary high or that local workers may be particularly skilled. In the quantitative model of Section 3, I microfound local productivity with the human capital of local residents.
} 
with $\omega \in(0,1)$. Workers consume their income each period. They only search when unemployed. Workers are freely mobile across locations. ${ }^{19}$

Employers and jobs. As is common in the search literature, the productive unit is an employer-worker match. Thus, the notions of employers, firms, establishments and jobs are interchangeable in the model. ${ }^{20}$ An employer pays a fixed $\operatorname{cost} c_{e}$ to open a new job. After paying $c_{e}$, the employer draws a job qualityor expected productivity $-z$ that informs their initial productivity draw. The population distribution of quality $z$ is $F_{z}$, with connected support $[\underline{z}, \bar{z}]$ and density $F_{z}^{\prime}$. After observing job quality $z$, employers choose a location $\ell$ to open their job and search for workers by posting a single vacancy in the local labor market. After they match with a worker, they draw their initial, idiosyncratic match productivity $y_{0}$ from a conditional distribution $G_{0}\left(y_{0} \mid z\right)$ that depends on employer quality $z$. Drawing a higher $z$ implies that the job will be more productive on average, in a sense made precise in Assumption 1 below. After observing this initial draw, the matched pair decides to start producing together or not. If not, the worker returns to unemployment, and the job disappears.

An active job with productivity $y_{t}$ in a location $\ell$ produces $y_{t} \ell$ : local productivity $\ell$ and job productivity $y_{t}$ are technological complements. Over time, every job's productivity evolves independently according to a geometric Brownian motion

$$
d \log y_{t}=-\delta d t+\sigma d W_{t}
$$

where $\delta>0$ implies that productivity depreciates on average. This assumption implies that all jobs eventually separate and is required to obtain a well-defined steady-state distribution. ${ }^{21} \sigma$ is the volatility of shocks. A geometric Brownian motion is the continuous-time analogue of a random walk with drift. Importantly, the productivity process is identical in all locations, so that any spatial differences in job loss must originate from differences between employers. For values to remain finite, I impose that $\rho+\delta>\frac{\sigma^{2}}{2}$. If the match breaks up, the job disappears.

Local labor markets. Unemployed workers search for jobs only in the location where they live, and employers search for workers only in the location where their job is open. Workers randomly meet vacancies in a single labor market in each location according to a Cobb-Douglas matching function $\mathcal{M}(\mathcal{U}(\ell), \mathcal{V}(\ell))=$ $m \mathcal{U}(\ell)^{\alpha} \mathcal{V}(\ell)^{1-\alpha} \cdot \mathcal{U}(\ell)$ denotes the local number of unemployed workers, and $\mathcal{V}(\ell)$ denotes the local number of vacancies in that market.

Local market tightness is $\theta(\ell)=\mathcal{V}(\ell) / \mathcal{U}(\ell)$. The local meeting rate for workers is then $f(\theta(\ell))=$ $m \theta(\ell)^{1-\alpha}$ while the vacancy meeting rate for employers is $q(\theta(\ell))=m \theta(\ell)^{-\alpha}$. Meeting rates differ from realized rates when some meetings do not result in viable jobs. Denote realized rates by $f_{R}(\ell)$ and $q_{R}(\ell)$.

\footnotetext{
${ }^{19}$ Ruling out borrowing and saving is immaterial given risk-neutrality. See Bilal and Rossi-Hansberg (2021) for a location choice model with risk-averse workers who borrow and save. I do not incoporate job-to-job mobility, for three reasons. First, job-to-job moves do not directly affect the unemployment rate: they relocate workers from one job to another. Second, I show in Figure 17(b) in Supplemental Material D.2 that, just like the job finding rate, the job-to-job mobility rate is only weakly correlated with the unemployment rate. Finally, adding job-to-job mobility would break the tractability of the model and make estimation and identification much more challenging.

${ }^{20}$ The model can also be seen as one in which there are large, constant-returns-to-scale firms that open many jobs at cost $c_{e}$ per job. For models with a well-defined notion of firm size through decreasing returns to scale and search frictions, see Bilal et al. (2022), Schaal (2017) and Elsby and Michaels (2013).

${ }^{21} \delta>0$ reflects the difference between parameters governing productivity growth at new jobs relative to incumbent jobs in endogenous growth models such as Engbom (2018).
} 
Flow value of unemployment. Unemployed workers in location $\ell$ consume $b \ell$. This specification captures the idea that unemployment benefits are a constant replacement rate of past wages, because wages will scale with local productivity $\ell$. It also helps with analytical tractability. ${ }^{22}$

Wage determination. Workers and employers set wages according to generalized Nash bargaining, with worker bargaining power $\beta$. For simplicity, I assume that renegotiation occurs each instant.

Ownership. A representative mutual fund owns housing and claims to employers' profits. The mutual fund rents land to workers at equilibrium rents $r(\ell)$ and collects profits from employers. For simplicity, I assume in this section that risk-neutral absentee owners receive the profits from housing rents and firms. ${ }^{23}$

\subsection{Value functions}

In what follows, the economy is in steady-state.

Unemployment and employment. Let $U$ be the value of unemployment. Because unemployed workers are freely mobile, their value is equalized across all locations that they populate. The Inada property of the matching function ensures that any populated location must have some unemployed workers. ${ }^{24}$

To keep the exposition simple in the main text, I consider wage functions $w^{*}(y, \ell)$ that only depend on productivity $y$ and the location $\ell$. As shown in Appendix B.1, this restriction is without loss of generality. Let $V(y, \ell)$ be the value of employment at wage $w^{*}(y, \ell)$ in location $\ell$. $U$ and $V$ satisfy the recursions

$$
\begin{aligned}
\rho U & =b \ell r(\ell)^{-\omega}+f(\ell) \mathbb{E}_{\ell}\left[\max \left\{V\left(y_{0}, \ell\right)-U, 0\right\}\right] \\
\rho V(y, \ell) & =w^{*}(y, \ell) r(\ell)^{-\omega}+\left(L_{y} V\right)(y, \ell),
\end{aligned}
$$

where the recursion for $V$ holds as long as the worker finds it optimal to remain in the match.

The first term on the right-hand-side reflects indirect utility when unemployed or employed. Workers spend a constant share $\omega$ of their income on housing due to Cobb-Douglas preferences, and local housing prices $r(\ell)$ enter indirect utility. The second term on the right-hand-side of equation (5) reflects future expected employment opportunities of unemployed workers. At rate $f(\ell)$, they meet potential employers. The latter then draw initial productivity $y_{0}$, with a distribution that may depend on location $\ell$ because employers may differ across locations. Provided initial productivity $y_{0}$ is high enough, the worker is hired and the matched pair starts producing together. The second term on the right-hand-side of equation (6) reflects the expected continuation value of employment due to productivity shocks. Given the geometric

\footnotetext{
${ }^{22}$ The specification can also be seen as home production or self-employment with the same production function as firms, but with an efficiency $b$. Because the model features aggregate constant returns to scale in production, defining unemployment benefits to be directly a constant replacement rate of past wages leads to multiplicity.

${ }^{23}$ Alternatively, the proceeds from land rents and profits can be rebated to workers as a flat earnings subsidy. Given riskneutrality, shares of the mutual fund could also be traded. In these cases the cross-sectional implications are unchanged. To keep the focus on the efficiency properties of the location choice of employers and abstract from distributional considerations between owners and workers, I use the flat earnings subsidy rebate in the quantitative exercises.

${ }^{24}$ This argument is valid under a trembling-hand equilibrium refinement in which workers and firms make small mistakes around their preferred location choices. The two-sided location choice of workers and employers can otherwise result in coordinating on empty locations. I impose this trembling-hand refinement in the sequel of this paper.
} 
Brownian motion assumption (4), the functional operator $L_{y}$ is defined by

$$
L_{y} V=\left(\frac{\sigma^{2}}{2}-\delta\right) y \frac{\partial V}{\partial y}+\frac{\sigma^{2}}{2} y^{2} \frac{\partial^{2} V}{\partial y^{2}} .
$$

Employers. The value of a matched employer with productivity $y$ in location $\ell$ solves

$$
\rho J(y, \ell)=y \ell-w^{*}(y, \ell)+\left(L_{y} J\right)(y, \ell)
$$

as long as the employer finds it optimal to keep the worker. Employers value flow profits $y \ell-w^{*}(y, \ell)$ as well as future productivity changes.

Joint surplus and wage determination. Generalized Nash bargaining implies that worker-employer pairs set wages by maximizing the Nash product. Even though the marginal utility of a dollar differs between workers and employers due to housing consumption, Lemma 4 in Appendix B.2 shows that the traditional microfoundation of generalized Nash bargaining with an alternative offers game $\grave{a}$ la Rubinstein (1982) continues to hold in my environment.

Lemma 4 lets me restrict attention to a single object that I call the adjusted surplus, defined as

$$
S(y, \ell)=J(y, \ell)+r(\ell)^{\omega}(V(y, \ell)-U) .
$$

The adjusted surplus is independent from wages because it puts each side's value on a common numeraire scale. Appendix B.1 shows that it follows a recursion similar to that of employers. Lemma 4 then states that wages split the adjusted surplus into constant shares:

$$
r(\ell)^{\omega}(V(y, \ell)-U)=\beta S(y, \ell), \quad J(y, \ell)=(1-\beta) S(y, \ell) .
$$

In particular, both sides agree to break up the match when the adjusted surplus drops to zero. In that case, a separation occurs. Existing matches therefore solve a forward-looking optimal stopping problem, which is detailed in Appendix B.2. I characterize its solution in the following Lemma.

Lemma 1. (Adjusted surplus)

There exists a unique adjusted surplus, given by

$$
S(y, \ell)=\frac{\ell \underline{y}(\ell)}{\underline{y}_{0}} \mathcal{S}\left(\frac{y}{\underline{y}(\ell)}\right), \quad \forall y \geq \underline{y}(\ell)
$$

and $S(y, \ell)=0$ for $y \leq \underline{y}(\ell)$, where

$$
\rho \frac{\underline{y}(\ell)}{\underline{y}_{0}}=b+v(\ell), \quad v(\ell)=\frac{f(\ell) r(\ell)^{\omega} \mathbb{E}_{\ell}\left[\max \left\{V\left(y_{0}, \ell\right)-U, 0\right\}\right]}{\ell}, \quad \mathcal{S}(Y)=\frac{\tau Y+Y^{-\tau}}{1+\tau}-1,
$$

and $\tau>0, \underline{y}_{0}>0$ are transformation of $\rho, \delta, \sigma$ given in Appendix B.2.

Proof. See Appendix B.2.

The local equilibrium separation threshold $\underline{y}(\ell)$ increases as the value of unemployment relative to housing prices, $b+v(\ell)$, rises. $v(\ell)$ is the productivity-adjusted value of future employment opportunities 
to a worker. The value of future employment opportunities $v(\ell)$ depends on the meeting rate $f(\ell)$ and the local mix of employers. The adjusted surplus $S$ is an increasing function of current productivity $y$ relative to the local endogenous threshold $\underline{y}(\ell)$. The nonlinearity in the function $\mathcal{S}$ arises because of the option value of separation, which rises as productivity $y$ approaches the threshold $\underline{y}(\ell)$. Hence, the adjusted surplus $S$ satisfies both the value matching and smooth-pasting conditions at the threshold: $S(\underline{y}(\ell), \ell)=\frac{\partial S}{\partial y}(\underline{y}(\ell), \ell)=0$.

Local reservation wages $\underline{w}(\ell)$ in efficiency units of local productivity $\ell$ satisfy

$$
\underline{w}(\ell)=\underline{w}_{0} \underline{y}(\ell)
$$

where $\underline{w}_{0}=(1-\beta) \rho / \underline{y}_{0}+\beta$ follows from the wage equation (29) in Appendix B.2. When the local separation threshold is higher, matches break up at higher productivity levels because workers value more the option to search for a different job in the same local labor market relative to local housing prices. Thus, the local reservation wage is higher.

The free mobility condition takes a simple form given reservation wages $\underline{w}(\ell)$ :

$$
U=\frac{\ell \underline{w}(\ell)}{\underline{w}_{0} \underline{y}_{0} r(\ell)^{\omega}}
$$

Across locations, higher housing prices compensate for either higher productivity or higher reservation wages. Employed workers do not move because their value exceeds the common value of unemployment.

With those results at hand, I describe in Section 2.3 below how spatial job loss and unemployment differentials emerge, taking as given the spatial distribution of employer quality $z(\ell)$. Section 2.4 then discusses how the location decision of employers shapes the spatial distribution of employer quality $z(\ell)$ in equilibrium.

\subsection{Equilibrium job loss and unemployment}

Suppose for now that the spatial distribution of employer quality is given by some function $z(\ell)$. At this stage it can be exogenous or determined in equilibrium. In every location, the job losing rate depends on three forces: the average starting productivity at new jobs, the productivity separation threshold, and how fast productivity depreciates from the starting productivity down to the threshold. The productivity depreciation rate is governed by the productivity process (4) and is constant across locations by assumption. Therefore, any differences in local job losing rates must arise because of differences between the average starting productivity and the separation threshold. Both are related to local quality $z(\ell)$ and the reservation threshold $\underline{y}(\ell)$.

To determine exactly how many workers lose their job per unit of time, it is necessary to solve for the invariant distribution of employment across productivities in each location $\ell$. Denote $g(y, \ell)$ its density function. In steady-state, $g(y, \ell)$ solves the Kolmogorov Forward Equation (KFE),

$$
0=\left(L_{y}^{*} g\right)(y, \ell)+n(\ell) g_{0}(y, \ell), \quad y>\underline{y}(\ell)
$$

where $g_{0}(\cdot, \ell)$ is the density associated with the entry distribution $G_{0}\left(y_{0} \mid z(\ell)\right)$, which in turn depends on the quality of jobs $z(\ell)$ that open in location $\ell . n(\ell)$ is the equilibrium inflow of unemployed workers into 
employment. The operator $L_{y}^{*}$ encodes how productivity shocks shape the distribution, and is given by

$$
\left(L_{y}^{*} g\right)(y)=-\left(\frac{\sigma^{2}}{2}-\delta\right) \frac{\partial}{\partial y}(y g(y, \ell))+\frac{\sigma^{2}}{2} \frac{\partial^{2}}{\partial y^{2}}\left(y^{2} g(y, \ell)\right) .
$$

By construction, the density $g$ integrates to unity in each location: $1=\int_{y(\ell)}^{\infty} g(y, \ell) d y$. Brownian shocks imply that the distribution satisfies the boundary condition $g(\underline{y}(\ell), \ell)=0 .^{25}$

To facilitate exposition, I assume that the starting distribution $G_{0}$ is Pareto in the main text. I require that the lower bound of its support is low enough that $\underline{y}(\ell) \geq Y$ in all locations. I show that the Pareto assumption is empirically plausible in Section 2.6. Nonetheless, I also provide more general distributional conditions under which my results hold in Supplemental Material E.5.

Assumption 1. (Initial productivity distribution)

The conditional starting distribution is Pareto with support $[Y,+\infty)$, with $Y \leq b \underline{y}_{0} / \rho$ :

$$
G_{0}\left(y_{0} \mid z\right)=1-\left(\frac{Y}{y_{0}}\right)^{\frac{1}{z}}, \quad z \in(0,1)
$$

Lemma 2 solves the KFE (11) under Assumption 1. Supplemental Material E.4 reports its general solution.

Lemma 2. (Employment distribution)

Let $\kappa=\frac{2 \delta}{\sigma^{2}}$. Under Assumption 1, the solution to the $\operatorname{KFE}(11)$ with $g(\underline{y}(\ell), \ell)=0$ satisfies

$$
g(y, \ell)=\frac{\kappa}{\kappa z(\ell)-1} \frac{1}{y}\left[\left(\frac{y}{y(\ell)}\right)^{-\frac{1}{z(\ell)}}-\left(\frac{y}{\underline{y}(\ell)}\right)^{-\kappa}\right], \quad \forall y \geq \underline{y}(\ell) .
$$

Proof. See Appendix B.3.2

The invariant distribution has two components. The first component reflects the productivity distribution of new jobs. The invariant distribution inherits the right tail from the starting distribution $1 / z(\ell)$. The right tail is thicker in locations with high quality $z(\ell)$. The second component reflects the productivity process. When the negative drift $\delta$ is higher, $\kappa$ is higher, implying that the distribution is more left-skewed as productivity depreciates faster. When volatility $\sigma$ is higher, $\kappa$ is lower and the distribution is more right-skewed: more jobs receive large positive shocks, while large negative shocks are truncated due to endogenous job loss. Finally, the entry rate $n$ does not appear because it simply scales the overall measure of employed workers, as in Hopenhayn and Rogerson (1993).

The equilibrium local job losing rate $s(\ell)$ (or separation rate into unemployment) follows from the invariant distribution in location $\ell$. The job losing rate depends on how many workers are close to the threshold in every location and the volatility of shocks:

$$
s(\ell)=\frac{\sigma^{2} \underline{y}(\ell)^{2}}{2} \frac{\partial g}{\partial y}(\underline{y}(\ell), \ell)
$$

\footnotetext{
${ }^{25}$ In a small time period, the Brownian motion shocks dominate the negative drift. Because these shocks are symmetric, half of the workers close to the threshold are pushed into unemployment in any small time period. Compounded over a non-zero time interval, this process leaves no workers at the threshold. Although it is a standard mathematical result, a formal proof is provided for completeness in Supplementary Material E.3.
} 
Appendix B.3.1 proves this standard accounting result for completeness. Close to the threshold, only workers who receive a negative shock become unemployed. The second order contribution of the measure of workers close to the threshold $\frac{\partial g}{\partial y}(\underline{y}(\ell), \ell)$ then shapes the number of job losers, because $g(\underline{y}(\ell), \ell)=0$.

Combining expression (12) for the local job losing rate with the solution to the distribution in Lemma 2 produces a simple solution for local labor market flows. The main text reports the expression under Assumption 1. Proposition 8 in Supplemental Material E.4 describes the general solution.

Proposition 1. (Spatial unemployment differentials)

Under Assumption 1, the local job losing, finding and unemployment rates in location $\ell$ are

$$
s(\ell)=\frac{\delta}{z(\ell)}, \quad f_{R}(\ell)=f(\theta(\ell)) \times\left(\frac{Y}{\underline{y}(\ell)}\right)^{\frac{1}{z(\ell)}}, \quad u(\ell)=\frac{s(\ell)}{s(\ell)+f_{R}(\ell)} .
$$

Proof. See Appendix B.3.3

When the negative drift $\delta$ is higher, productivity depreciates faster everywhere and job losing rates rise uniformly. In locations with low quality $z(\ell)$, new jobs draw from a left-skewed productivity distribution and enter close to the equilibrium threshold $\underline{y}(\ell)$. They fall below the threshold early on and the local job losing rate is high. Where quality $z(\ell)$ is high, jobs start far from the threshold $y(\ell)$. There, it takes more time for productivity to depreciate and the job losing rate is low. ${ }^{26}$

Of course, the reservation threshold $\underline{y}(\ell)$ depends on quality $z(\ell)$ in equilibrium. But the threshold rises less than one-for-one with quality because of discounting. Unemployed workers must search for some time before finding a job and earning wages comparable to those of employed workers. The strength of this discounting effect thus increases with the discount rate $\rho$ and decreases with the equilibrium job finding rate $f_{R}(\ell)$ as shown in Appendix B.4.3.

Two forces in turn shape the job finding rate $f_{R}(\ell)$ : the worker meeting rate $f(\theta(\ell))$ and the probability that a given meeting results in a job, the success probability of a meeting $(Y / \underline{y}(\ell))^{1 / z(\ell)}$. Whether these forces closely balance depends on the cross-sectional patterns of labor market tightness $\theta(\ell)$ and employer quality $z(\ell)$. In equilibrium, they are determined by the location choice of employers.

\subsection{The location choice of employers}

An employer with quality $z$ contemplates the expected value from entering in each location, and chooses the location that delivers the highest payoff. After matching at rate $q(\ell)$, the employer receives a share $1-\beta$ of the adjusted surplus. The expected payoff of employer $z$ in location $\ell, \bar{J}(z, \ell)$, then follows from integrating over the initial productivity distribution $G_{0}\left(y_{0} \mid z\right)$ :

$$
\rho \bar{J}(z, \ell)=q(\ell)(1-\beta) \int S\left(y_{0}, \ell\right) G_{0}\left(d y_{0} \mid z\right)
$$

\footnotetext{
${ }^{26}$ The volatility $\sigma$ does not affect the job losing rate. When volatility rises, matches receive larger negative shocks, pushing them to break up more frequently. But matches also receive larger positive shocks, raising the option value of producing and lowering the threshold. With a Pareto entry distribution, both channels exactly offset each other.
} 
Under Assumption 1, I show in Appendix B.4.1 that the expected payoff of employer $z$ in location $\ell$ satisfies

$$
\log \left((\bar{\rho} \bar{J}(z, \ell))^{\frac{z}{1-z}}\right)=\underbrace{\frac{z}{1-z} \log \bar{S}(z)}_{\begin{array}{c}
\text { Absolute } \\
\text { advantage }
\end{array}}+\underbrace{\frac{z}{1-z} \log \ell}_{\begin{array}{c}
\text { Production } \\
\text { complementarities }
\end{array}}+\underbrace{\frac{z}{1-z} \log q(\ell)}_{\begin{array}{c}
\text { Pooling } \\
\text { complementarities }
\end{array}}-\underbrace{\log \underline{w}(\ell)}_{\begin{array}{c}
\text { Cost of } \\
\text { labor }
\end{array}},
$$

where $\bar{\rho}=\rho+\frac{\beta}{1-\beta} \underline{y}_{0}$ and $\bar{S}(z)=\left(Y / \underline{w}_{0}\right)^{1 / z} \frac{z}{1-z} \frac{\tau z}{\tau z+1}$.

Four forces shape how employers value different locations. The first term on the right-hand-side of equation (14) encodes the absolute advantage of employers according to their job quality $z$. High quality jobs draw from a better starting distribution, have higher productivity on average and earn higher profits everywhere. This term does not affect the location choice of employers.

The second term reflects standard technological complementarities in production. Some locations may be particularly well-suited for production for reasons unrelated to labor market frictions. The production function implies that more productive employers benefit relatively more from high local productivity $\ell$. As a result, they value locating in highly productive locations more than unproductive employers.

The third term in equation (14) lies at the core of the mechanism this paper uncovers. It reveals that more productive employers value relatively more locations where recruiting is easy - where the vacancy meeting rate $q(\ell)$ is high. Because more productive employers generate higher profits, waiting longer until they meet a worker and start producing is relatively more costly for them. Higher foregone profits thus translate into a higher opportunity cost of time for more productive employers. ${ }^{27}$

The vacancy meeting rate $q(\ell)=m \theta(\ell)^{-\alpha}$ depends on local labor market tightness $\theta(\ell)$ in equilibrium. Ultimately, it depends on the pool of employers and workers who choose to locate in $\ell$. Therefore, I follow Marshall (1920)'s terminology and call the complementarity between employer quality $z$ and local recruiting conditions $q(\ell)$ a labor market pooling complementarity. In contrast to technological complementarities in the assignment literature without frictions, the pooling complementarity emerges because the location choice of heterogeneous employers interacts with local labor market frictions.

The fourth term in equation (14) simply reflects the expected cost of labor in a particular location $\ell$, which can be summarized by the reservation wage $\underline{w}(\ell)$. All employers prefer locations with low labor costs where the reservation wage is low.

An employer with quality $z$ thus solves

$$
\ell^{*}(z)=\underset{\ell}{\operatorname{argmax}} \frac{z}{1-z} \log \ell+\frac{z}{1-z} \log q(\ell)-\log \underline{w}(\ell) .
$$

Employers face a trade-off between local productivity, recruiting conditions and wages. The technological complementarity implies that more productive employers are willing to pay more to locate in places with high productivity. There, unproductive employers are priced out by high wages and locate instead in low-productivity places.

The pooling complementarity implies that more productive employers are willing to pay more to locate in places with favorable recruiting conditions. There, unproductive employers are priced out

\footnotetext{
${ }^{27}$ Some meetings do not result in a viable match, so that the vacancy filling rate and the vacancy meeting rate differ. The probability that a meeting results in a match, $(Y / \underline{y}(\ell))^{1 / z}$, depends on both the employer type $z$ (first term in equation (14)) and on local reservation wages $\underline{w}(\ell)$ through the separation threshold $\underline{y}(\ell)$ (last term in equation (14)).
} 
by high wages. At the margin, they self-select into low wage areas with low vacancy meeting rates. Importantly, the pooling complementarity determines employer sorting conditional on local productivity $\ell$. Unconditionally, both local productivity and recruiting conditions drive location decisions, and sorting patterns are more complex.

The differential valuation of locations by different employers plays the role of single-crossing conditions. Although employers face a dynamic optimal stopping problem in each location, Lemma 1 simplifies location decisions to equation (15), which resembles standard static assignment problems. Apart from the underlying dynamic production decision, another distinction with static assignment problems arises. Traditional assignment problems resolve the sorting between two-sided markets with exogenous payoffs. By contrast, in the present model, local labor markets clear through the adjustment of labor market tightness $\theta(\ell)$. The latter in turn feeds back into recruiting conditions, adding an additional layer of general equilibrium effects to the payoffs that determine the assignment. This feedback acts as an agglomeration force, with two implications. First, cities with different ex-post characteristics emerge in equilibrium even in the absence of ex-ante heterogeneity. Second, well-known multiplicity issues may arise. ${ }^{28}$

I define an assignment pair as a pair of functions $\ell \mapsto(z(\ell), \underline{w}(\ell))$, where $z(\ell)$ is the assignment function of employers to locations. It is the inverse of $\ell^{*}(z)$. In this paper, I call $z(\ell)$ the assignment function, while $\mathcal{M}$ is the matching function that determines meetings in the labor market. $\underline{w}(\ell)$ is the equilibrium reservation wage that supports this location choice. Proposition 2 below characterizes the assignment.

\section{Proposition 2. (Sorting)}

Impose Assumption 1. Fix the equilibrium value of unemployment $U$ and the measure of new jobs $M_{e}$. There exists a unique solution $\ell \mapsto(z(\ell), \underline{w}(\ell))$ to $(15)$ among all possible assignments with increasing $z$. There exists a threshold $\underline{\alpha}>0$ such that for all $\alpha \in[0, \underline{\alpha}]$, this solution is unique among all possible assignments. $z$ and $\underline{w}$ are strictly increasing. In addition, the job losing rate $s(\ell)$ is decreasing in $\ell$.

Proof. See Appendix B.4.4.

Proposition 2 establishes existence of the assignment with positive assortative matching between local productivity $\ell$ and employer quality $z$ : more productive employers go to more productive locations. Restricting attention to assignments that exhibit positive assortative matching is only a mild restriction, for two reasons. First, positive assortative matching is the only possibility when the matching function elasticity $\alpha$ is not too large. Proposition 9 in Supplemental Material E.5 extends this result to more general distributional conditions for $G_{0}$. Second, any other potential steady-state assignment is dynamically unstable for any value of $\alpha$, in a sense made precise in Proposition 10 in Supplemental Material E.6.

The spatial sorting of employers immediately implies that job losing rates $s(\ell)=\delta / z(\ell)$ given in Proposition 1 are decreasing in local productivity $\ell$. This monotonicity property equips the model to account for large dispersion in job losing rates across local labor markets.

The equilibrium response of local reservation wages $\underline{w}(\ell)$ sustains the assignment. Reservation wages adjust up to the point where the marginal employer $z(\ell)$ is indifferent between locations $\ell$ and $\ell+d \ell$. Reservation wages reflect expected future wages conditional on starting work, which depend on equilibrium

\footnotetext{
${ }^{28}$ See Sattinger (1993), Topkis (1998), Villani (2003), Galichon (2016) and Davis and Dingel (2020) for standard assignment models. Gaubert (2018) generates differences across cities when employer technology depends directly on population. See Grossman and Rossi-Hansberg (2012) for multiple equilibria in a spatial context with agglomeration economies. See Chade and Eeckhout (2019) for multiplicity in a search and matching context.
} 
employer quality $z(\ell)$. Therefore, reservation wages rise with $\ell$. However, recall that reservation wages rise less than one-for-one relative to wages of employed workers due to discounting.

Worker mobility limits the variation in both components of job finding rates $f_{R}(\ell)=f(\theta(\ell)) \times$ $(Y / \underline{y}(\ell))^{1 / z(\ell)}$ given in Proposition 1. Even though high quality employers value slack labor markets at the margin, workers out-migrate from locations with excessively slack labor markets. Thus, there can be only limited spatial variation in worker meeting rates $f(\theta(\ell))$. Similarly, the sucess probability of meetings $(Y / \underline{y}(\ell))^{1 / z(\ell)}$ reflects offsetting forces. Locations with high quality employers $z(\ell)$ tend to have higher success probabilities of meetings because jobs start out further away from any given threshold $\underline{y}(\ell)=\underline{w}(\ell) / \underline{y}_{0}$. There, however, workers are also more selective and have high reservation thresholds $\underline{y}(\ell)$. These forces need not offset each other exactly, but when they nearly do, the job finding rate is close to flat across locations.

\subsection{Equilibrium and comparative statics}

Having described how the location choice of employers shapes spatial unemployment differentials, I close the economy in the decentralized equilibrium. Local housing and labor markets clear in each location $\ell$ :

$$
r(\ell)=\omega L(\ell)(u(\ell) b \ell+(1-u(\ell)) \bar{w}(\ell)), \quad \theta(\ell)=\frac{M_{e} F_{z}^{\prime}(z(\ell)) z^{\prime}(\ell)}{u(\ell) L(\ell) F_{\ell}^{\prime}(\ell)}
$$

where $L(\ell)$ is population in location $\ell$, and $\bar{w}(\ell)=\int w^{*}(y, \ell) g(y, \ell) d y$ is the average wage in location $\ell$.

Local housing prices reflect local expenditures on housing. Labor market clearing simply states that labor market tightness is the ratio between the number of vacancies and the number of unemployed workers in locations with productivity $\ell$. The number of unemployed workers is the unemployment rate times total population across the $F_{\ell}^{\prime}(\ell) d \ell$ locations with productivity in $[\ell, \ell+d \ell)$. The number of vacancies in a location reflects the total number of new jobs, $M_{e}$, but also the spatial sorting of employers. There are fewer employers in locations where the assignment function $z$ is steep. In that case, a given measure of employers is stretched across a wider set of locations.

Employers enter freely each period, so that the cost of entry is equal to the expected value from entering. Population in the economy adds up to unity:

$$
c_{e}=\int \bar{J}\left(z, \ell^{*}(z)\right) d F_{z}(z), \quad 1=\int L(\ell) d F_{\ell}(\ell) .
$$

A decentralized equilibrium is comprised of a measure of entering employers $M_{e}$, a value of unemployment $U$, an assignment function $z(\ell)$, a reservation wage function $\underline{w}(\ell)$, wages of employed workers $w^{*}(y, \ell)$, an employment distribution $g(y, \ell)$, a distribution of unemployment $u(\ell)$ and market tightness $\theta(\ell)$, housing prices $r(\ell)$, and a population distribution $L(\ell)$, such that $(5),(6),(8)$, the definitions in Lemma 1, (9), (10), (15), (11), (12), (16), and (17) hold. Proposition 3 guarantees that there exists a unique steady-state equilibrium with positive assortative matching, when there is not too much dispersion in spatial and productivity primitives.

Proposition 3. (Existence and uniqueness)

Under Assumption 1, there exists a decentralized steady-state equilibrium with positive assortative matching. There exist $d_{z}, d_{\ell}>0$ such that, for $|\bar{z}-\underline{z}|<d_{z}$ and $|\bar{\ell}-\underline{\ell}|<d_{\ell}$, the equilibrium is unique. 
Proof. See Appendix B.5.

I shed further light on how the labor market pooling complementarity shapes spatial unemployment gaps using a particular limiting equilibrium and Proposition 3. Suppose that ex-ante spatial differences in $\ell$ become arbitrarily small. In that case, the pooling complementarity alone drives sorting and any ex-post differences across locations. Corollary 1 below shows that spatial gaps in job losing and unemployment rates arise even in the absence of any ex-ante heterogeneity between locations.

Corollary 1. (Equilibrium spatial gaps with ex-ante identical locations)

Suppose that the conditions in Proposition 3 hold and that the matching function elasticity $\alpha$ is strictly positive. Then the variance of local job losing and unemployment rates remain strictly positive and bounded above zero as the variance in exogenous differences $\ell$ goes to zero.

Proof. See Appendix B.6.

This result highlights that the pooling complementarity suffices to sustain sorting in equilibrium, irrespectively of technological complementarities. ${ }^{29}$ When technological differences $\ell$ vanish, locations are ex-ante identical and ex-post differences emerge endogenously. In particular, job losing and unemployment rates differ across locations. This is possible because housing prices adjust in the background to allow differences in reservation wages. By contrast, if housing played no role $\omega=0$, all locations would become ex-post identical because free mobility (10) would equalize reservation wages across locations.

Propositions 1, 2, 3 and Corollary 1 conclude the positive implications of the theory. Before turning to its normative implications, the next section proposes reduced-form empirical evidence supporting the key mechanisms that determine job losing and finding rates in the model.

\subsection{Model validation}

This section provides empirical support for two crucial mechanisms. The first mechanism is the link between labor productivity and job losing rates. The second mechanism is the response of labor market tightness that determines job finding rates.

Labor productivity and job losing rates. The productivity process (4) and the distribution in Lemma 2 deliver testable implications linking labor productivity to job losing rates.

Corollary 2. (Labor productivity and job losing rates)

1. Matches with higher labor productivity are less likely to separate into unemployment in all locations.

2. Log labor productivity growth of incumbent jobs is independent from location.

3. Average log labor productivity is higher in locations with lower job losing rates.

4. The labor productivity distribution first-order stochastically decreases with local job losing rates.

5. The labor productivity distribution has a Pareto tail with index $1 / z(\ell)$ in each location.

${ }^{29}$ The limit of arbitrarily small differences selects one particular equilibrium in the limit without any exogenous spatial heterogeneity. When exogenous spatial differences are exactly zero, locations can be arbitrarily reshuffled. There are only two possible spatial distributions of equilibrium outcomes: the mixing distribution in which all locations are identical, and the separating distribution in which locations differ due to sorting. Taking the limit under vanishing spatial heterogeneity always selects the separating distribution. In addition, the mixing distribution is trembling-hand unstable. 
Figure 4: Labor productivity, job loss and labor market tightness in France.

(a) Job loss by employer productivity. (b) Labor productivity distributions.

(c) Labor market tightness.
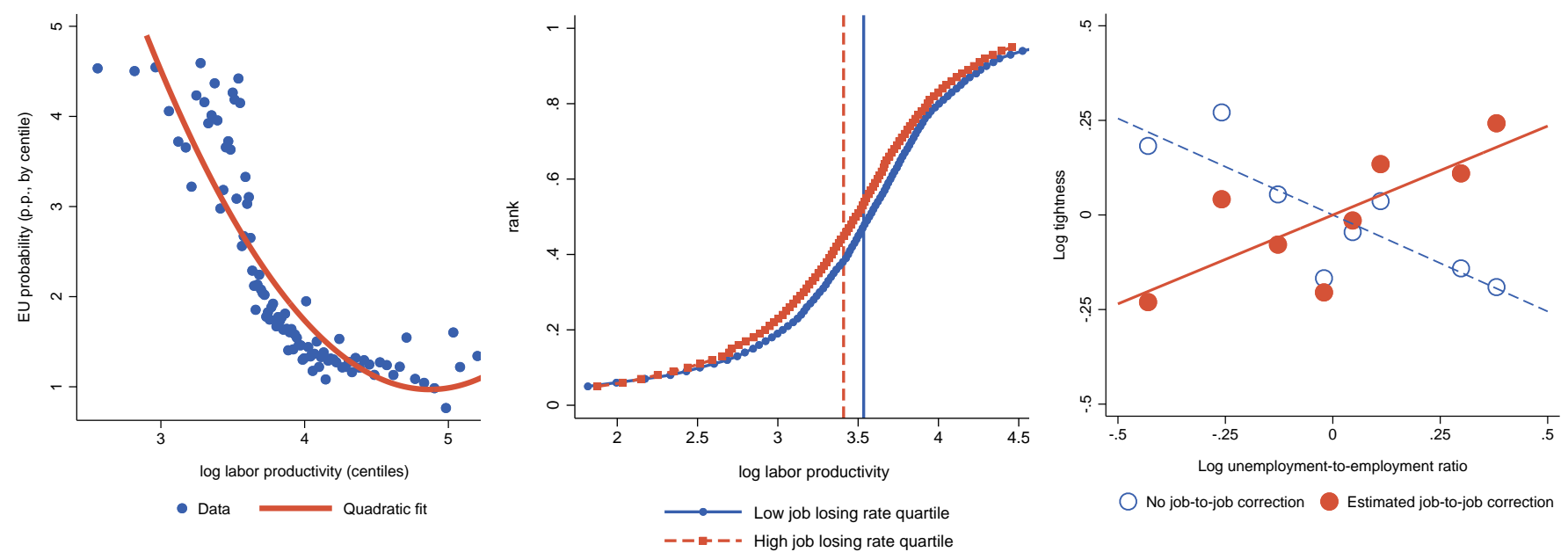

Note: Figure 4(a) scatterplots the employment-to-unemployment transition probabilities for workers, across percentiles of their employer's labor productivity. Figure 4(b) plots empirical cumulative labor productivity distribution functions in the bottom and top quartiles of commuting zones, ranked by job losing rate. Vertical lines mark within-quartile averages of labor productivity. Figure 4(c) scatterplots two measures of log labor market tightness across 8 groups of French commuting zones $c$. Blue circles represent the raw measure of labor market tightness without job-to-job adjustments: $\theta_{c}=\mathcal{V}_{c} / \mathcal{U}_{c}$, where $\mathcal{V}_{c}$ is the number of vacancies and $\mathcal{U}_{c}$ the number of unemployed workers. Orange dots represent the adjusted measure that include employed workers as effective job seekers: $\tilde{\theta}_{c}=\mathcal{V}_{c}\left(\mathcal{U}_{c}+\xi \mathcal{E}_{c}\right)$, where $\mathcal{V}_{c}$ is the number of vacancies, $\xi$ the relative search efficiency of employed workers, and $\mathcal{E}_{c}$ the number of employed workers.

\section{The ratio of Pareto tails indices equals the ratio of job losing rates between locations.}

Proof. See Appendix B.7.1.

To test implications 1 to 6 , I compute labor productivity in single-establishment firms using the firm-level balance sheet data described in Section 1.1. Figure 4(a) tests implication 1. It scatterplots job losing rates for workers across percentiles of their employer's labor productivity. Consistent with persistence in the productivity process (4) that ties together the productivity of a match at a given point in time and the probability of job loss, matches at more productive employers are more stable. Table 7 in Appendix B.7 correlates labor productivity growth with local job losing rates. Consistent with a single productivity process across locations and implication 2, there is no evidence of systematic variation of labor productivity growth.

Figure 4(b) tests implications 3 and 4 . It displays the labor productivity distribution in the bottom and top quartiles of commuting zones, ranked by their job losing rate. The vertical lines are local averages. Consistent with implication 3, average labor productivity is higher in locations with low job losing rates. Consistent with the more subtle implication 4, the cumulative distribution function of labor productivity in low job losing rate locations is always below the cumulative distribution function in high job losing rate locations: the labor productivity distribution first-order stochastically decreases with the job losing rate. Figure 14 in Appendix B.7 provides empirical support for implications 5 and 6 and therefore the Pareto assumption.

Labor market tightness. Proposition 1 delivers a single robust prediction for labor market tightness: spatial variation in labor market tightness must be small relative to spatial variation in job losing rates. 
Otherwise, job finding rates would vary too much relative to the data.

Should tightness correlate positively or negatively with local unemployment? The answer is ambiguous in general. Corollary 1 indicates that, without any variation in local fundamentals $\ell$ across locations, tightness and unemployment should be positively correlated as the labor market pooling complementarity pulls stable jobs towards slack labor markets. Corollary 1 is an extreme case however. When firms sort based on local fundamentals $\ell$ as well as the labor market pooling complementarity, the correlation between tightness and unemployment can take any sign. In fact, I show numerically in Section 4.1 that the model can generate both positive and negative correlations depending on parameter values.

I use establishment-level vacancy data from France to evaluate the cross-sectional variation in labor market tightness. I correct for job-to-job search and construct tightness using effective job seekers to be consistent with the model. ${ }^{30}$

Figure 4(c) reveals that the cross-sectional dispersion in tightness is unambiguously small relative to the variation in job losing rates in Figure 2(a), regardless of the job-to-job correction. The variation in tightness is similar to that in job finding rates in Figure 2(b). If anything, labor market tightness after the job-to-job correction correlates positively with local unemployment rates. Without the correction, the correlation is negative. Thus, the correlation between tightness and unemployment remains largely ambiguous both theoretically and empirically.

\subsection{Efficiency and planning allocation}

Having validated the positive implications of the model, this section investigates its normative properties. A utilitarian planner maximizes a possibly weighted sum of values of all individuals in the economy, taking search frictions as given. ${ }^{31}$ The planner decides where to send workers to search for jobs and when to break up matches. The infinite-dimensional distribution of employment across productivities and locations is a state variable because idiosyncratic productivity shocks are persistent. Nevertheless, I establish a well-defined planner problem building on Moll and Nuño (2018) in Supplemental Material F.1.1. For brevity, I simply characterize its solution in the main text. Denote with $S P$ superscripts variables in the planning solution, and with $D E$ superscripts variables in the decentralized equilibrium.

Proposition 4. (Planning solution)

- Sorting (Proposition 2), local labor market flows (Proposition 1), and existence and uniqueness (Proposition 3) results extend to the planning solution under the same conditions using Negishi utility weights from equation (55).

- The decentralized equilibrium is inefficient for all values of $\alpha, \beta \in(0,1]$.

- Suppose $\beta=\alpha$. Under the conditions of Proposition 3, for all $\ell$ :

$\circ z^{S P}(\ell) \geq z^{D E}(\ell)$ with equality if and only if $\ell \in\{\underline{\ell}, \bar{\ell}\}$.

$\circ \frac{\partial \log \underline{w}^{D E}}{\partial \ell}(\ell)>\frac{\partial \log \underline{w}^{\mathrm{SP}}}{\partial \ell}(\ell)$.

\footnotetext{
${ }^{30}$ In the data, employed workers capture a sizable fraction of vacancies, while in the model only unemployed workers apply to vacancies. Therefore, I estimate the relative search intensity of employed workers $\xi$ in Supplemental Material E.7. I then adjust the number of effective job seekers to compute labor market tightness in city $c: \hat{\theta}_{c}=\frac{\mathcal{V}_{c}}{\mathcal{U}_{c}+\xi \mathcal{E}_{c}}$, where $\mathcal{V}_{c}$ is the number of vacancies, $\mathcal{U}_{c}$ the number of unemployed workers, and $\mathcal{E}_{c}$ the number of employed workers.

${ }^{31}$ Because the planner can reallocate the final good across locations while workers can only consume their income in the decentralized equilibrium, only one set of utility weights delivers planning allocations that may coincide with the decentralized equilibrium. They are standard Negishi weights and defined in equation (55), Supplemental Material F.1.
} 
- The planning and decentralized equilibrium allocations coincide when search is directed.

Proof. See Supplemental Material F.1.2.

Proposition 4 first establishes that the basic sorting, labor market flows, existence and uniqueness properties of the decentralized equilibrium also hold in the planning solution. To interpret the normative implications of Proposition 4, recall that in a single-location search model such as Mortensen and Pissarides (1994), the only sources of inefficiency are the entry and separation margins. Both margins are efficient only when employers are compensated for opening and shutting down jobs by exactly as much as they congest the matching function. This is the case when the Hosios (1990) condition $\alpha=\beta$ holds. The same logic carries through to the multi-location model for the overall entry and separation decisions.

With geography, employers make an additional location decision. When employers enter a local labor market, the composition of local competitors impacts their ability to recruit: they are pooled in the same matching function. The labor market pooling complementarity in equation (14) embeds this externality. This externality ultimately distorts the location decisions of employers regardless of whether the Hosios (1990) condition $\alpha=\beta$ holds. Thus, I call it a labor market pooling externality.

To understand the nature of the labor market pooling externality, first recall the composition externality that arises when different employers compete in the same labor market as in Acemoglu (2001). Consider two locations $\ell_{1}<\ell_{2}$. Each location is populated with employers $z_{1}=z\left(\ell_{1}\right)<z\left(\ell_{2}\right)=z_{2}$. Consider a marginal employer $z \in\left(z_{1}, z_{2}\right)$ contemplating entry in locations $\ell_{1}$ or $\ell_{2}$. If employer $z$ enters in location $\ell_{2}$, it is worse than the average local employer. Due to labor market frictions however, it meets as many workers as its more productive competitors. This composition externality is socially harmful, as workers are redirected towards a less productive employer, $z<z_{2}$. Symmetrically, entrant $z$ meets as many workers as its less productive competitors if it enters in location $\ell_{1}$. The composition externality is socially beneficial in this case, as workers are redirected towards a more productive employer, $z>z_{1}$.

The labor market pooling externality materializes once employers decide where to locate. It is a spatial manifestation of the composition externality in Acemoglu (2001), although all locations have a single employer quality in equilibrium. Consider the private and the planner's values of entry of job $z$ in a particular location. Conditional on the separation threshold $\underline{y}(\ell)$, they satisfy

$$
\left(\frac{\bar{J}^{D E}(z, \ell)}{\bar{J} S P(z, \ell)}\right)^{\frac{1-\alpha}{\alpha}}=\frac{\overline{\mathcal{S}}\left(z^{D E}(\ell)\right)}{\overline{\mathcal{S}}(z)} \cdot(Y / \underline{y}(\ell))^{\frac{1}{z^{D E}(\ell)}-\frac{1}{z}} .
$$

where $\overline{\mathcal{S}}(z)$ is increasing and defined in Appendix B.4.1. The planner's valuation of opening job $z$ in location $\ell$ only depends that particular job quality $z$. The planner internalizes that it is suboptimal to pool different employers in the same local labor market and chooses as if all jobs of the same quality located identically. By contrast, the private value from entering in the same location $\ell$ for job $z$ also depends on the quality of local competitors $z^{D E}(\ell)$. Private employers take their competitors' location decisions as given, which determine the local vacancy meeting rate in equilibrium.

Every employer $z$ has an incentive to free-ride favorable recruiting conditions in better locations than the planner's choice. Indeed, the vacancy meeting rate of employer $z$ does not reflect that employer $z$ is worse than its competitors in locations where $z<z^{D E}(\ell)$. In equation (18), $z^{D E}(\ell)$ is increasing, leading employers to over-value opening jobs in locations where other employers are productive. This free-riding 
incentive emerges off equilibrium since all locations end up with a single employer type in equilibrium. Yet, on net, employers concentrate too much in the best labor markets relative to the social optimum. The labor market pooling externality trickles down across locations and generates misallocation throughout the economy. Reservation wages rise faster in equilibrium than the planner's shadow value. For any location $\ell$, local employers are not productive enough in the decentralized equilibrium, and $z^{D E}(\ell) \leq z^{S P}(\ell)$.

The labor market pooling externality rests on the assumption that matches are formed with some degree of randomness. In that case, wages are bargained after matches are formed. This lack of commitment prevents wages from fully pricing meeting rates. By contrast, the decentralized equilibrium is efficient when search is fully directed. In that case, the key assumptions are that employers can commit to contracts, and that workers can frictionlessly arbitrage between contracts in segmented submarkets within each location. Employers then internalize that by entering in a local labor market with higher quality than their own, they depress their meeting rate as workers direct their search away towards the more productive jobs. As a result, wage contracts exactly price congestion effects, which leads to efficiency. Whether search is directed or random is ultimately an empirical question with data requirements that go beyond the scope of this paper. In principle, reality is likely to lie between both models.

Nevertheless, I propose two checks to lend credibility to this paper's welfare implications. First, I allow employers to post many vacancies in the extended model of Section 3.1. More productive employers post more vacancies than less productive ones. Thus, they meet with relatively more workers, mitigating the strength of the externality, akin to directed search. The vacancy cost elasticity then determines where the model lies between random and directed search. At the estimated elasticity, I find large welfare effects from place-based policies. Second, Table 1 in Section 4.1 shows that re-estimating the model under the directed search assumption delivers too little dispersion in local unemployment rates relative to the data and misses the variance decomposition into job losing and finding rates described in Section 1. The directed search model lacks the labor market pooling externality, which increases the incentives for productive employers to co-locate. Thus, spatial sorting is weaker and job losing and unemployment rate differentials are smaller under directed search. Conditional on the rest of the model and in this spatial context, the data thus supports the random search assumption among those two extreme cases.

\subsection{Optimal policy}

Given that the decentralized equilibrium does not attain the first best, a natural question is whether it can be restored using standard policy instruments. An optimal policy should achieve the following. First, it should correct the pooling externality by incentivizing employers to open jobs in low profitability locations. Second, it should enforce the Hosios (1990) condition. I introduce place-based policies into the model in Supplemental Material F.2. Proposition 5 shows that they can implement the first best.

Proposition 5. (Optimal policy)

Constrained efficiency is restored with a combination of place-based policies:

- A labor subsidy increasing in local productivity $\ell$ if and only if $\beta<\alpha$.

- A profit subsidy $\tau^{*}$ decreasing in local productivity $\ell$. Under the conditions of Proposition 3 and when $\alpha$ is small enough, to first order: $\frac{\tau^{*}\left(\ell_{2}\right)}{\tau^{*}\left(\ell_{1}\right)}=\left(\frac{s^{D E}\left(\ell_{2}\right)}{s^{D E}\left(\ell_{1}\right)}\right)^{\frac{r \alpha}{1-\alpha}}$, where $r$ is a general equilibrium constant. 


\section{- A lump-sum transfer to owners. ${ }^{32}$}

Proof. See Supplemental Material F.2.

The labor subsidy implements the Hosios (1990) condition. As in Kline and Moretti (2013), spatial variation in workers' value of search makes that policy place-specific. Similarly to their results, labor needs to be taxed more heavily in low productivity locations on the empirically relevant side of the Hosios (1990) condition $\beta<\alpha$. Because this particular trade-off has been extensively studied, I focus primarily on the externality in the location choice of jobs.

A profit subsidy - or corporate tax credit relative to a base rate - is the simplest way to correct the spatial misallocation that results from the labor market pooling externality. The profit subsidy corrects the labor market pooling externality that equation (18) obviates. Subsidies rise as local productivity $\ell$ diminishes. Hence, subsidies are more generous in locations with high job losing rates $s(\ell)$ as per Proposition 1. The local job losing rate thus provides a sufficient statistic for the direction of optimal place-based policies.

Proposition 5 provides a formula for the optimal policy under additional restrictions. The optimal policy depends on few parameters and outcomes. The profit subsidy $\tau^{*}$ is increasing in the job losing rate with a combined elasticity $\frac{r \alpha}{1-\alpha}$ that rises with the matching function elasticity $\alpha$. When $\alpha=0$, recruiting conditions are exogenous, there is no labor market pooling externality and so there is no need for policy. The combined elasticity also depends on a constant $r$ that captures the surplus and success probability elasticities consistently with equation (18). This constant $r$ ultimately depends on parameters of the productivity process and the observed success probability, and turns out to be close to 2 in the estimated model of Section 3.1. Although the closed-form formula holds only under additional restrictions, it provides a reasonable approximation to the exact optimal policy as shown in Figure 16, Appendix C.13.

The optimal policy thus resembles real-world place-based policies that target areas with high job losing and unemployment rates. For instance, the Empowerment Zone program in the United States and its French equivalent - the "Zones Franches Urbaines"-both grant large effective corporate tax credits for firms that open jobs in distressed areas. The labor market pooling externality offers a structural justification for subsidizing these high unemployment areas: high productivity employers fail to internalize their positive labor market spillovers there. To the best of my knowledge, this is the first paper to propose a structural justification for such policies based on frictional labor markets and two-sided mobility of workers and employers.

In practice, profit subsidies raise clear concerns of fiscal optimization and profit-shifting between establishments within firms. Can the first best be attained with employment, wage or value added tax or subsidies alone? I explore alternative tax schemes in Supplemental Material F.2. A value added subsidy restores the efficient location decisions provided its distortive effects on job creation and separations are offset by wage or unemployment subsidies. Yet, value added subsidies are subject to similar concerns to profit subsidies. Employment and wage subsidies alone cannot restore efficiency. They affect the location decision of employers through reservation wages, thereby distorting job creation and separation.

These differences between different subsidies can help rationalize why the evidence on place-based policies remains ambiguous. If the mix of actual subsidies changes from case to case, the results in

\footnotetext{
${ }^{32}$ Alternatively, if there are no absentee owners and profits are rebated to workers with a flat earnings subsidy, then a flat earnings tax replaces the lump-sum tax on owners.
} 
Supplemental Material F.2 indicate that effects should be variable. I leave the design of a robust subsidy scheme to fully or at least partially correct the labor market pooling externality for future research. Instead, I focus on the optimal profit subsidies to highlight the potential gains from place-based policies.

So far the spatial and individual heterogeneity in the model has remained minimal. To quantitatively account for local labor market flows and the welfare effects of place-based policies, I enrich this baseline framework in Section 3 below.

\section{$3 \quad$ Extended model and estimation}

In this section, I first describe the extensions of the model. I then establish how the results from Section 2 extend to the richer environment. Finally, I detail the estimation strategy, identification and validation.

\subsection{Quantitative setup}

Geography. Locations now differ both in productivity $p$ and residential amenities $a$. Locations are indexed by productivity-amenity pairs $\ell=(p, a)$ with cumulative function $F_{\ell}$ on a connected support. This flexible parametrization of amenities captures unobserved physical or institutional attributes that attract workers beyond labor and housing market conditions, such as pleasant weather, or high quality schools and hospitals. Quantitatively, amenities let the model fit joint variation in population, wages, and unemployment across places.

Housing supply. Perfectly competitive land developers now use the final good to produce housing on a unit endowment of land with an isoelastic production function. The resulting housing supply curve $H(r(\ell))=H_{0} r(\ell)^{\eta}$ flexibly captures local congestion from housing prices. ${ }^{33}$

Migration frictions. Workers now receive the opportunity to move at Poisson rate $\mu \geq 0$. When hit by this moving opportunity, they draw a set of Frechet-distributed preference shocks for locations $\left\{\varsigma_{\ell}\right\}_{\ell}$ with shape parameter $1 / \varepsilon$, and choose where to locate. Those shocks stay constant until the next moving opportunity arrives. $1 / \varepsilon$ then governs the migration elasticity to real income differences. ${ }^{34}$

Preferences. The flow utility function becomes $u(c, h, a, \bar{\varsigma})=\left(\frac{c}{1-\omega}\right)^{1-\omega}\left(\frac{h}{\omega}\right)^{\omega} a \bar{\varsigma}$, where $\bar{\varsigma}$ denotes the product of all past taste shocks the worker received for locations they chose. ${ }^{35}$

Non-participation. Workers now exit the labor force at Poisson rate $\Delta>0$. When they do, a single new worker replaces them.

Scarring effects and human capital. Workers now differ in their time-varying human capital $k$. When employed, human capital grows at rate $\lambda \geq 0$. When unemployed, human capital grows at rate $\lambda-\varphi$.

\footnotetext{
${ }^{33}$ The distribution of location types $F_{\ell}$ together with unit land in each location can capture long-run land use policies such as zoning restrictions in a stylized way. Zoning restrictions manifest in part as a limited supply of high-productivity locations. The model captures this pattern if the distribution $F_{\ell}$ puts low mass in high- $\ell$ places.

${ }^{34}$ The shifter is normalized to $1 / \Gamma(1-\varepsilon)$, where $\Gamma$ is Euler's Gamma function, because it is not separately identified from amenities $a$. This normalization ensures that preferences shocks have mean 1. Supplemental Material G.4 extends standard discrete choice results to a continuum of locations.

${ }^{35}$ As in Desmet et al. (2018) and Caliendo et al. (2019), $\bar{\varsigma}_{t}=\prod_{i=1}^{N_{t}} \varsigma_{t_{i}}\left(\ell_{t_{i}}\right)$, where $\left(t_{i}\right)_{i=1}^{N_{t}}$ denote times when workers received migration opportunities between calendar times 0 and $t$.
} 
The scarring rate $\varphi \geq 0$ encodes the relative depreciation rate of human capital during unemployment. For simplicity, the distribution of human capital of new workers $k_{t}$ shifts at rate $\lambda .{ }^{36}$ All workers in the same location search in the same labor market: potential employers cannot discriminate between workers with different human capital before meeting them.

Production. Employers now use housing in production, to capture that local congestion due to higher population affects production costs. The production function becomes $(y p k)^{\frac{1}{1+\psi}} h^{\frac{\psi}{1+\psi}}$, where $y$ is employer productivity, $p$ is location productivity, $k$ is worker human capital, and $h$ is housing.

Recruiting intensity. Employers can now adjust their recruiting efforts. This channel potentially mitigates the strength of labor market pooling externalities. Employers with open jobs may post many vacancies $v$ at $\operatorname{cost} \frac{c_{v}}{1+1 / \gamma} v^{1+1 / \gamma}$.

\subsection{Characterization}

The extensions preserve the basic structure of the location choice of employers. Supplemental Material $G$ shows that, to a first order when migration opportunites are rare enough $\mu \ll 1$ and the depreciation rate of human capital is small enough $\varphi \ll 1$, the location choice of employer $z$ in equation (15) becomes

$$
\underset{(p, a)=\ell}{\operatorname{argmax}} \frac{z}{1-z}\{\underbrace{\log \left(p^{\mathcal{Q}} a^{-\psi \mathcal{P}}\right)}_{\begin{array}{c}
\text { Exogenous } \\
\text { production \& housing } \\
\text { complementarities }
\end{array}}+\underbrace{\log \left(C(\underline{w}(\ell), z(\ell))^{\psi \mathcal{P}}\right)}_{\begin{array}{c}
\text { Endogenous } \\
\text { housing } \\
\text { complementarity }
\end{array}}+\underbrace{\log \left(\bar{k}(u(\ell))^{\mathcal{Q}}\right)}_{\begin{array}{c}
\text { Endogenous } \\
\text { human capital } \\
\text { complementarity }
\end{array}}+\underbrace{\log q(\ell)}_{\begin{array}{c}
\text { Endogenous } \\
\text { pooling } \\
\text { complementarity }
\end{array}}\}-\underbrace{\log \underline{w}(\ell)}_{\begin{array}{c}
\text { Endogenous } \\
\text { cost of } \\
\text { labor }
\end{array}} .
$$

$\bar{k}(u(\ell))$ in location $\ell=(p, a)$ denotes average human capital. Supplemental Material G.6 defines the constants $\mathcal{P}>0, \mathcal{Q}>0$ and the function $C$.

Equation (19) highlights that three additional channels determine the location decision of employers in the extended model. First, exogenous technological complementarities now also depend on amenities $a$. Higher productivity still makes locations more lucrative for jobs. Yet, higher amenities reduce profitability by bringing in more workers, raising housing prices and driving up production costs with elasticity $\psi$. I identify a pair $\ell=(p, a)$ with the combined index of local advantage

$$
\ell(p, a) \equiv p^{\mathcal{Q}} a^{-\psi \mathcal{P}}
$$

since I will show that it is a sufficient statistic for the location choice of employers.

Second, the housing price channel also introduces an endogenous source of complementarity. The function $C(\underline{w}(\ell), z(\ell))$ encodes that local expenditures on housing increase with local wages, driving up housing prices and thus operation costs of employers.

Third, employers internalize human capital differences across locations. Localized scarring effects of unemployment imply that average human capital $\bar{k}(u(\ell))$ is proportional to $\frac{\Delta}{\Delta+\varphi u(\ell)}$ and thus decreases

\footnotetext{
${ }^{36}$ The rescaled distribution $k_{t} e^{-\lambda t}$ for new workers does not depend on calendar time $t$, and is denoted $F_{k}$. This assumption can be microfounded if young workers learn from older workers before entering in the labor force. The economy is therefore on a balanced growth path determined by $\lambda$. In levels, the distribution of knowledge of new workers is a "traveling wave with constant shape." I also assume that $F_{k}$ has a density with full support equal to $\mathbb{R}_{+}$.
} 
with the local unemployment rate $u(\ell)$. Human capital complements production, so that high quality employers find it less profitable to enter in a location where workers have less human capital. There, only low quality job open, further worsening unemployment in equilibrium. Human capital and scarring effects thus play two roles. They microfound part of the production complementarities that were fully exogenous in Section 2. They also add feedback effects linking unemployment and human capital in equilibrium.

Labor market pooling complementarities remain unchanged and still depend only on the local vacancy meeting rate. Similarly, the expected cost of labor continues to be summarized by local reservation wages $\underline{w}(\ell)$. Because the structure of the location choice of employers in equation (19) closely resembles its more stylized version in equation (15), virtually all the analytical results from Section 2 carry through.

Proposition 6. (Characterization of the extended model)

To a first order when the migration rate $\mu$ and the scarring effects of unemployment $\varphi$ are not too large, Propositions 1, 2, 3, 4, 5 and Corollary 1 obtain in the extended framework under the same conditions, with three modifications. First, replace the local unemployment rate by $u(\ell)=\frac{s(\ell)+\mu+\Delta}{s(\ell)+\mu+\Delta+f_{R}(\ell)}$. Second, replace $\ell$ with the combined index of local advantage $\ell(p, a)$. Third, population depends on the pair $(\ell(p, a), a)$ : $L(p, a) \equiv L(\ell(p, a), a)$.

Proof. See Supplemental Material G.

Population cannot be summarized solely by the local advantage index $\ell(p, a)$ because workers value amenities directly, while employers value amenities through housing prices only. As a result, amenities generate variation in population conditional on the local advantage index $\ell(p, a)$. Supplemental Material G.7 provides more details. With the extended framework at hand, I turn to the structural estimation.

\subsection{Identification}

Despite its rich structure, the quantitative model is transparent enough to produce estimating equations for all but one of the parameters. No simulation is required until the last step, which estimates the entry cost. This section discusses how to recover recursively each parameter given the data I choose. This recursive scheme recovers parameters one after the other, so that parameters estimated early on do not depend on estimates of parameters estimated later on. A proposition at the end of this subsection summarizes the formal identification of the model. Different specific estimators are used for different parameters, but all can be nested into an overarching Generalized Methods of Moments (GMM) estimator.

In total, there are 19 parameters to be estimated: $\rho, \Delta, \omega, \psi, \delta, \sigma, \beta, b, Y, \eta, \mu, \varepsilon, \alpha, \gamma, c_{v}, m, \lambda, \varphi, c_{e}$; together with two distributions $F_{z}, F_{p, a}$. I first recover these distributions non-parametrically. Next, I estimate functional forms to simulate counterfactuals, adding another 7 parameters.

The 26 parameters can be divided into three groups. Parameters in the first group $-\rho, \Delta, \omega, \psi$, $\mu, b, c_{v}, m$ - directly map into empirical counterparts or can be normalized, thus only requiring simple Minimum Distance Estimators (MDE). Parameters in the second group - $\delta, \sigma, \beta, Y, \eta, \varepsilon, \alpha, \gamma, \lambda, \varphi-$ require more involved estimating equations, together with different estimators. The third group of parameters consists of distributional functional forms. The fourth group of parameters only contains the entry cost $c_{e}$, which is estimated by numerical search (Method of Simulated Moments). Before describing how to estimate each group of parameters, I briefly discuss the data used to construct empirical targets. 
Data. I use data from France for all years between 1997 to 2007. A quarter is the time period $[t, t+1)$. Most of the estimation uses averages over the entire period. For some parameters, I split the sample into two subperiods, with averages for 1997-2001 and for 2002-2007. I index locations (cities) in the data by c. I use aggregate data for the household housing expenditure share. I measure expenditures on real estate for firms in the firm-level balance sheet data. The DADS provide measures of local unemployment rates $u_{c}$, local job losing rates for stayers $s_{c}$, local job finding rates for stayers $f_{R c}$, local average wages $W_{c}$, population shares $L_{c}$, and the aggregate mobility rate of workers. The DADS also enable finer disaggregation of job losing rates and wages by tenure and location. I measure the average job offer acceptance probability in the LFS. I obtain housing prices $r_{c}$ from the online realtor MeilleurAgents.com.

First group (8 parameters). The mobility rate for individuals transitioning into unemployment at the same time directly identifies the moving opportunity rate $\mu .^{37}$ The labor force exit rate identifies $\Delta$. The interest rate identifies $\rho$ through the effective discount rate of individuals $\rho+\Delta .^{38}$ The household housing expenditure share $\omega$ maps into the value reported by INSEE, $23 \% .{ }^{39}$ The employer real estate expenditure share out of value added $\psi$ maps into my estimate of $11 \%{ }^{40}$ The remaining parameters in this first group can be normalized: $b=c_{v}=m=1 .^{41}$

\section{Second group (10 parameters).}

Productivity process $\delta$ and $\boldsymbol{\sigma}$. I use data on job losing rates and wage growth by tenure to estimate $(\delta, \sigma)$. I leverage a closed-form solution for the job losing rate in the first year in the model, which follows from an explicit solution to the time-dependent KFE. The job losing rate in the first year of a job in city $c$ is $s_{1}\left(s_{c}, \hat{\delta}\right)$. The function $s_{1}$ depends on the average job losing rate $s_{c}$ that captures the initial productivity distribution. $s_{1}$ is decreasing in $\hat{\delta}=\frac{\delta}{\sigma}$ given $\mu, \Delta$. Intuitively, if the volatility $\sigma$ is much larger than the drift $\delta$, many separations occur at early tenure. Details are in Appendix C.2. Denoting $s_{1 c}$ the measured job losing rate in the first year in city $c$, I recover $\hat{\delta}$ directly by estimating

$$
s_{1 c}=s_{1}\left(s_{c}, \hat{\delta}\right)
$$

with Non-Linear Least Squares (NLLS), treating residuals as measurement error.

Given the estimated ratio $\hat{\delta}=\frac{\delta}{\sigma}$, the same solution to the time-dependent KFE enables to explicitly compute wage growth by tenure when $\beta$ is not too large. Appendix C.3 shows that it identifies the common scale of $\delta, \sigma$. Intuitively, when productivity depreciates faster, wages at continuing jobs fall behind wages at new jobs at a faster pace. Thus, a regression similar to (21) estimates $\delta$ when $\beta$ is small. ${ }^{42}$

\footnotetext{
${ }^{37}$ In the model, unemployed and employed workers always change location and enter unemployment when they receive the moving opportunity at rate $\mu$. With a continuum of locations, there is always a location with a high enough preference draw. The moving rate must be time-aggregated quarterly.

${ }^{38}$ Although workers are not allowed to borrow or save in the model, $\rho+\Delta$ is their intertemporal marginal rate of substitution and would coincide with the interest rate in a complete markets version of the model.

${ }^{39}$ INSEE's calculations reflect both renters and homeowners.

${ }^{40}$ Balance sheet data lists all rental expenditures, as well as the book value of land, building and structures owned by the firm. I annuitize the value of those properties using a $5 \%$ annual interest rate and add the annuitized value to the rental expenditures. This defines expenditures on real estate.

${ }^{41}$ The unemployment income parameter $b$ is not separely identified from productivity $\ell$. The shifter of the vacancy cost function $c_{v}$ and the matching function efficiency are not separately identified from the entry cost $c_{e}$.

${ }^{42}$ When $\beta$ is large, $\delta$ and $\beta$ are estimated jointly. At the estimated bargaining power $\beta$ however, the difference is negligible.
} 
Bargaining power $\boldsymbol{\beta}$. Wages relative to value added in location $c$ are $\beta+\frac{1-\beta}{H\left(s_{c}\right)}$, where $H$ only depends on $\delta$ and $\sigma$. I target aggregate wages relative to value added to identify $\beta$ by MDE.

Learning and scarring rates $\lambda$ and $\varphi$. Wage changes for workers coming out of unemployment reflect human capital losses, which grow with unemployment duration. For worker $i$ who loses their job at time $t_{0}$ and finds a new job at time $t_{1}$ in location $c$, wages satisfy

$$
\log W_{i c t_{1}}=(\lambda-\varphi)\left(t_{1}-t_{0}\right)+\Phi_{c}+\log W_{i c t_{0}}+v_{i c}
$$

where $v_{i c}$ is a mean-zero random variable that reflects draws from the local new job distribution, and $\Phi_{c}$ is a location fixed effect. Hence, OLS consistently estimate $\lambda-\varphi$ using equation (22) because new productivity draws are independent from unemployment duration. Aggregate real wage growth identifies $\lambda$ directly. Thus, I recover $\varphi$. Details are in Appendix C.5. ${ }^{43}$

Local quality and threshold. For the remainder of the estimation, I recover estimates of the local job quality $z_{c}$ and the local productivity threshold $\underline{y}_{c}$ in each city $c$. They are equilibrium outcomes, not fixed primitives of the economy. Given the estimate for $\delta$, local job losing and finding rates directly identify job quality and the threshold in each city as per Proposition 1,

$$
z_{c}=\frac{\delta}{s_{c}}, \quad \underline{y}_{c}=\frac{b \underline{y}_{0}}{\hat{\rho}} \frac{\beta f_{R c} \bar{S}\left(z_{c}\right)}{\hat{\rho}-\beta f_{R c} \bar{S}\left(z_{c}\right)}
$$

where $\hat{\rho}=\rho+\Delta+\mu+\varphi-\lambda$, and $\underline{y}_{0}$ and the function $\bar{S}$ can be calculated from known parameters.

Lower bound of initial productivity draws $\boldsymbol{Y}$. The success probability of a meeting for workers in city $c$ is $\left(Y / \underline{y}_{c}\right)^{1 / z_{c}}$ in the model. I construct an empirical counterpart using data on job search behavior from the LFS in Supplemental Material H. I estimate the average success probability for workers at 20.6\%, and find $Y$ to match this target. ${ }^{44}$

Housing elasticity $\boldsymbol{\eta}$. At this stage of the recursive scheme, housing prices in each city satisfy $\log r_{c}=r_{1}+\frac{1}{1+\eta} \log r_{0}\left(W_{c}, L_{c}, u_{c}, z_{c}, \underline{y}_{c}\right)$, where Appendix C.7 details the known function $r_{0}$. I then obtain $\eta$ with OLS, assuming that measurement error is the only residual. ${ }^{45}$

Migration elasticity $1 / \varepsilon$. Migration shares by destination $\pi_{c}$ satisfy

$$
\log \pi_{c}=\pi_{0}+\frac{1}{\varepsilon} \log \bar{U}_{c}+\log a_{c}
$$

\footnotetext{
${ }^{43}$ In practice, mechanisms left out from the model may generate endogeneity issues. To address those concerns, Table 8 in Appendix C.5 proposes several other specifications with more flexible controls (for instance, industry fixed effects, worker fixed effects, past wage controls, employed workers as control group). The point estimate of $\varphi$ remains stable around $1 \%$ per quarter and statistically significant across specifications.

${ }^{44}$ Faberman et al. (2017) suggest an acceptance probability of $29.6 \%$ in the United States. Only this worker success probability in the model maps transparently to data. Paying the entry $\operatorname{cost} c_{e}$ and the productivity draw $z$ define a job in the model. Repeated draws of the same quality $z$ after several unsuccessful meetings can correspond to situations where employers interview several candidates for a given position.

${ }^{45}$ Omitted factors like heterogeneous housing supply elasticities may be a source of endogeneity. With repeated crosssections of housing prices, difference-in-difference specifications using shift-share shocks as instruments could be used to correct for endogeneity. With only one cross-section, these approaches are not possible.
} 
where $\bar{U}_{c}=\frac{\bar{w}_{c}}{\left(1-\beta+\beta H\left(s_{c}\right)\right) r_{c}^{\omega}}$ can now be computed in the model, and $\pi_{0}$ is a general equilibrium constant. Unobserved amenities $a_{c}$ are correlated with $\bar{U}_{c}$. Hence, I split the sample into two subperiods 0 and 1 and first-difference equation (24). Then, I use local productivity shocks based on shift-share projections of economy-wide industry shocks as instruments for the change $\log \frac{\bar{U} c, 1}{\bar{U} c, 0}$. I thus estimate $1 / \varepsilon$ with Two Stage Least Squares (2SLS) using (24) in first differences. I interpret the data in each subperiod as a different steady-state of the model. The identification assumption is that economy-wide industry-level shocks are orthogonal to local changes in amenities. I further discuss how to map industry-level shocks into the model and the identification assumption in Appendix C.8.

Non-parametric distributions of local productivity, amenities and job quality. Equation (51) in Appendix C.6 shows that local productivity $p_{c}$ follows from inverting the model's predictions for local wages. Given the migration elasticity estimate, inverting the population equation (65) in Supplemental Material G.5 then delivers an estimate of local amenities $a_{c}$ in each city. Together, the estimates $\left(p_{c}, a_{c}\right)$ provide a non-parametric estimate of the distribution $F_{p, a} \cdot{ }^{46}$ Appendix C.9 shows that the density function of job losing rates across locations identifies the density function of job quality $f_{z}$ using (23).

Matching function and vacancy cost elasticities $\boldsymbol{\alpha}$ and $\gamma$. I express local job finding rates as a function of estimated labor market tightness and the values of employers in equation (52), Appendix C.10, together with more details. I then use a shift-share approach in first differences to estimate $\alpha, \gamma$ jointly with 2SLS, similarly to the estimation of the migration elasticity $1 / \varepsilon$.

Together with details in Appendix C, the previous arguments prove Proposition 7.

\section{Proposition 7. (Identification)}

To a first order when $\mu, \Delta, \delta, \beta$ are not too large, the parameters $\mu, \Delta, \rho, \omega, \psi, \delta, \sigma, \beta, \lambda, \varphi, \eta, \varepsilon, Y, \alpha, \gamma$, as well as the distribution of firms qualities $F_{z}$, the joint distribution of local productivities and amenities $F_{p, a}$, are exactly identified by an overarching GMM estimator. The other parameters can be normalized except the entry cost.

Third group (7 parameters). I estimate a joint lognormal distribution for local amenities and productivities, with respective standard deviations $\sigma_{a}, \sigma_{\ell}$ and correlation $c_{\ell, a}$. I estimate a Beta distribution for the distribution of employer quality. Its shape parameters are $g_{1}, g_{2}$ and its support is $[\underline{z}, \bar{z}]$.

Fourth group (1 parameter). A numerical search finally estimates the entry cost $c_{e}$ by targeting the aggregate unemployment rate.

\subsection{Parameter estimates}

Table 9 in Appendix C.11 reports the parameter estimates. Overall, they are close to values found in the literature. The housing shares for workers $\omega=0.23$ is close to the commonly used value of 0.3 for the United States. Similarly, the housing share for firms $\psi=0.11$ is in the range of estimates reported in Desmet et al. (2018). The negative drift $\delta$ of the worker-level productivity process is close to the quarterly value of $0.5 \%$ implied by the estimates in Engbom (2018), and the volatility $\sigma$ is somewhat

\footnotetext{
${ }^{46}$ Altenatively, amenities could be obtained as residuals from the migration share equation (24). Because the estimation relies on observed population shares, I choose to match population rather than migration shares. In practice, they are highly correlated.
} 
Figure 5: First year job losing rates and housing prices across cities.

(a) First year job losing rate: model vs. data.

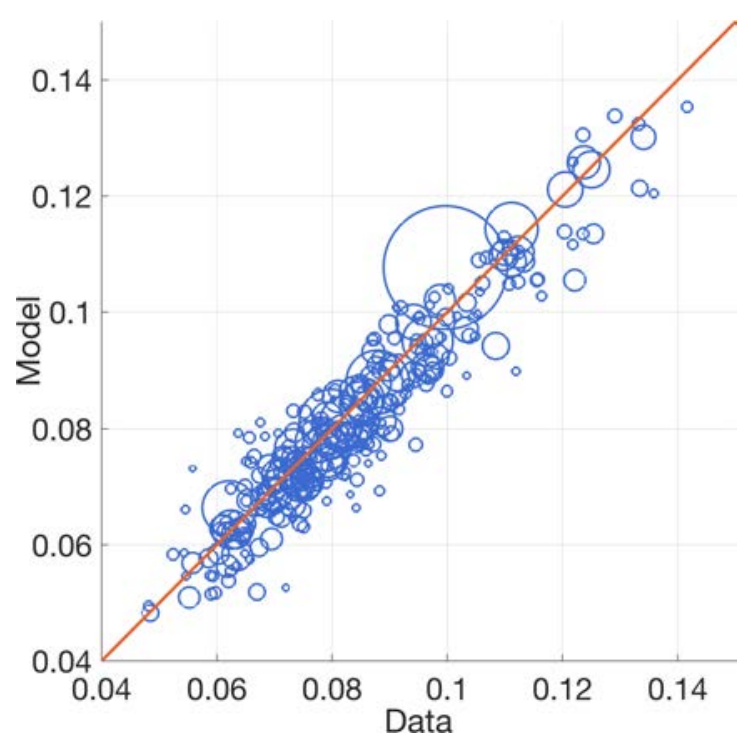

(b) Housing prices: model vs. data.

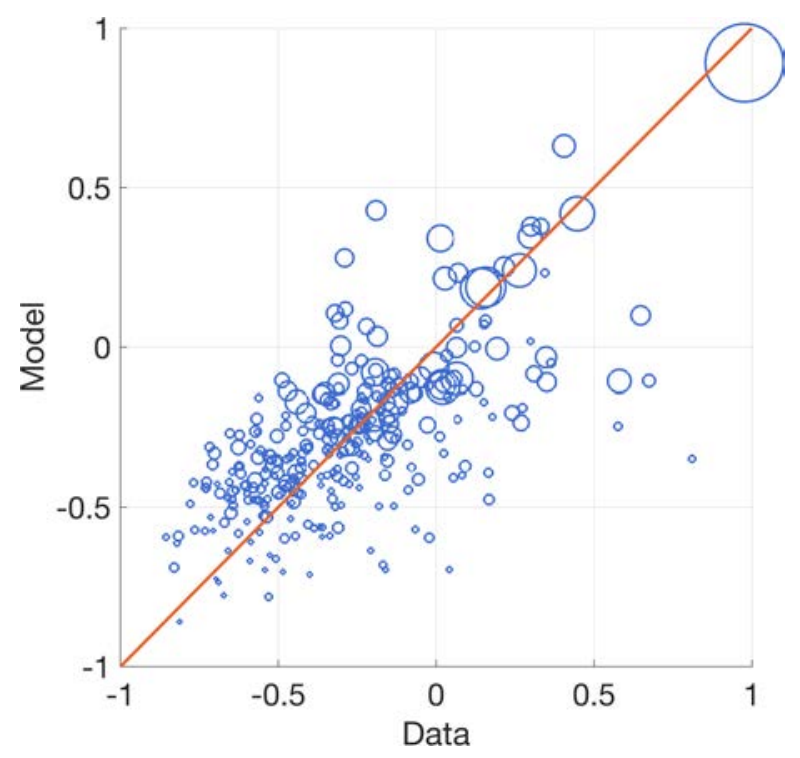

Note: Figure 5(a): annual job losing rate in first year of job, model against data. Figure 5(b): housing prices in model against data. Cities in model identified by their job losing rate. Blue circles proportional to city size.

smaller. The bargaining power $\beta$ is 0.08 , close to the estimate in Hagedorn and Manovskii (2008) and references therein. The housing supply elasticity $\eta$ implies a price-to-population elasticity of 0.28 , within the range reported in Saiz (2010) for the United States. The migration elasticity $1 / \varepsilon$ is 4.72 , within but towards the high end of the values reported in the literature between 0.5 and $5 .{ }^{47}$ The matching function elasticity $\alpha$ is 0.3 , within the range reported in Petrongolo and Pissarides (2001). The inverse vacancy cost elasticity $\gamma$ implies that the cost function is close to quadratic, in line with existing estimates. The scarring rate $\varphi$ implies a $4 \%$ relative wage loss for workers who spend a year unemployed, consistently with Jarosch (2021). ${ }^{48}$

\subsection{Over-identification exercises}

Job loss in first year. With the estimated model at hand, I start with two exercises that support the estimates of the productivity process $\delta$ and $\sigma$. First, Figure 5(a) shows that the model closely fits the full cross-sectional variation of job losing rates in the first year, despite relying on a single degree of freedom $\delta / \sigma$ to predict them as per (21). Job loss is more frequent in the first year than on average, indicating a declining tenure profile.

Second, I compute firm-level labor productivity growth relative to aggregate labor productivity growth with balance sheet data. I obtain a relative decline of $0.1 \%$ quarterly, close to the estimate of $\delta .{ }^{49}$

\footnotetext{
${ }^{47}$ The estimate for $\mu$ implies an annual migration rate of about $1 \%$. The overall migration rate in my sample is about $3 \%$. This discrepancy arises because many migrants are employed workers moving with a job at hand. However, in steady-state, the migration elasticity is the key driver of population movements, not the migration rate.

${ }^{48}$ Jarosch (2021) also includes negotiation capital losses that account for half of his overall $10 \%$ wage loss.

${ }^{49} \mathrm{I}$ focus on large and high labor productivity firms to minimize survival selection bias. These firms are the least likely to exit in the data and according to theories of firm dynamics with frictional labor markets such as Bilal et al. (2022).
} 
Housing prices. How well does the estimated housing supply elasticity account for cross-sectional dispersion in housing prices? Figure 5(b) plots housing prices in the model against the data. Despite using a single parameter $\eta$, the model's predictions are centered around the 45 degree line in orange with moderate residual dispersion.

Amenities. Unobserved local amenities allow the model to match the dispersion in city-level population. A natural check of the non-parametric amenity estimates $a_{c}$ is to correlate them with local characteristics that should affect the value of living in a particular location. I correlate estimated log amenities on the $\log$ of sun hours per month, as well as a the log density of residential service establishments of various kinds. Table 10 in Appendix C.12 shows that more sun hours and a higher density of health or commercial services are all positively associated with higher amenities. ${ }^{50}$ These results support the view that estimated amenities capture salient features of residential attractiveness.

Having established the ability of the estimated model to speak to a number of targeted and nontargeted moments in addition to the validation exercises in Section 2.6, I now turn to the main structural results of this paper: the breakdown of spatial unemployment gaps into job loss and job finding, and the welfare effects of place-based policies.

\section{Spatial unemployment gaps and place-based policies}

This section first shows that the model quantitatively accounts for spatial unemployment differentials. Next, this section discusses the employment and welfare effects of place-based policies.

\subsection{Spatial job loss differentials and unemployment}

The estimated model replicates closely the key role of job loss in the data. Figure 6 plots the model equivalent of Figure 2-the graphical decomposition of spatial unemployment gaps into job losing and job finding rates - together with the data for comparison. Job losing rates account for most of the variation in local unemployment rates because employers sort strongly across locations, as per Proposition 2 . The job finding rate is nearly flat across locations because of the opposing forces highlighted in Proposition 1. As a result, the unemployment rate largely follows the spatial patterns of the job losing rate.

Neither the location decision of employers, nor the spatial variation in job finding rates, are constrained by the estimation. The spatial variation in job losing rates results from $(i)$ the distribution $f_{z}$, that is constrained by the estimation, but also (ii) the equilibrium assignment of employers to locations $z(\ell)$, that is left entirely free. The estimation does not limit the spatial variation in job finding rates apart from the two coefficients that identify $\alpha$ and $\gamma$. The job losing and job finding variance shares are therefore useful moments to assess the model's ability to speak to spatial unemployment differentials.

Does the model account quantitatively for spatial unemployment gaps? Table 1 reports the dispersion in local unemployment rates and its breakdown into job losing and job finding rates. The first two columns of Table 1 reveal that the model accounts for over $75 \%$ of the cross-sectional standard deviation of local unemployment rates, 0.019 against 0.025. The decentralized equilibrium also closely replicates

\footnotetext{
${ }^{50}$ For instance, doubling the number of sun hours per month raises the amenity value of a location by $12 \%$. Doubling the density of health establishments increases amenities by $6.7 \%$.
} 
Figure 6: Local job losing and finding rates against unemployment-employment ratios in model.

(a) Job losing rate

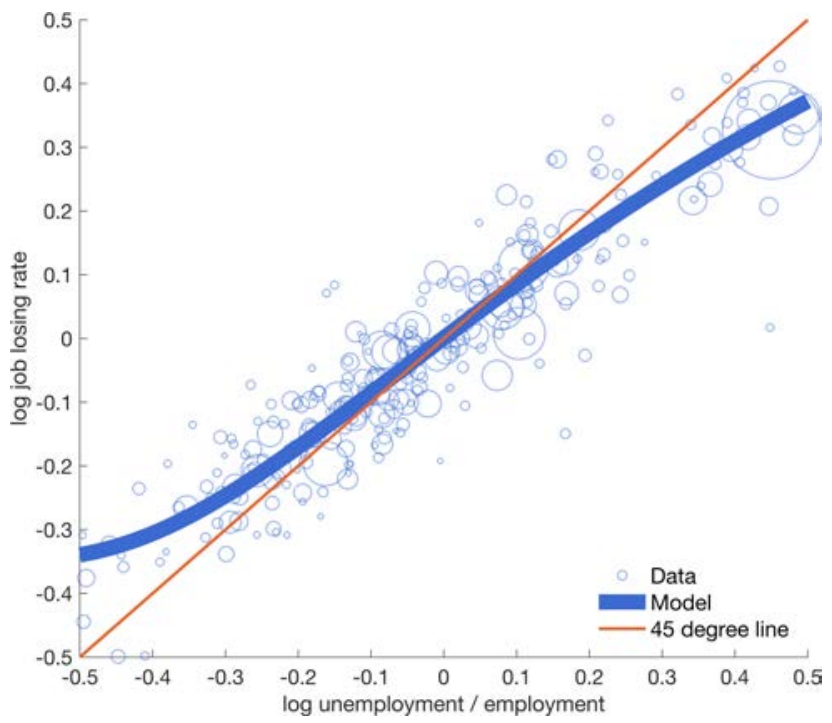

(b) Job finding rate

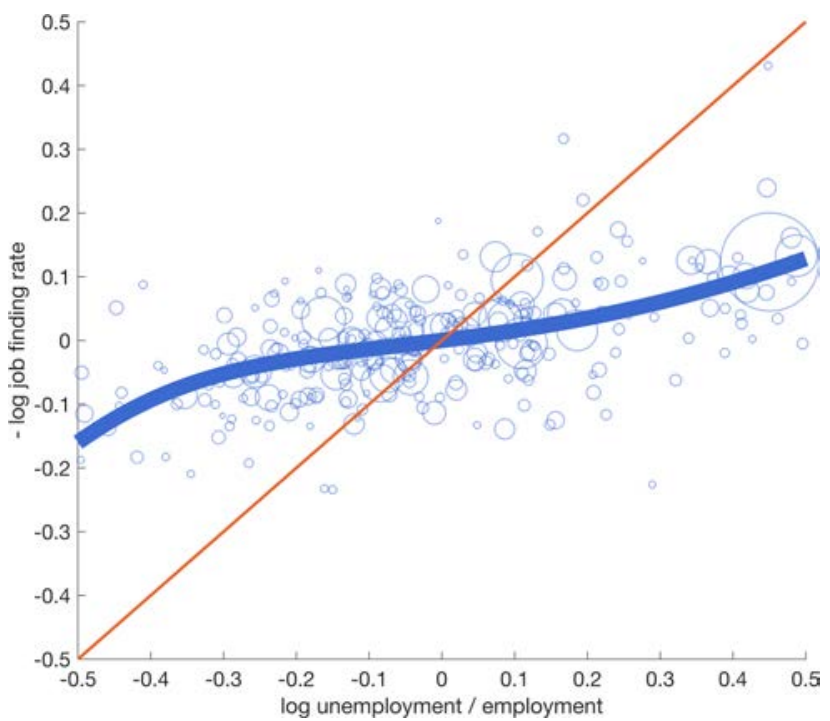

Note: Figure 6(a) plots the log of the job losing rate against the log of the unemployment-employment ratio, across cities in the DADS data and in the estimated model. Figure 6(b) plots minus the log of the job finding rate against the log of the unemployment-employment ratio, across cities in the DADS data and in the estimated model.

the contribution of job losing rates to spatial unemployment differentials. The job losing share is $73 \%$ in the estimated model against $77 \%$ in the data.

I evaluate the role of labor market pooling complementarites in the third column of Table 1 . It reports the same decomposition as the second column, but after shutting down the labor market pooling externality. The labor market pooling externality is key in generating spatial differences in unemployment rates. The cross-sectional standard deviation of local unemployment rates drops to 0.003 without labor market pooling externalities, $15 \%$ of its baseline value and $12 \%$ of its value in the data. Hence, the pooling externality yields over a five-fold amplification of spatial unemployment gaps.

The labor market pooling externality matters quantitatively because it magnifies the spatial sorting of employers. It induces excess clustering of the most productive employers with stable jobs in the best locations. As a result, only employers that are not productive enough, with jobs that are too unstable, remain in high unemployment locations. Consistently, the job losing rate share drops to $45 \%$.

I confirm the key role of the pooling externality by re-estimating an efficient model without the externality. In the fourth column of Table 1, I impose directed search instead of random search before estimating the model. ${ }^{51}$ Even when re-estimated, the efficient allocation falls short of replicating the empirical dispersion in local unemployment rates as well as the central role of job loss. The dispersion in local unemployment rates again drops to $12 \%$ of its value in the data, and the job losing rate generates barely more than half of this variation.

This comparison between the baseline and the re-estimated efficient allocation confirms that the estimation does not place strong constraints on the dispersion in unemployment, job losing and job finding rates. These moments therefore provide informative over-identification restrictions to evaluate the

\footnotetext{
${ }^{51}$ The directed search and planning allocations coincide under the same parameters as per Proposition 4. In practice, parameter estimates under the re-estimated efficient allocation are close to estimates in the decentralized equilibrium.
} 
Table 1: Aggregate and local unemployment rates in the decentralized equilibrium.

\begin{tabular}{lcccc} 
& Data & Baseline & No pooling & Est. planner \\
\hline Aggregate unemployment rate & 0.097 & 0.097 & 0.093 & 0.097 \\
St. dev. unemployment rate & 0.025 & 0.019 & 0.003 & 0.003 \\
Var. log unemp. / emp. & 0.072 & 0.048 & 0.002 & 0.001 \\
$\quad$ Job losing rate & $77 \%$ & $73 \%$ & $45 \%$ & $51 \%$ \\
$\quad$ Job finding rate & $23 \%$ & $27 \%$ & $55 \%$ & $49 \%$ \\
\hline
\end{tabular}

Note: All statistics are population-weighted. 'Data' column reports moments in the data. 'Baseline' column reports moments in the estimated model. 'No pooling' reports moments in the estimated model after shutting down the labor market pooling externality. 'Est. planner' reports moments for a fully re-estimated model under directed search. Its allocation coincides with the social planner's allocation.

ability of the model to account for spatial unemployment gaps and discriminate between different sets of assumptions. Table 1 strongly favors the baseline version of the model that includes the labor market pooling externality, against the efficient economy that does not feature this amplification force.

Labor market flows, wages, population and vacancies. Can the model also account for the comovement between labor market flows, wages, population and vacancies? Table 2 displays the results from worker-level OLS regressions of job losing and finding rates onto local wages and population. It compares results in the baseline model to the data.

Wages correlate negatively with job loss both in the data (-0.12) and in the model (-0.19). This negative correlation reflects the spatial sorting of employers. Employers who offer stable jobs also pay high wages. Thus, cities with high wages are also those with low rates of job loss. Consistent with the moderate spatial variation in the job finding rate in Figure 6(b), the job finding rate is not strongly correlated with wages or population, both in the model and in the data.

Job losing and job finding rates correlate more weakly with local population after controlling for local wages, both in the model and in the data. This weaker correlation reflects the difference in location decisions between workers and employers. Recall that Proposition 6 implies that labor market flows and wages are one-to-one with the local index $\ell(p, a)$, while population depends on amenities $a$ conditional on $\ell(p, a)$ because of the residential choice of workers. Population thus exhibits additional dispersion relative to wages which drives the coefficient on population towards zero.

Can the model reproduce the co-movement between unemployment and vacancies in the data? Section 2.6 highlighted that this co-movement is ambiguous theoretically and empirically. Consistently with this ambiguity, Figure 15 in Appendix C.13 reveals that the co-movement between labor market tightness and unemployment can take any sign depending on parameter values. At baseline estimates, this co-movement is positive and consistent with the correlation between unemployment and tightness after adjusting for job-to-job search. With less elastic recruiting costs $\gamma=3$, the co-movement is negative and consistent with the correlation between unemployment and tightness without the job-to-job adjustment.

\subsection{Place-based policies}

Having demonstrated that the model accounts for spatial unemployment and job loss gaps, this final section presents two policy counterfactuals. Both counterfactuals quantify the local and general equilibrium 
Table 2: OLS regressions of worker-level job loss and job finding probabilities.

\begin{tabular}{llllll}
\hline & \multicolumn{2}{c}{ Job loss } & & \multicolumn{2}{c}{ Job finding } \\
\cline { 2 - 3 } & Data & Model & & Data & Model \\
\hline Log city wage & $-0.12^{* * *}$ & -0.19 & & 0.01 & 0.06 \\
& $(0.03)$ & & & $(0.02)$ & \\
Log city population & 0.04 & -0.06 & & 0.02 & 0.00 \\
& $(0.07)$ & & & $0.06)$ & \\
Industry-year \& worker fixed effects & $\checkmark$ & & \multicolumn{2}{c}{$\checkmark$} & \\
\hline Obs. & 2825413 & & 394678 & \\
$R^{2}$ & 0.124 & & 0.228 & \\
\hline
\end{tabular}

Dependent variables relative to unconditional mean. Independent variables standardized to unit standard deviation. Data: Standard errors in parenthesis, two-way clustered by city and 3-digit industry. $+p<0.10,{ }^{*} p<0.05,{ }^{* *} p<0.01,{ }^{* * *} p<0.001$. City population density by $\mathrm{km}^{2}$. Quarterly frequency. 1997-2007. Movers only. Model: population moments. Worker-level regressions. Wages net of human capital in the model.

welfare gains from place-based policies in the long run by comparing steady-states. The first counterfactual studies the policy that corrects the labor market pooling externality. The second counterfactual contrasts this policy with the real-world French Enterprise Zone (EZ) program in France.

I start by examining the quasi-optimal policy that corrects the labor market pooling externality. Under this policy, the economy is not fully efficient since the Hosios (1990) condition needs not hold. Instead, the quasi-optimal policy focuses on the location choice of employers. The quasi-optimal policy takes the form of a corporate tax credit whose generosity rises with the local job losing rate, consistently with Propositions 5 and 6 . The policy is financed with a non-distortionary flat earnings tax. ${ }^{52}$

I contrast the effects of the quasi-optimal policy with a real-world example of an economy-wide set of place-based policies. Federal programs such as the Empowerment Zones program in the United States proposed considerable tax breaks for firms opening jobs in high unemployment areas. In France, a similar EZ program was rolled out in 1996 and subsequently expanded-the "Zones Franches Urbaines." The labor market pooling externality provides a theoretical basis for such policies. By changing incentives to open jobs across locations, the policies effectively relocate jobs and affect the general equilibrium of the economy. ${ }^{53}$

Figure 7 displays the cross-sectional patterns of the equilibrium under the laissez-faire, the quasioptimal policy and a budget-equivalent version of the French EZ program. The EZ subsidy is much smaller than the quasi-optimal one in scale and scope. However, it shares the same qualitative pattern. The leftward shifts in the job losing rate indicate that both policies relocate more productive employers towards high-unemployment locations. Under the EZ program few marginal jobs change location, with minor effects on the job losing rate. By contrast, the quasi-optimal policy heavily relocates productive jobs towards initially high unemployment locations, resulting in a large drops in the job losing rate.

\footnotetext{
${ }^{52}$ To compute welfare gains without taking a stand on distributional issues between owners and workers, I use the equivalent formulation where profits and rents are rebated to workers with a non-distortionary flat earnings subsidy.

${ }^{53}$ Ideally, the estimation would account for the policy during the sample period. However, the necessary estimates of local policy expenditures are difficult to obtain. In practice, the policy is small and has modest local and general equilibrium effects. Therefore, it is unlikely to affect parameter estimates and counterfactuals substantially.
} 
Figure 7: Outcomes under the decentralized equilibrium, quasi-optimal policy and French EZ program.
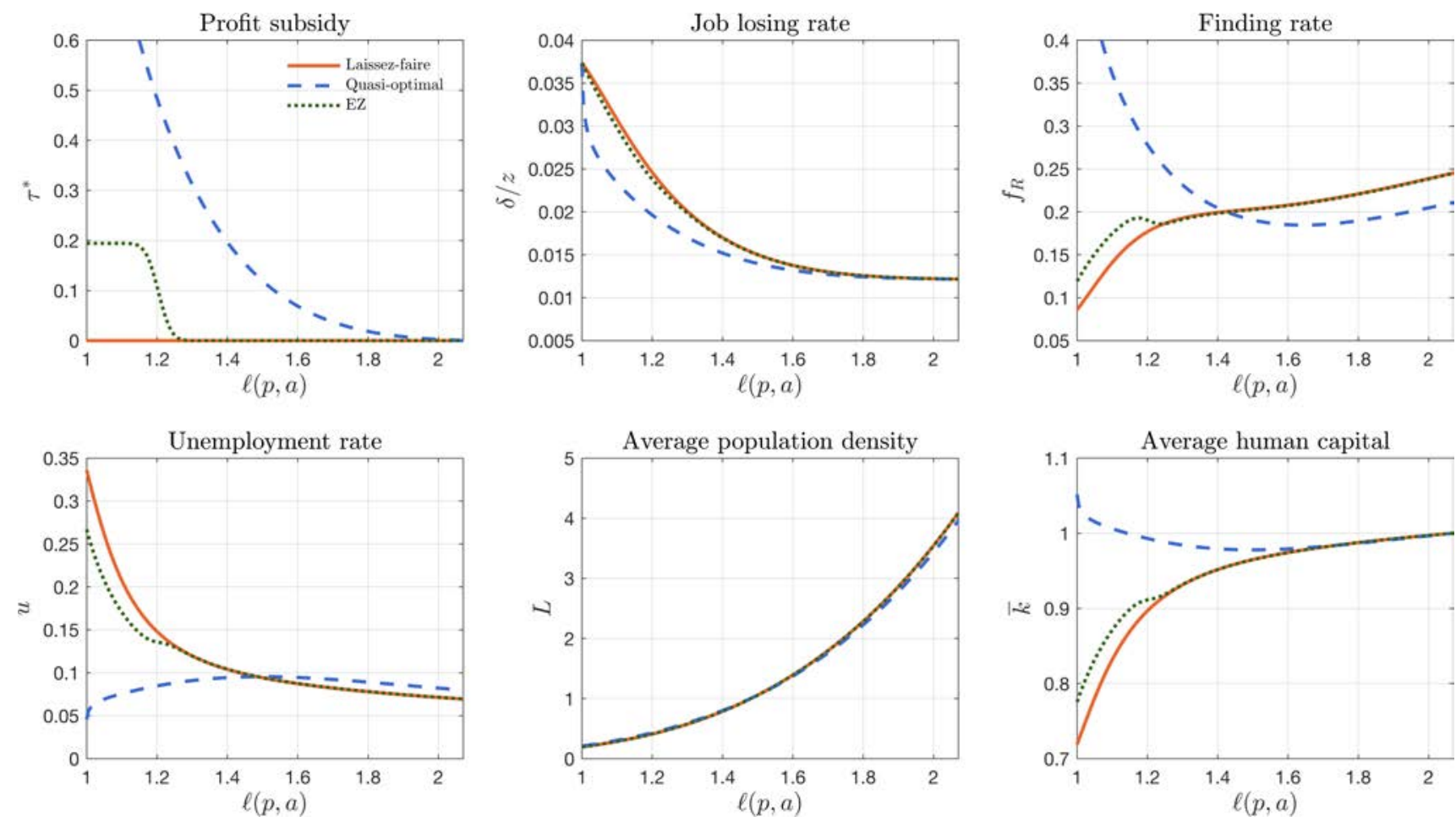

The job finding rate is more sensitive to policy than the job losing rate because of the opposing forces highlighted in Proposition 1. The EZ program increases the job finding rate because of a volume effect. Despite only a moderate decline in the job losing rate, the EZ program attracts more jobs to high unemployment locations. Hence, the unemployment rate declines in treated locations.

The employment response is broadly consistent with difference-in-difference evidence evaluating actual place-based policies. Mayer et al. (2015) evaluate the French EZ program and find that employment increases by $23 \%$ in treated locations. Although less directly comparable, Busso et al. (2013) find a 12\% employment response for a similar EZ program in the United States. In the model, employment increases by a more modest $7 \%$ in treated locations. ${ }^{54}$

The quasi-optimal policy also strongly increases the job finding rate in initially high unempoyment locations. There, the combined reduction in job losing rates and increase in job finding rates result in large drops in local unemployment rates that can exceed 10 percentage points. Consequently, spatial unemployment differentials plummet.

Mirroring the falling unemployment rate, average human capital $\bar{k}(u(\ell))$ steeply rises across locations in the laissez-faire. Localized scarring effects imply human capital gaps of over $25 \%$ between residents of the best and worst locations in the laissez-faire. The EZ program alleviates localized scarring effects due to the reduction in local unemployment rates in treated locations. In line with the drastic reduction in unemployment under the quasi-optimal policy, human capital accumulation improves dramatically in initially high unemployment locations.

Figure 8 depicts the welfare gains for residents across all locations. Locations are ranked by their

\footnotetext{
${ }^{54}$ The discrepancy may arise for at least two reasons. First, the French EZ program is stylized in the model relative to its implementation in practice. Second, the model lacks a labor market participation decision.
} 
Figure 8: Welfare gains from the quasi-optimal policy and the French EZ program.
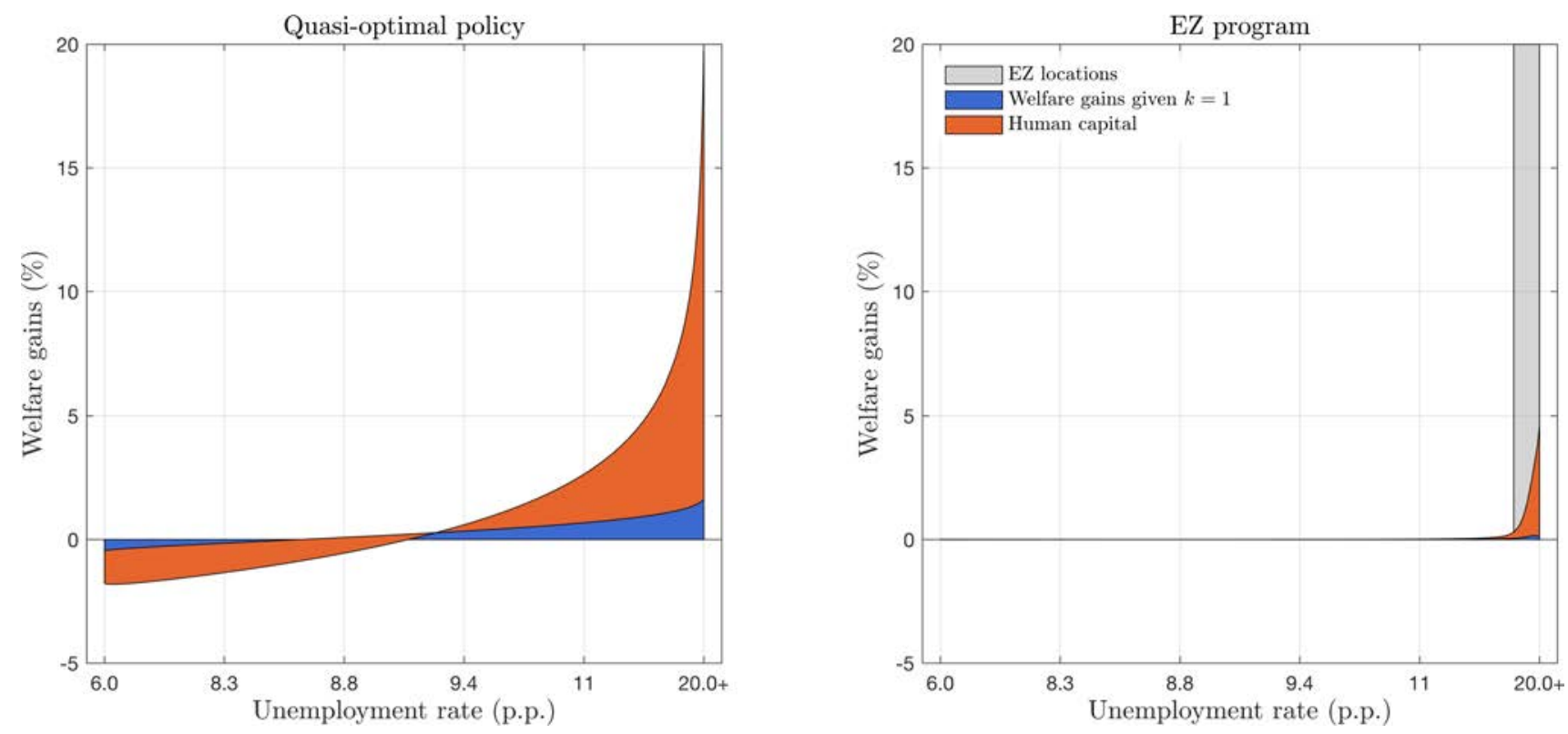

Note: Expected welfare gains of residents who never receive the moving opportunity. Split into the average gain to a worker conditional on $k=1$, and human capital gain defined as changes in the $W^{w}(\ell)$ and $\bar{k}(\ell)$ components as per equation (73) in Supplemental Material G.11. Locations ranked by their unemployment rate in the laissez-faire. X-axis reflects population-weighted quantiles. Left panel: quasi-optimal policy. Right panel: French EZ program.

unemployment rate in the laissez-faire equilibrium, and grouped into population-weighted quantiles to reflect how many workers experience a given welfare increase. The quasi-optimal policy achieves large welfare gains that exceed $10 \%$ in initially high unemployment locations.

What is the role of localized scarring effects of unemployment? The different colored areas correspond to an exact welfare decomposition in equation (73), Supplemental Material G.11. The blue area represents direct gains to the average resident worker, conditional on unit human capital. It is equal to the steadystate welfare gains of an unemployed worker who never received the moving opportunity and so stayed in the same location, with $k=1$. Figure 8 shows that direct gains steadily rise with pre-policy local unemployment under both policies. ${ }^{55}$

Reductions in scarring effects of unemployment are central to welfare gains from place-based policies. By lowering local unemployment, both policies alleviate localized scarring effects and let workers accumulate more human capital. The orange area in Figure 8 reveals that diminishing scarring effects account for the majority of welfare gains in most locations. Because the quasi-optimal policy relocates jobs away from the best locations, residents there experience welfare losses. By contrast, the EZ program has more modest effects, with welfare gains peaking below $5 \%$ and concentrated in treated, high unemployment areas.

To highlight the spatial distribution of these local welfare gains, Figure 9(a) maps the welfare gains from the quasi-optimal policy across all French commuting zones. Because welfare gains are strongly correlated with the local unemployment rate, the southern Mediterranean coast benefits most. In suburban areas close to Paris, several high unemployment commuting zones also benefit substantially. Local welfare gains are accompanied by substantial TFP improvements, as more productive employers relocate towards

\footnotetext{
${ }^{55}$ The blue area also corresponds to each location's contribution to the aggregate welfare gains for workers with $k=1$.
} 
Figure 9: Local gains from the quasi-optimal policy

(a) Welfare gains (\%)

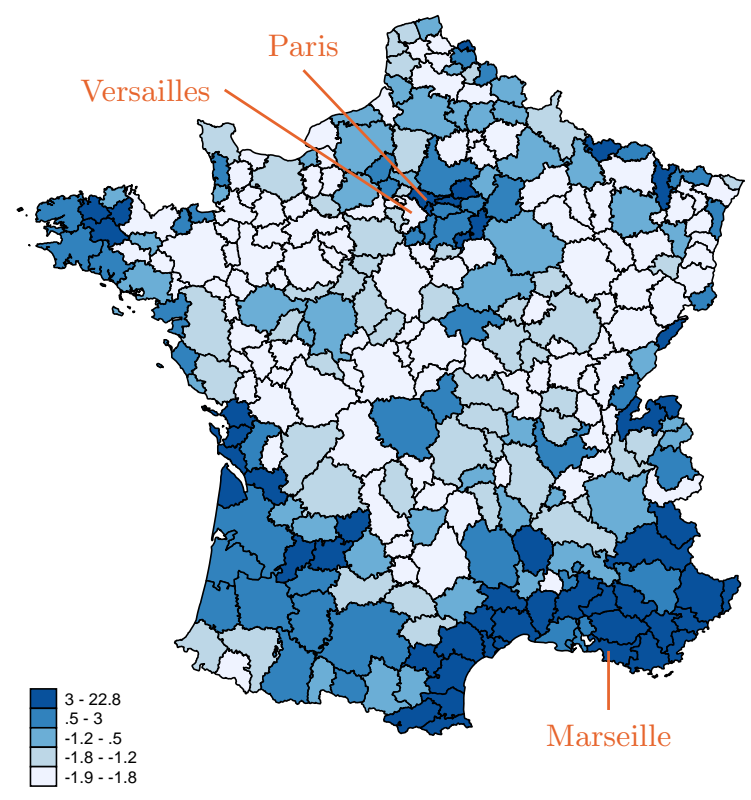

(b) TFP gains (\%)

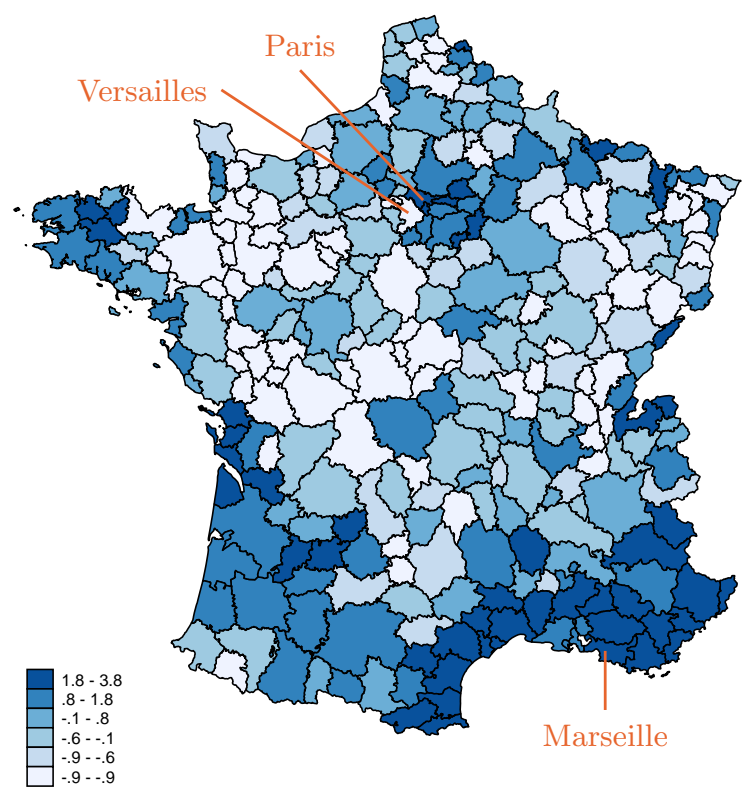

Note: Figure 9(a) maps welfare gains from the quasi-optimal policy by commuting zone in mainland France. Figure 9(b) maps TFP gains from the quasi-optimal policy by commuting zone in mainland France. Corsica and overseas territories omitted for exposition.

areas with more generous tax credits.

I aggregate local welfare gains and compute aggregate welfare gains from the quasi-optimal policy and the EZ program in Table 3. The quasi-optimal policy achieves just under 1\% aggregate welfare gains. The quasi-optimal policy also reduces spatial unemployment differentials more than five-fold as in Table 1. Despite its relatively small size, the EZ program reduced spatial unemployment differentials by over $10 \%$ and raised aggregate welfare by $0.1 \%$. Reductions in scarring effects of unemployment account for three quarters to nine tens of overall welfare gains.

It is not surprising that the EZ policy delivers smaller gains than the quasi-optimal policy since it consists in a much smaller subsidy scheme. Aggregate expenditures on the EZ policy represent redistributing 0.04\% of Gross Domestic Product (GDP). Expenditures under the quasi-optimal policy are over 50 times larger. If scaling up the redistribution-efficiency ratio of the EZ policy was possible, welfare would rise by about $5 \%$ for every percent of GDP redistributed. The quasi-optimal policy is ten times less efficient, indicating that decreasing returns rapidly kick in. Indeed, one should expect the planner's problem to be concave in the profit subsidy around the quasi-optimal policy. Thus, the largest gains for a marginal increase in the profit subsidy should arise close to the laissez-faire.

This comparison suggests that smaller place-based policies may be more efficient than larger ones in the presence of additional frictions. Albeit a full investigation is beyond the scope of this paper, many economic forces left out of the model may generate dead-weight losses that scale with the policy intervention. Fiscal optimization across establishments within firms, fiscal externalities or political economy constraints are a few examples. In this case, interventions of the scale of the EZ program are likely to be more robust than the quasi-optimal policy. 
Table 3: Aggregate gains from place-based-policies

\begin{tabular}{lccc} 
& Laissez-faire & Quasi-optimal & EZ program \\
\hline Aggregate unemployment rate & 0.097 & 0.093 & 0.096 \\
St. dev. unemployment rate & 0.019 & 0.003 & 0.016 \\
\hline Aggregate welfare gains (\%) & 0.831 & 0.090 \\
$\quad$ Unemployed & 0.150 & 0.005 \\
$\quad$ Employed & 0.039 & 0.002 \\
$\quad$ Human capital & 0.641 & 0.083 \\
\hline Resdistribution (\% of GDP) & 2.101 & 0.040 \\
\hline $\begin{array}{l}\text { Note: Unemployed, employed and human capital gains defined as change in the } W^{u}, W^{e}, W^{k} \text { compo- } \\
\text { nents in equation (75) in Supplemental Material G.11, respectively. }\end{array}$
\end{tabular}

\section{Conclusion}

This paper has proposed an alternative view of spatial unemployment differentials. I have shown that high localized unemployment arises because workers repeatedly lose their job, not because finding a job is particularly hard. Differences in job losing rates emerge as employers with unstable jobs self-select into similar locations, while employers with stable jobs locate in others. I have developed a theory in which labor market pooling complementarities are a central driver of the location choice of heterogeneous employers. As a result, employers with stable jobs over-value locating close to each other due to labor market pooling externalities. This view implies that redistributing from low unemployment locations towards high unemployment locations is welfare improving.

Of course, the idea that pooling externalities result in too much concentration in the best options available to workers and employers is more general than the particular spatial context put forward in this paper. For instance, investigating the implications of pooling externalities for the allocation of workers and employers across occupations and industries could lead to interesting policy insights. Indeed, in the spatial context alone, pooling externalities quantitatively account for the lion's share of differences in unemployment across locations.

Consequently, the view of this paper emphasizes that spatial unemployment differentials are not an immutable characteristic of the economic landscape. Instead, place-based policies have the potential to drastically reshape the spatial distribution of unemployment, and ameliorate employment prospects at the aggregate level. While a long tradition of research has found that agglomeration economies call for taxes on poor locations, the implications thereof have remained at odds with a wide range of realworld spatial policies. The view that labor market pooling externalities lie at the heart of the location decisions of employers helps reconcile theory with the intuition that incentivizing businesses to open in distressed areas may help rather than harm individuals. Yet, the inherently local nature of many economic interactions gives rise to many other externalities. Therefore, any policy recommendation should account for as many sources of agglomeration and congestion as possible. As individuals who grow up and live in different places seem to face increasingly divergent economic opportunities, place-based policies appear more relevant than ever. 


\section{References}

Abowd, John M., Kramarz, Francis, and Margolis, David N. (1999). "High Wage Workers and High Wage Firms". Econometrica 67.2, pp. 251-333.

Acemoglu, Daron (2001). "Good Jobs versus Bad Jobs". Journal of Labor Economics 19.1, pp. 1-21.

Amior, Michael and Manning, Alan (2018). "The Persistence of Local Joblessness". American Economic Review 108.7, pp. 1942-70.

Amiti, Mary and Pissarides, Christopher A. (2005). "Trade and industrial location with heterogeneous labor". Journal of International Economics 67.2, pp. 392-412.

Austin, Benjamin A, Glaeser, Edward L, and Summers, Lawrence H (2018). "Jobs for the Heartland: Place-Based Policies in 21st Century America". Brookings Papers on Economic Activity Spring, pp. 151-255.

Bartik, Timothy (1991). Who Benefits from State and Local Economic Development Policies? W.E. Upjohn Institute for Employment Research.

Bilal, Adrien and Lhuillier, Hugo (2021). "Outsourcing, Inequality and Aggregate Output". National Bureau of Economic Research Working Paper Series 29348.

Bilal, Adrien and Rossi-Hansberg, Esteban (2021). "Location as an Asset". Econometrica 89.5, 2459-2495.

Bilal, Adrien G., Engbom, Niklas, Mongey, Simon, and Violante, Giovanni L. (2022). "Firm and Worker Dynamics in a Frictional Labor Market". Econometrica 90.4, pp. 1425-1462.

Blanchard, Olivier Jean and Katz, Lawrence F. (1992). "Regional Evolutions". Brookings Papers on Economic Activity 23.1, pp. 1-76.

Blundell, Richard, Pistaferri, Luigi, and Preston, Ian (2008). "Consumption Inequality and Partial Insurance". American Economic Review 98.5, pp. 1887-1921.

Bonhomme, Stéphane, Lamadon, Thibaut, and Manresa, Elena (2019). "A Distributional Framework for Matched Employer Employee Data". Econometrica 87.3, pp. 699-739.

Brancaccio, Giulia, Kalouptsidi, Myrto, Papageorgiou, Theodore, and Rosaia, Nicola (2020). "Search Frictions and Efficiency in Decentralized Transportation Markets". National Bureau of Economic Research, Working Paper Series 27300.

Burdett, Kenneth and Mortensen, Dale T. (1998). "Wage Differentials, Employer Size, and Unemployment". International Economic Review 39.2, pp. 257-273.

Busso, Matias, Gregory, Jesse, and Kline, Patrick (2013). "Assessing the Incidence and Efficiency of a Prominent Place Based Policy". American Economic Review 103.2, pp. 897-947.

Cahuc, Pierre, Postel-Vinay, Fabien, and Robin, Jean-Marc (2006). "Wage Bargaining with On-the-Job Search: Theory and Evidence". Econometrica 74.2, pp. 323-364.

Caliendo, Lorenzo, Dvorkin, Maximiliano, and Parro, Fernando (2019). "Trade and Labor Market Dynamics: General Equilibrium Analysis of the China Trade Shock". Econometrica 87.3, pp. 741-835. 
Caliendo, Lorenzo, Opromolla, Luca David, Parro, Fernando, and Sforza, Alessandro (2021). "Goods and Factor Market Integration: A Quantitative Assessment of the EU Enlargement". Forthcoming, Journal of Political Economy.

Card, David, Heining, Jörg, and Kline, Patrick (May 2013). "Workplace Heterogeneity and the Rise of West German Wage Inequality". The Quarterly Journal of Economics 128.3, pp. 967-1015.

Chade, Hector and Eeckhout, Jan (2019). "Competing Teams". The Review of Economic Studies 87.3, pp. 1134-1173.

Combes, Pierre-Philippe, Duranton, Gilles, Gobillon, Laurent, Puga, Diego, and Roux, Sébastien (2012). "The Productivity Advantages of Large Cities: Distinguishing Agglomeration From Firm Selection". Econometrica 80.6, pp. 2543-2594.

Couture, Victor, Gaubert, Cecile, Handbury, Jessie, and Hurst, Erik (2019). "Income Growth and the Distributional Effects of Urban Spatial Sorting". National Bureau of Economic Research, Working Paper Series 26142.

Şahin, Ayşegül, Song, Joseph, Topa, Giorgio, and Violante, Giovanni L. (2014). "Mismatch Unemployment". American Economic Review 104.11, pp. 3529-64.

Davis, Donald R. and Dingel, Jonathan I. (2020). "The comparative advantage of cities". Journal of International Economics 123, p. 103291.

Desmet, Klaus, Nagy, Dávid Krisztián, and Rossi-Hansberg, Esteban (2018). "The Geography of Development". Journal of Political Economy 126.3, pp. 903-983.

Desmet, Klaus and Rossi-Hansberg, Esteban (2013). "Urban Accounting and Welfare". American Economic Review 103.6, pp. 2296-2327.

Diamond, Peter A. (1982). "Wage Determination and Efficiency in Search Equilibrium". Review of Economic Studies 49.2, pp. 217-227.

Diamond, Rebecca (2016). "The Determinants and Welfare Implications of US Workers' Diverging Location Choices by Skill: 1980-2000". American Economic Review 106.3, pp. 479-524.

Eeckhout, Jan and Kircher, Philipp (2018). "Assortative Matching With Large Firms". Econometrica 86.1, pp. 85-132.

Elsby, Michael W. L., Hobijn, Bart, and Şahin, Ayşegül (May 2013). "Unemployment Dynamics in the OECD". The Review of Economics and Statistics 95.2, pp. 530-548.

Elsby, Michael W. L. and Michaels, Ryan (2013). "Marginal Jobs, Heterogeneous Firms, and Unemployment Flows". American Economic Journal: Macroeconomics 5.1, pp. 1-48.

Engbom, Niklas (2018). "Firm and Worker Dynamics in an Aging Labor Market". Society for Economic Dynamics, 2018 Meeting Papers 1009.

Engbom, Niklas and Moser, Christian (2021). "Earnings Inequality and the Minimum Wage: Evidence from Brazil". National Bureau of Economic Research, Working Paper Series 28831. 
Faberman, R. Jason, Mueller, Andreas I., Şahin, Ayşegül, and Topa, Giorgio (2017). "Job Search Behavior among the Employed and Non-Employed". National Bureau of Economic Research, Working Paper Series 23731.

Fajgelbaum, Pablo D. and Gaubert, Cecile (2020). "Optimal Spatial Policies, Geography, and Sorting". The Quarterly Journal of Economics 135.2, pp. 959-1036.

Fajgelbaum, Pablo D., Morales, Eduardo, Suárez Serrato, Juan Carlos, and Zidar, Owen (Sept. 2018). "State Taxes and Spatial Misallocation". The Review of Economic Studies 86.1, pp. 333-376.

Fujita, Shigeru and Ramey, Garey (2009). "The Cyclicality of Separation and Finding Rates". International Economic Review 50.2, pp. 415-430.

Galichon, Alfred (2016). Optimal Transport Methods in Economics. Princeton University Press. ISBN: 9780691172767.

Gaubert, Cecile (2018). "Firm Sorting and Agglomeration". American Economic Review 108.11, pp. 311753.

Giannone, Elisa (2017). "Skill-Biased Technical Change and Regional Convergence". Society for Economic Dynamics, 2017 Meeting Papers 190.

Glaeser, Edward L. and Gottlieb, Joshua D. (2008). "The Economics of Place-Making Policies". Brookings Papers on Economic Activity Spring, pp. 155-254.

Glaeser, Edward L., Kim, Hyunjin, and Luca, Michael (2018). "Nowcasting Gentrification: Using Yelp Data to Quantify Neighborhood Change". American Economic Association Papers and Proceedings 108, pp. 77-82.

Grossman, Gene M. and Rossi-Hansberg, Esteban (2012). "Task Trade Between Similar Countries". Econometrica 80.2 , pp. 593-629.

Hagedorn, Marcus and Manovskii, Iourii (2008). "The Cyclical Behavior of Equilibrium Unemployment and Vacancies Revisited". American Economic Review 98.4, pp. 1692-1706.

Hall, Robert E. (1972). "Turnover in the Labor Force". Brookings Papers on Economic Activity 3.3, pp. 709-764.

- (2005). "Employment Fluctuations with Equilibrium Wage Stickiness". American Economic Review 95.1, pp. 50-65.

Hanson, Andrew (2009). "Local employment, poverty, and property value effects of geographically-targeted tax incentives: An instrumental variables approach". Regional Science and Urban Economics 39.6, pp. $721-731$.

Hopenhayn, Hugo and Rogerson, Richard (1993). "Job Turnover and Policy Evaluation: A General Equilibrium Analysis". Journal of Political Economy 101.5, pp. 915-938.

Hosios, Arthur J. (1990). "On the Efficiency of Matching and Related Models of Search and Unemployment". The Review of Economic Studies 57.2, pp. 279-298.

Jarosch, Gregor (2021). "Searching for Job Security and the Consequences of Job Loss". National Bureau of Economic Research, Working Paper Series 28481. 
Kennan, John and Walker, James R. (2011). "The Effect of Expected Income on Individual Migration Decisions". Econometrica 79.1, pp. 211-251.

Kline, Patrick and Moretti, Enrico (2013). "Place Based Policies with Unemployment". American Economic Review 103.3, pp. 238-43.

Krugman, Paul (1991). Geography and Trade. MIT Press, Cambridge.

Krusell, Per, Mukoyama, Toshihiko, Rogerson, Richard, and Şahin, Ayşegül (2017). "Gross Worker Flows over the Business Cycle". American Economic Review 107.11, pp. 3447-76.

Luenberger, David G. (1997). Optimization by Vector Space Methods. 1st. New York, NY, USA: John Wiley \& Sons, Inc. ISBN: 047118117X.

Luttmer, Erzo G. J. (2007). "Selection, Growth, and the Size Distribution of Firms". The Quarterly Journal of Economics 122.3, pp. 1103-1144.

Mangin, Sephorah and Julien, Benoît (2021). "Efficiency in search and matching models: A generalized Hosios condition". Journal of Economic Theory 193, p. 105208.

Marinescu, Ioana and Rathelot, Roland (2018). "Mismatch Unemployment and the Geography of Job Search". American Economic Journal: Macroeconomics 10.3, pp. 42-70.

Marshall, Alfred (1920). Principles of Economics. London: MacMillan.

Mayer, Thierry, Mayneris, Florian, and Py, Loriane (Oct. 2015). "The impact of Urban Enterprise Zones on establishment location decisions and labor market outcomes: evidence from France". Journal of Economic Geography 17.4, pp. 709-752.

Moll, Benjamin and Nuño, Galo (2018). "Social Optima in Economies with Heterogeneous Agents". Review of Economic Dynamics 28, pp. 150-180.

Mortensen, Dale T. (1982). "The Matching Process as a Noncooperative Bargaining Game". In: The Economics of Information and Uncertainty. NBER Chapters. National Bureau of Economic Research, Inc, pp. 233-258.

Mortensen, Dale T. and Pissarides, Christopher A. (1994). "Job Creation and Job Destruction in the Theory of Unemployment". The Review of Economic Studies 61.3, pp. 397-415.

Neumark, David and Simpson, Helen (2014). "Place-Based Policies". National Bureau of Economic Research, Working Paper Series 20049.

OECD (2005). "How Persistent Are Regional Disparities in Employment? The Role of Geographic Mobility". OECD Employment Outlook 2005 Edition.

Osborne, Martin J. and Rubinstein, Ariel (1994). A Course in Game Theory. Vol. 1. MIT Press Books 0262650401. The MIT Press. IsBn: ARRAY(0x448056b8).

Ossa, Ralph (2017). "A Quantitative Analysis of Subsidy Competition in the U.S." National Bureau of Economic Research, Working Paper Series 20975.

Petrongolo, Barbara and Pissarides, Christopher A. (2001). "Looking into the Black Box: A Survey of the Matching Function". Journal of Economic Literature 39.2, pp. 390-431. 
Pham, Huyn (2009). Continuous-time Stochastic Control and Optimization with Financial Applications. 1st. Springer Publishing Company, Incorporated. ISBN: 3540894993, 9783540894995.

Pissarides, Christopher A. (1985). "Short-Run Equilibrium Dynamics of Unemployment, Vacancies, and Real Wages". The American Economic Review 75.4, pp. 676-690.

Roback, Jennifer (1982). "Wages, Rents, and the Quality of Life". Journal of Political Economy 90.6, pp. $1257-1278$.

Rubinstein, Ariel (1982). "Perfect Equilibrium in a Bargaining Model". Econometrica 50.1, pp. 97-109.

Saiz, Albert (Aug. 2010). "The Geographic Determinants of Housing Supply". The Quarterly Journal of Economics 125.3, pp. 1253-1296.

Sattinger, Michael (1993). "Assignment Models of the Distribution of Earnings". Journal of Economic Literature 31.2 , pp. 831-880.

Schaal, Edouard (2017). "Uncertainty and Unemployment". Econometrica 85.6, pp. 1675-1721.

Schmutz, Benoît and Sidibé, Modibo (Sept. 2018). "Frictional Labour Mobility". The Review of Economic Studies 86.4, pp. 1779-1826.

Shimer, Robert (2005). "The Cyclical Behavior of Equilibrium Unemployment and Vacancies". American Economic Review 95.1, pp. 25-49.

Shimer, Robert and Smith, Lones (2000). "Assortative Matching and Search". Econometrica 68.2, pp. 343369.

Slattery, Cailin and Zidar, Owen (2020). "Evaluating State and Local Business Incentives". Journal of Economic Perspectives 34.2, pp. 90-118.

Slattery, Calin (2019). "Bidding for Firms: Subsidy Competition in the U.S". Working Paper.

Tao, Terence (2006). Nonlinear Dispersive Equations: Local and Global Analysis. American Mathematical Society and Conference Board of the Mathematical Sciences.

Topel, Robert H. (1984). "Equilibrium Earnings, Turnover, and Unemployment: New Evidence". Journal of Labor Economics 2.4, pp. 500-522.

Topkis, Donald M. (1998). Supermodularity and Complementarity. Princeton University Press. ISBN: 9780691032443.

Villani, Cedric (Jan. 2003). Topics in Optimal Transportation Theory. Vol. 58. American Mathematical Society. 


\section{APPENDIX}

\section{A Descriptive evidence}

\section{A.1 Transition rates}

\section{A.1.1 Time aggregation and three state model}

Time aggregation correction. Consider first the case in which each city is isolated and workers never leave or enter the labor force which size is normalized to 1. Assume constant job losing and finding rates $s, f$. Then unemployment and employment in each city evolves according to the ODE system

$$
\dot{u}=s e-f u \quad ; \quad \dot{e}=f u-s e \quad \quad \quad \quad \quad \quad \quad=1-u \text {. }
$$

This system admits the solution $u(t)=u_{\infty}+\left(u_{0}-u_{\infty}\right) e^{-(s+f) t}$ and $e(t)=e_{\infty}+\left(e_{0}-e_{\infty}\right) e^{-(s+f) t}$, where $u_{\infty}=\frac{s}{s+f}$ and $e_{\infty}=\frac{f}{s+f}$. Therefore, the transition probabilities in any given time interval $[0, t]$ are

$$
\mathbb{P}_{t}[E \rightarrow U]=\left.u(t)\right|_{u_{0}=0}=\frac{s\left(1-e^{-(s+f) t}\right)}{s+f} \quad ; \quad \mathbb{P}_{t}[U \rightarrow E]=\left.e(t)\right|_{u_{0}=1}=\frac{f\left(1-e^{-(s+f) t}\right)}{s+f}
$$

Hence, the instantaneous quarterly transition rates can be recovered from time-aggregated transition probabilities from $s=\mathcal{T} \times \mathbb{P}_{1}[E \rightarrow U]$ and $f=\mathcal{T} \times \mathbb{P}_{1}[U \rightarrow E]$, where one quarter is the interval $[t, t+1)$, and the time aggregation correction factor is

$$
\mathcal{T}=-\frac{\log \left(1-\mathbb{P}_{1}[E \rightarrow U]-\mathbb{P}_{1}[U \rightarrow E]\right)}{\mathbb{P}_{1}[E \rightarrow U]+\mathbb{P}_{1}[U \rightarrow E]}
$$

Three state model. I now consider a three-state version of the model, still with isolated locations and the total number of individuals normalized to 1 in each lcation. Denote now by $n(t)$ the number of individuals out of the labor force, so that $u(t)+e(t)+n(t)=1$. There are transitions between all states, such that

$$
\dot{u}=s e-f u+r n-d u \quad ; \quad \dot{n}=s_{n} e-f_{n} n-r n+d u,
$$

where $s_{n}$ is the separation rate into non-participation, $f_{n}$ the finding rate out of non-participation, $r$ the reentry rate $(\mathrm{NU})$ and $d$ the drop-out rate $(\mathrm{UN})$. In steady-state, $d u-r n=s e-f u$ and $d u-r n=f_{n} n-s_{n} e$. Finally, the unemployment rate $u_{R}$ is $u_{R}=\frac{u}{e+u}=\frac{u}{1-n}$. Using $e=1-u-n$ and combining both equations,

$$
u_{R}=\frac{s\left(f_{n}+r\right)+r s_{n}}{f_{n}(d+f+s)+r\left(f+s_{n}+s\right)} \Longrightarrow \frac{u_{R}}{1-u_{R}}=\frac{s\left(f_{n}+r\right)+r s_{n}}{f_{n}(d+f)+r f}
$$

Defining $p=\frac{s\left(f_{n}+r\right)+r s_{n}}{f_{n}(d+f)+r f}-\frac{s}{s+f}$, I obtain

$$
\log \frac{u_{c}}{1-u_{c}}=\log s_{c}-\log f_{c}+\log p_{c}+e_{c}
$$


Table 4: Variance decomposition of local unemployment-employment ratio.

\begin{tabular}{lrrrr} 
& \multicolumn{2}{c}{ France } & & U.S. \\
\cline { 2 - 3 } & DADS & LFS & CPS \\
\hline Direct flows: job losing and finding rates (\%) & 92 & 105 & 96 \\
Job losing rate & & & \\
\% direct flows & 78 & 59 & 73 \\
\% total & 72 & 62 & 70 \\
\% total, time-aggregated & 71 & 55 & 62 \\
Job finding rate & & & \\
\% direct flows & 22 & 41 & 27 \\
$\%$ total & 20 & 43 & 26 \\
\% total, time-aggregated & 21 & 50 & 34 \\
Non-participation (\%) & & & \\
Residual (\%) & 10 & -4 & -4 \\
\hline
\end{tabular}

Note: Variance decomposition of log unemployment-employment ratio following equation

(26). Direct flows represent the contributions of job losing and job finding rates.

where $e_{c}$ is a residual that captures migration flows, local dynamics and measurement error. The exact variance decomposition of the log unemployment-employment ratio writes

$$
\begin{aligned}
\operatorname{Var}\left[\log \frac{u_{c}}{1-u_{c}}\right] & =\overbrace{\mathbb{C o v}\left[\log \frac{u_{c}}{1-u_{c}}, \log s_{c}\right]}^{\operatorname{Cov}\left[\log \frac{u_{c}}{1-u_{c}},-\log f_{c}\right]} \\
& +\underbrace{\operatorname{Cov}\left[\log \frac{u_{c}}{1-u_{c}}, \log p_{c}\right]}_{\text {Non-participation }}+\underbrace{\operatorname{Cov}\left[\log \frac{u_{c}}{1-u_{c}}, e_{c}\right]}_{\text {Residual }} .
\end{aligned}
$$

Time aggregation and three state model in the data. Table 4 reports the variance decomposition of local unemployment on job losing rates, job finding rates, non-participation flows and a structural residual for non-time-aggregated and time-aggregated flows.

\section{A.1.2 Changes over time}

Figure 10 plots the analogue of the decomposition in equation (1) in changes over time. I find that changes in job losing rates account for $44 \%$ of the variation in changes in local unemployment rates. By contrast, job finding rates account for $56 \%$ of that variation. Thus, over 5 -year intervals, changes in cities' unemployment rates are consistent with the conventional business cycle view that job finding rates are the primary determinant of unemployement rates. Only in the long run do job losing rates matter. 
Figure 10: Job losing and finding rates across cities and over time in France.

(a) Job losing rate

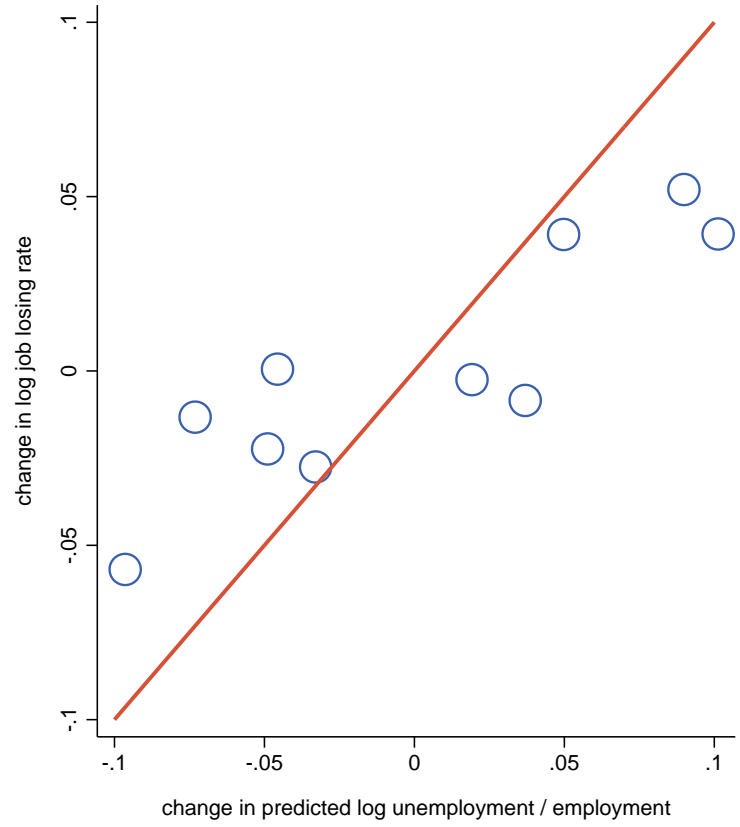

(b) Job finding rate

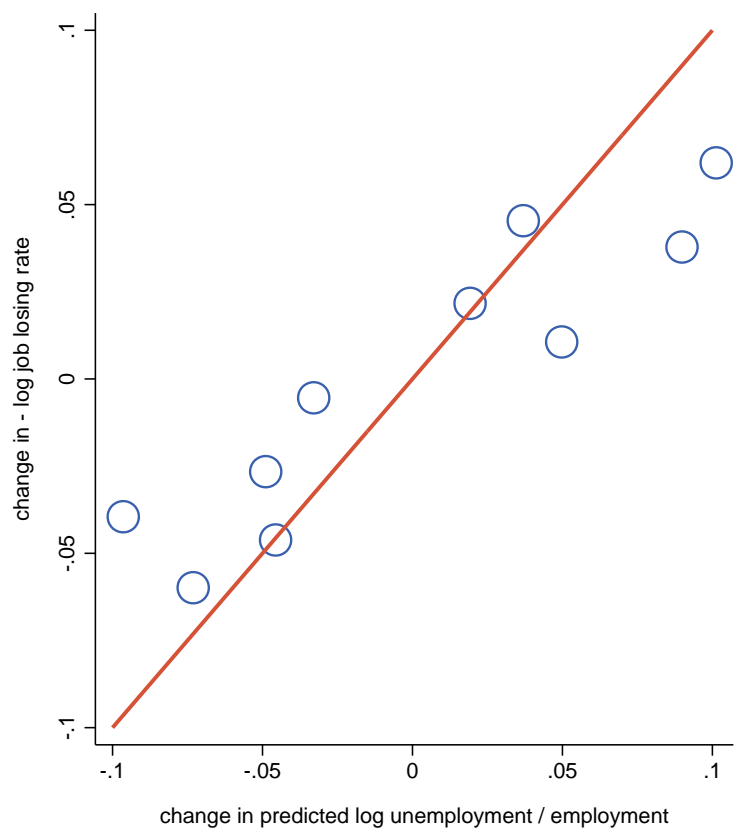

Note: Decomposition of changes in predicted unemployment to employment ratio $\Delta \log \frac{\hat{u}_{c}}{1-\hat{u}_{c}} \equiv \Delta \log s_{c}-\Delta \log f_{c}$ into changes in job losing and changes in job finding rates. Cities binned into population-weighted deciles. Changes between 1997-2001 and 2002-2007 averages.

\section{A.2 Composition}

Fixed effect models. To estimate the three-way and two-way fixed effect models in (2), I cluster employers, workers and cities into groups prior to estimation. I start by computing the unconditional EU probability for every employer, worker and city. Next, I define groups of employers ad populationweighted quantiles of employers' unconditional EU probability. Similarly, I define groups of workers and cities as population-weighted quantiles of their unconditional EU probability. As long as there is positive sorting between employers, workers and cities, grouping based on the unconditional EU probability is asymptotically consistent with the true employer, worker and city effect.

Firm-level correlates. Figure 11 plots firm-level observables against an estimated job losing firm fixed effect.

Industry and skill composition. In principle, differences in the local industry mix and worker skill mix may account for some or all of the differences in the average worker and employer effects highlighted in Figure 3. To assess the role of industry and skill heterogeneity across cities, I first reproduce Figure 2 separately by industry. I distinguish between industries with tradable output goods (agriculture, mining and manufacturing), non-tradable output goods (construction, retail, hospitality and personal services), and industries with output goods of intermediate tradability (utilities, finance, insurance and real estate, public, education, health, transportation and other services). I assign workers to their last industry of employment to construct industry-specific unemployment and job finding rates.

Figure 12 reveals that in both tradable and non-tradable industries, job losing rates co-move strongly 
Figure 11: Firm-level correlates of firm-specific job losing rates in France.

(a) Job losing rate

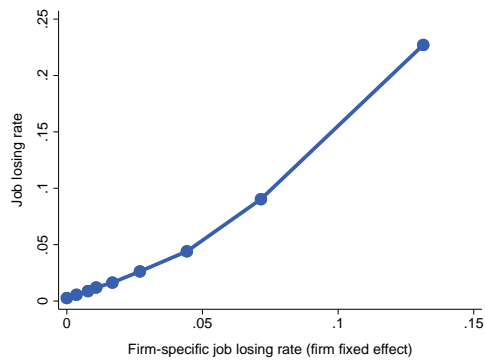

(d) Labor productivity

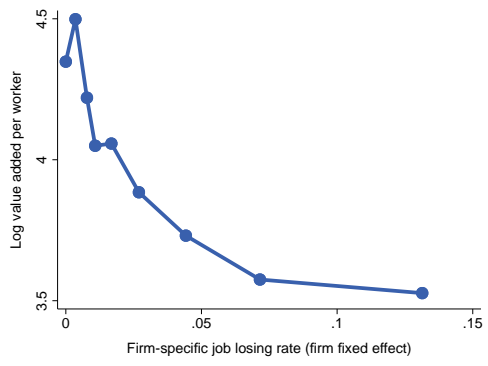

(g) Wage

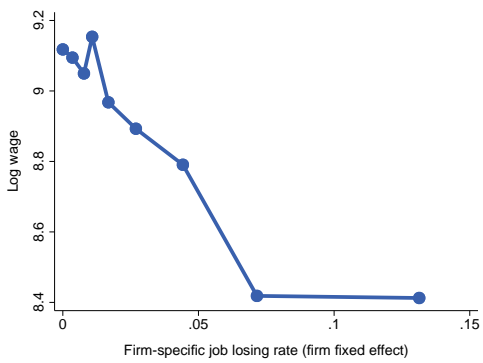

(b) Sales

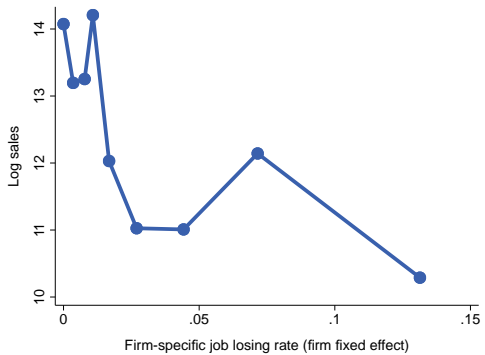

(e) Capital intensity

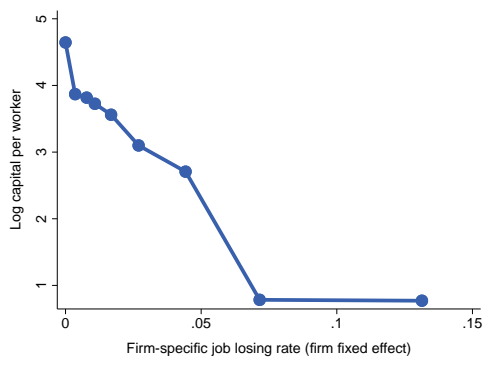

(h) Labor share

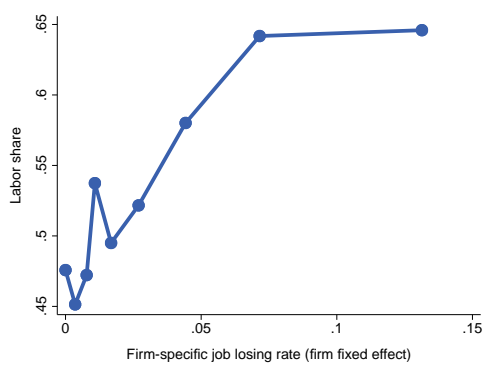

(c) Employment

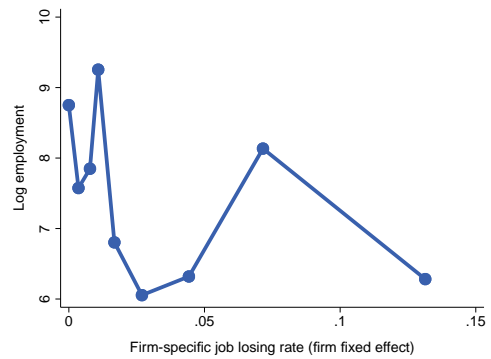

(f) Profitability

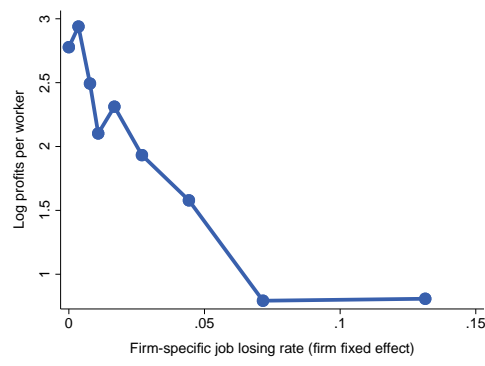

(i) Tradable industry

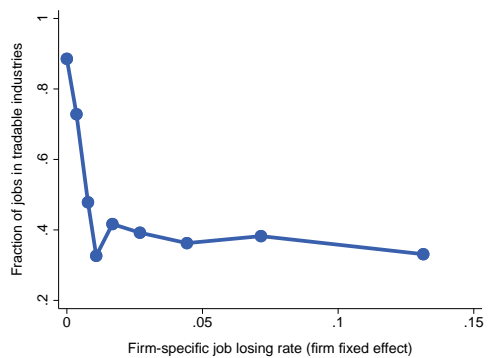

Note: Graphs exclude firms with no separations to unemployment in the sample. Job losing rate in panel (a) is the unconditional EU probability at the firm. Profitability in panel (f) defined as accounting profits ("Excedent brut d'exploitation") per worker. In panel (i), industries with tradable output are agriculture, mining and manufacturing. Industries with non-tradable output are construction, retail, hospitality and personal services. For panel (i) only, I exclude industries with output of intermediate tradability: utilities, finance, insurance and real estate, public, education, health, transportation and other services.

with local unemployment rates across space for all industries, while job finding rates remain nearly constant. While tradable industries have lower job losing rates and marginally higher job finding rates overall, the job losing rate gap between tradables and non-tradables is nearly constant across space.

Yet, if non-tradable industries are more prevalent in high-unemployment cities can industry heterogeneity account for a sizeable share of spatial unemployment differentials. In fact, the employment share of tradable industries drops from $38 \%$ to $14 \%$ when comparing cities in the lowest to the highest decile of local unemployment rates.

To assess quantitatively the role of industry and skill heterogeneity, I next estimate three-way fixed effect econometric models of the following form:

$$
Y_{i, t}=\alpha_{C(i, t)}+\beta_{I(i, t)}+\gamma_{S(i)}+e_{i, t}
$$

where $C$ denotes a city, $I$ denotes a 3 -digit industry, $S$ denotes a skill group, $i$ denotes a worker identifier, 
Figure 12: Job losing and finding rates by city and industry against unemployment-employment ratios in France.

(a) Job losing rate

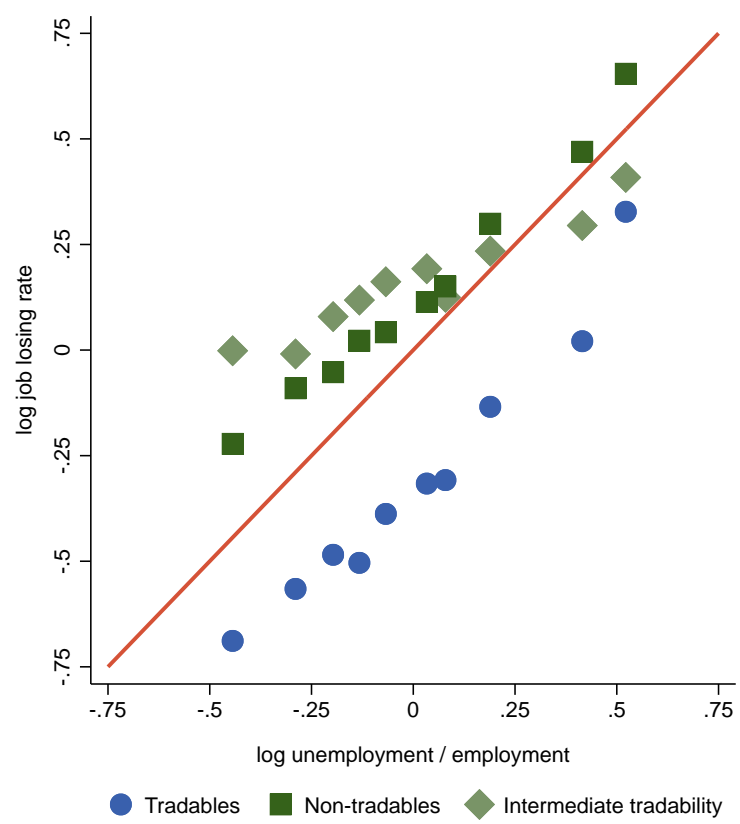

(b) Job finding rate

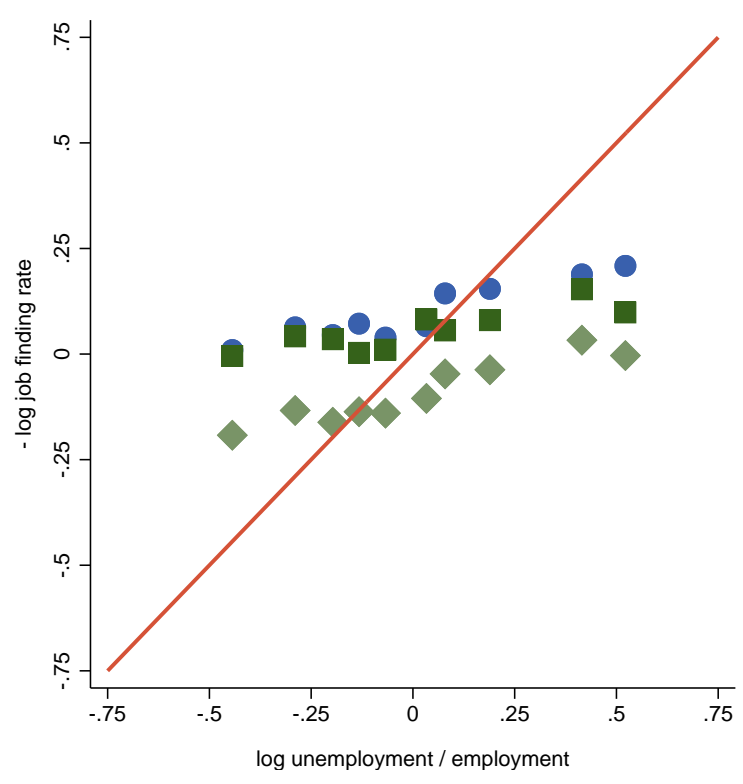

Note: Bin-scatterplots the log of the job losing rate and job finding rate against the log of the unemployment-employment ratio, across commuting zones and industries in France (DADS panel).Tradables (blue circles): agriculture, mining and manufacturing. Non-tradables (dark green squares): construction, retail, hospitality and personal services. Intermediate tradability (light green diamonds): utilities, finance, insurance and real estate, public, education, health, transportation and other services. City bins constructed using city-level unemployment rates, averaged across industries.

and $t$ is a quarter. $\alpha_{C}$ is a city effect, $\beta_{I}$ an industry effect, and $\gamma_{S}$ a skill effect. $e_{i, t}$ is a conditionally mean zero residual. $Y_{i, t}$ is an outcome of interest, that is either a job loss indicator, a job finding indicator, or an unemployment indicator. For unemployed workers, I define industry as their last industry of employment. I estimate linear probability models with 232 industry fixed effects and 300 skill fixed effects. Then, I replicate Figure 2 with the estimated city fixed effects $\hat{\alpha}_{c}$.

Figure 13 reveals that industry and worker composition do not contribute significantly to spatial unemployment differentials. While controlling for industry and skill heterogeneity does reduce the crosssectional variation in local unemployment rates from 2.4 p.p. to 2.1 p.p., Figure 13 shows that the job losing rate remains the dominant source of spatial unemployment gaps.

Table 5 reports variance decompositions of the unconditional job losing rate across French commuting zones into employer, worker and city components with different definitions of employers. In all specifications, employers account for the largest share of variation in local job losing rates. When exploiting multi-establishment firms to separately identify city effects from firm effects, I find that city effects account for no more than $22 \%$ of the overall variation in local job losing rates.

Table 6 reports linear regressions of changes in individual-level EU probabilities on changes in city-level EU probabilities upon moving. Columns (1) and (5) show that the individual EU probability of movers tracks the city average. This conclusion holds when the city average is computed using all individuals or movers only. Columns (2) and (6) reveal that much of this association vanishes when controlling for the average EU probability of the worker's employer: in both cases, the coefficient drops substantially. and 
Figure 13: Local job losing and finding rates against unemployment-employment ratios in France. City fixed effects net of local industry and worker composition.

(a) Job losing rate

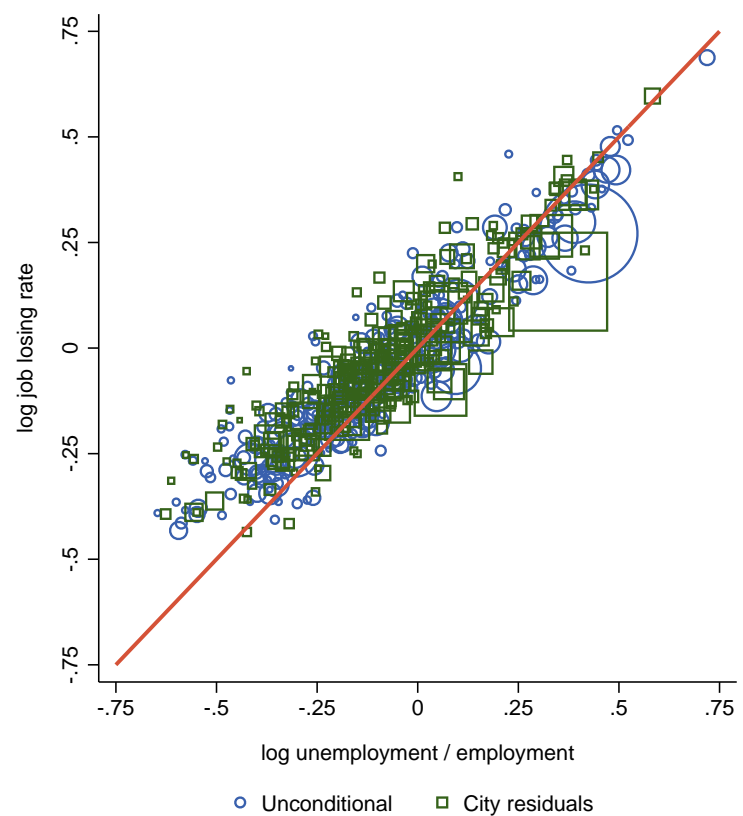

(b) Job finding rate

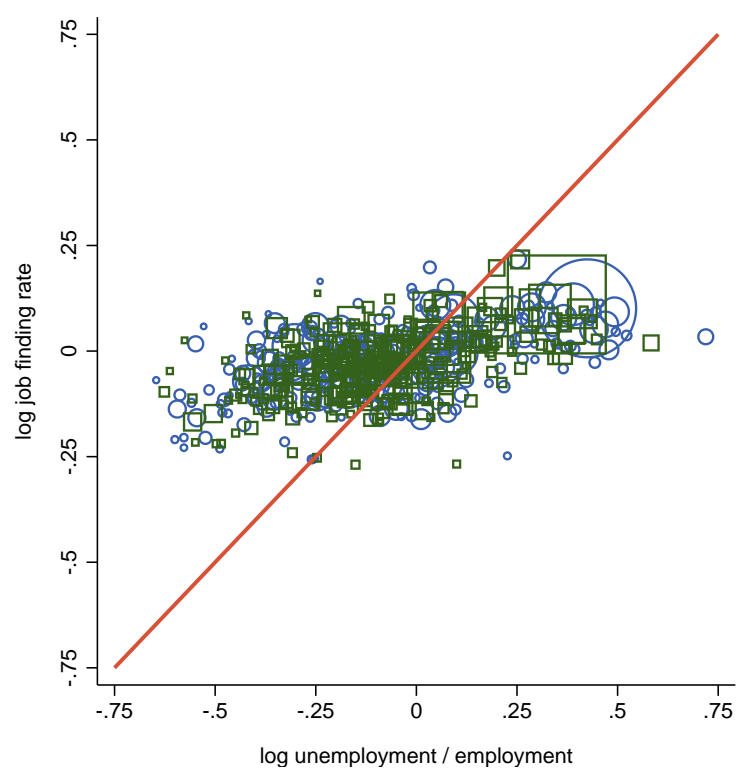

Note: Scatterplots the log of the unconditional (blue circles) and residual (green squares) job losing rate and residual job finding rate against the log of the residual unemployment-employment ratio, across commuting zones in France (DADS panel). Residual defined as the estimated city fixed effect from the three-way fixed effect model in (27).

becomes either insignificant or nearly insignificant. This finding is consistent with Figure 3 showing that local employers account for the majority of the variation in local job losing rates.

The remaining results in Table 6 check whether the conditional random mobility assumption that underpins identification in equation (2) is likely to be violated. If individuals receive an unobserved shock that increases their individual job losing rates and at the same time move towards either cities or firms with systematically higher job losing rates, the conditional random mobility assumption is violated. In this case, the association between individual and city or firm job losing rates should be stronger when restricting attention to either moves towards cities with higher or lower job losing rates.

Columns (3-4) and (7-8) of Table 6 indicate that the association between individual and local job losing rates remains weak and mostly insignificant when restricting attention to either moves towards cities with higher or lower job losing rates. Columns (9-10) of Table 6 reveal that the association between individual and firm job losing rates remains statistically indistinguishable from 1, while the association with local job losing rates remains much weaker, after restricting attention to moves towards firms with higher or low job losing rates. These results thus support the conditional random mobility assumption.

\section{B Baseline model}

\section{B.1 Value functions}

In this Appendix I solve the more general model without assuming that wages depend only on productivity and the location. 
Table 5: Variance decomposition of city job losing rates on worker and employer contributions.

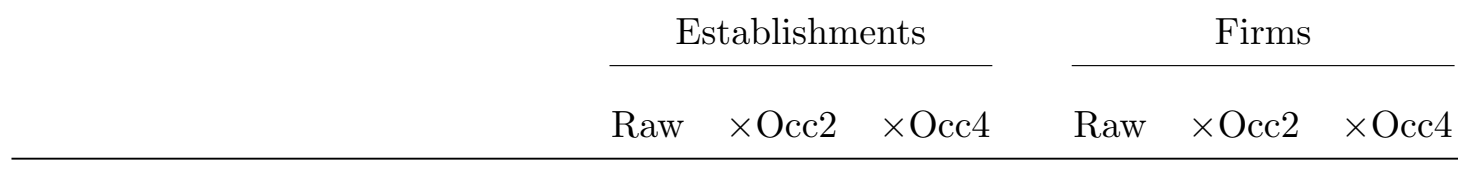

Variance shares (\%): 10 groups

Employer fixed effects $\quad 59$

Worker fixed effects

$59 \quad 57$

$57 \quad 66$

44

46

52

City fixed effects

41

43

34

35

36

26

Variance shares (\%): 50 groups

Employer fixed effects

62

59

68

47

50

52

Worker fixed effects

38

41

32

33

34

24

City fixed effects

20

16

24

Variance shares (\%): 300 groups

Employer fixed effects

$\begin{array}{ll}62 & 59 \\ 38 & 41\end{array}$

68
32

47

$49 \quad 52$

Worker fixed effects

$41 \quad 32$

32

34

24

City fixed effects

\begin{abstract}
Note: Variance decomposition of average commuting zone job losing rate into worker and employer components as per equation (3). I vary the definition of an employer: an establishment (SIRET identifier, column 1), an establishment by 2-digit occupation (column 2), an establishment by 4-digit occupation (column 3), a firm (SIREN identifier, column 4), a firm by 2-digit occupation (column 5), a firm by 4-digit occupation (column 6). When using firms, equation (3) is enriched with a city fixed effect. I cluster workers and employers into groups based on their unconditional mean job losing rate. I use 10, 50 and 300 groups.
\end{abstract}

Values. When the wage needs not depend on $(y, \ell)$ but only follows a Markov process, workers' values become

$$
\rho U=b \ell r(\ell)^{-\omega}+f(\ell) \mathbb{E}_{\ell}\left[V\left(w^{*}\left(y_{0}, \ell\right), \ell\right)-U\right] \quad ; \quad \rho V(w, \ell)=w r(\ell)^{-\omega}+\left(L_{w} V\right)(w, \ell)
$$

where the expectation is taken over the starting productivity $y_{0}$ in location $\ell . L_{w}$ is the integro-differential infinitesimal generator that encodes the continuation value of employment due to wage changes. It needs not be explicitly specified at this stage.

Worker surplus. Workers' surplus from being employed $V-U$ solves

$$
\rho(V(w, \ell)-U)=r(\ell)^{-\omega}(w-(b+v(\ell)) \ell)+L_{w}(V-U)(w, \ell)
$$

where I denote $v(\ell) \ell=f(\ell) \mathbb{E}\left[V\left(w^{*}\left(y_{0}, \ell\right)\right)-U\right]$ the efficiency value of search in location $\ell$.

Employers. The value of a filled job paying wage $w$ with productivity $y$ in location $\ell$ solves

$$
\rho J(w, y, \ell)=y \ell-w+\left(L_{y} J\right)(y, w, \ell)+\left(L_{w} J\right)(y, w, \ell) .
$$


Table 6: Changes in individual EU probability upon moving.

\begin{tabular}{|c|c|c|c|c|c|c|c|c|c|c|}
\hline & \multicolumn{2}{|c|}{ No split } & \multicolumn{2}{|c|}{ Split by city } & \multicolumn{2}{|c|}{ No split } & \multicolumn{2}{|c|}{ Split by city } & \multicolumn{2}{|c|}{ Split by firm } \\
\hline & (1) & (2) & (3) & (4) & (5) & (6) & (7) & (8) & $(9)$ & (10) \\
\hline & All & All & Down & Up & All & All & Down & Up & Down & Up \\
\hline$\Delta$ city EU prob. (all) & $\begin{array}{l}1.615^{*} \\
(0.659)\end{array}$ & $\begin{array}{l}-0.070 \\
(0.506)\end{array}$ & $\begin{array}{c}-0.133 \\
(0.779)\end{array}$ & $\begin{array}{l}-0.450 \\
(0.760)\end{array}$ & & & & & & \\
\hline$\Delta$ city EU prob. (movers) & & & & & $\begin{array}{l}1.209^{* * *} \\
(0.248)\end{array}$ & $\begin{array}{l}0.414^{*} \\
(0.191)\end{array}$ & $\begin{array}{l}0.324 \\
(0.356)\end{array}$ & $\begin{array}{l}0.687^{*} \\
(0.336)\end{array}$ & $\begin{array}{l}0.521^{*} \\
(0.239)\end{array}$ & $\begin{array}{l}0.211 \\
(0.235)\end{array}$ \\
\hline$\Delta$ firm EU prob. (movers) & & $\begin{array}{l}1.029^{* * *} \\
(0.022)\end{array}$ & $\begin{array}{l}1.022^{* * *} \\
(0.027)\end{array}$ & $\begin{array}{l}1.004^{* * *} \\
(0.032)\end{array}$ & & $\begin{array}{l}1.024^{* * *} \\
(0.022)\end{array}$ & $\begin{array}{l}1.019^{* * *} \\
(0.027)\end{array}$ & $\begin{array}{l}1.000^{* * *} \\
(0.032)\end{array}$ & $\begin{array}{l}1.007^{* * *} \\
(0.029)\end{array}$ & $\begin{array}{l}0.993^{* * *} \\
(0.040)\end{array}$ \\
\hline Obs. & 3209 & 3209 & 1721 & 1877 & 3209 & 3209 & 1721 & 1877 & 2057 & 1781 \\
\hline$R^{2}$ & 0.002 & 0.415 & 0.452 & 0.344 & 0.007 & 0.416 & 0.452 & 0.346 & 0.373 & 0.262 \\
\hline
\end{tabular}

Note: Standard errors in parenthesis. ${ }^{+} p<0.10,{ }^{*} p<0.05,{ }^{* *} p<0.01,{ }^{* * *} p<0.001$. First four columns: city-level EU probability computed using all individuals. Last four columns: city-level EU probability computed using only movers. Last four columns: city-level EU probability computed using only movers. All: linear regression using all movers in sample that move exactly once. Down: restricting to individuals who move to cities or firms with weakly lower EU probability. Up: restricting to individuals who move to cities or firms with weakly higher EU probability.

\section{B.2 Adjusted surplus, wages and proof of Lemma 1}

\section{B.2.1 Adjusted surplus}

To characterize wages and values, it is useful to define the adjusted surplus

$$
S(y, \ell)=J(y, w, \ell)+r(\ell)^{\omega} \cdot(V(y, w, \ell)-U)
$$

which is indepedent from wages, and solves the recursion

$$
\rho S(y, \ell, a)=\ell \cdot(y-b-v(\ell))-L_{y} S
$$

for continuing matches. Renegotiation every instant means that employers and workers bargain over flow surpluses

$$
r(\ell)^{-\omega}(w-(b+v(\ell)) \ell) \quad ; \quad y \ell-w .
$$

Without loss of generality, these flow surpluses can be written as values

$$
W(w)=W_{0} w-W_{1} \quad ; \quad F(w)=F_{1}-w .
$$

The following Lemma lets me make progress.

\section{B.2.2 Wage determination}

Lemma 3. (Bargaining solution)

Suppose that a worker and an employer set wages either under generalized Nash bargaining, or play an alternating offer game à la Rubinstein (1982) with static surpluses $W(w)=W_{0} w-W_{1}$ and $F(w)=F_{1}-w$, and worker effective bargaining power $\beta$. Define the adjusted surplus $S(w)=F(w)+\frac{W(w)}{W_{0}}$. Then

- The adjusted surplus is independent from wages $S(w) \equiv S$ 
- The equilibrium wage $w^{*}$ solves

$$
\frac{W\left(w^{*}\right)}{W_{0}}=\beta S \quad ; \quad F\left(w^{*}\right)=(1-\beta) S
$$

Proof. See Supplemental Material E.1.

\section{B.2.3 Solving for the adjusted surplus}

Using Lemma 3, the solution to the dynamic bargaining problem immediately follows.

Lemma 4. (Bargaining solution)

Under either generalized Nash bargaining or alternative offers, equilibrium wages $w^{*}(y, \ell)$ split the adjusted surplus into constant shares:

$$
J\left(y, w^{*}(y, \ell), \ell\right)=(1-\beta) S(y, \ell) \quad ; \quad V\left(y, w^{*}(y, \ell), \ell\right)-U=\beta r(\ell)^{-\omega} \cdot S(y, \ell) .
$$

Because of static renegotiation, wages for continuing matches can then be immediately calculated

$$
w^{*}(y, \ell)=[(1-\beta)(b+v(\ell))+\beta y] \ell
$$

However, all matches eventually break up. Hence, the adjusted surplus $S$ solves an optimal stopping problem, and thus a Hamilton-Jacobi-Bellman-Variational-Inequality (HJB-VI): ${ }^{56}$

$$
0=\max \left\{(y-(b+v(\ell))) \ell+\left(L_{y} S\right)(y, \ell)-\rho S(y, \ell), S(y, \ell)\right\} \quad, \quad \forall y \geq 0 .
$$

With equation (30) at hand, Lemma 1 obtains following closely the steps and references in Luttmer (2007), with the definitions

$$
\tau=\frac{2 \delta}{\sigma^{2}}\left\{\sqrt{1+\frac{2 \rho \sigma^{2}}{\delta^{2}}}-1\right\} \quad ; \quad \underline{y}_{0}=\frac{1+\tau}{\tau} \frac{\rho}{\rho+\delta-\sigma^{2} / 2} .
$$

For completeness, a full proof is given in Supplemental Material E.2.

\section{B.3 Endogenous job loss and unemployment}

\section{B.3.1 Proof of equation (12)}

Consider a single location $\ell$ and omit location subscripts $\ell$. I will work in $\log$ productivity, $x=\log y$. Denote $g^{x}(t, x)$ the density in logs, and $g^{y}(t, y)$ the density in levels. These densities are related by $g^{x}(t, x)=g^{y}\left(t, e^{x}\right) e^{x}$. When unambiguous, I will slightly abuse notation and simply denote $g(t, x)$ the density in logs, and $g(t, y)$ the density in levels. I denote the steady-state densities by $g$ but without time arguments.

Consider a unit measure of workers who start employment with some distribution in $\operatorname{logs} g(0, x)$. Their

\footnotetext{
${ }^{56}$ See Pham (2009) for a formal derivation of the HJB-VI from the sequential formulation.
} 
distribution then evolves according to the KFE without entry:

$$
g_{t}(t, x)=\delta g_{x}(t, x)+\frac{\sigma^{2}}{2} g_{x x}(t, x)
$$

where subscripts denote partial derivatives. Let $M(t)=\int_{x}^{\infty} g(t, x) d x$ denote the measure of employed workers at time $t$, with $M(0)=1$. Integrating (31) over $[\underline{x},+\infty)$ and using $g(t, \underline{x})=0$ for all times $t$ leads to $M^{\prime}(t)=0-\frac{\sigma^{2}}{2} g_{x}(t, \underline{x})$. Therefore, the initial job losing rate is $-\frac{M^{\prime}(0)}{M(0)}=\frac{\sigma^{2}}{2} g_{x}(0, \underline{x})=\frac{\sigma^{2}}{2} g_{y}(0, \underline{y}) e^{2 \underline{x}}=$ $\frac{\sigma^{2}}{2} \underline{y}^{2} g_{y}(0, \underline{y})$. In steady-state, the job losing rate thus follows the same expression evaluated at the steadystate distribution: $s=\frac{\sigma^{2}}{2} g_{x}(\underline{x})=\frac{\sigma^{2} \underline{y}^{2}}{2} g_{y}(\underline{y})$.

\section{B.3.2 Proof of Lemma 2}

Impose Assumption 1. Consider a single location $\ell$ and omit location subscripts $\ell$. Thus, in $\operatorname{logs} x=\log y$, the new job distribution function is $g_{0}(x)=g_{0} e^{-\zeta(x-\underline{x})}$ where $\zeta=1 / z$. Slightly abusing notation, denote $g(x)$ the invariant density in logs, and $h(x)=g^{\prime}(x)$. Then the KFE becomes $0=\delta h(x)+\frac{\sigma^{2}}{2} h^{\prime}(x)+$ $g_{0} e^{-\zeta(x-\underline{x})}$.

The homogeneous solution is $h_{H}(x)=A e^{-\kappa(x-\underline{x})}$. Varying the constant, I obtain $\frac{\sigma^{2}}{2} A^{\prime}(x) e^{-\kappa(x-\underline{x})}+$ $g_{0} e^{-\zeta(x-\underline{x})}=0$, and so $A(x)=\tilde{A}_{0}-\frac{2 g_{0}}{\sigma^{2}} \int_{0}^{x-\underline{x}} e^{(\kappa-\zeta) t} d t=A_{0}-\frac{2 g_{0}}{\sigma^{2}(\kappa-\zeta)} e^{(\kappa-\zeta)(x-\underline{x})}$. Therefore, $g^{\prime}(x)=$ $h(x)=A_{0} e^{-\kappa(x-\underline{x})}-\frac{2 g_{0}}{\sigma^{2}(\kappa-\zeta)} e^{-\zeta(x-\underline{x})}$. Given the integrability condition for $g$, the integration constants must cancel out, and $g(x)=B e^{-\kappa(x-\underline{x})}+\frac{2 g_{0}}{\sigma^{2} \zeta(\kappa-\zeta)} e^{-\zeta(x-\underline{x})}$. Finally, $g(\underline{x})=0$ pins down $B$, so that $g(x)=g_{1}\left[e^{-\zeta(x-\underline{x})}-e^{-\kappa(x-\underline{x})}\right]$, with $g_{1}=\frac{2 g_{0}}{\sigma^{2} \zeta(\kappa-\zeta)}$.

In equilibrium, the measure of entrants is $g_{0} / \zeta=\frac{\sigma^{2}}{2} g^{\prime}(\underline{x})$ and simply scales the overall measure of employed workers. To define a probability density function, set $g_{0}$ - and thus $g_{1}$ - so that $g$ integrates to 1. I obtain $1=g_{1} \cdot \frac{\kappa-\zeta}{\zeta \kappa}$. Therefore, $g(x)=\frac{\zeta \kappa}{\kappa-\zeta}\left[e^{-\zeta(x-\underline{x})}-e^{-\kappa(x-\underline{x})}\right]=\frac{\kappa}{\kappa z-1}\left[e^{-(x-\underline{x}) / z}-e^{-\kappa(x-\underline{x})}\right]$. Reverting back to levels $y=e^{x}$, I obtain $g^{y}(y)=g^{x}(\log y) / y$, and so $g(y)=\frac{\kappa}{\kappa z-1} \frac{1}{y}\left[(y / \underline{y})^{-1 / z}-(y / \underline{y})^{-\kappa}\right]$.

\section{B.3.3 Proof of Proposition 1}

Job losing rate. From Lemma 2 and equation (12), the job losing rate is $s \zeta \kappa=\delta \zeta=\delta / z$.

Job finding rate. To express job finding, it suffices to use the definition of workers' value of search. Under Assumption 1, they follow equation (34). The realized finding rate is thus

$$
f_{R}(\ell)=f(\ell)\left(\frac{B}{b+v(\ell)}\right)^{1 / z(\ell)}=\frac{\rho v(\ell)}{\beta(b+v(\ell)) \bar{S}(z(\ell))} \equiv \Phi_{R}(v(\ell), 1 / z(\ell)) .
$$

Substituting in the definition of reservation wages delivers the expression for $f_{R}$ in Proposition 1, with $\underline{w}_{1}=b\left(1-\beta+\beta \underline{y}_{0} / \rho\right)$.

Unemployment rate. The expression for the unemployment rate then follows from the two-state model as in Section 1.1. 


\section{B.4 Sorting}

\section{B.4.1 Proof of equations (13) and (14)}

Given the bargaining solution and the adjusted surplus, the value of employer $z$ in location $\ell$ satisfies

$$
\rho J(z, \ell)=(1-\beta) q(\ell) \ell(b+v(\ell)) \bar{S}(z, \underline{y}(\ell)) \quad, \quad \bar{S}(z, \underline{y}) \equiv \int \mathcal{S}\left(\frac{y_{0}}{\underline{y}}\right) G_{0}\left(d y_{0} \mid z\right) .
$$

Under Assumption 1, the integral can be explicitly computed and equation (32) becomes

$\rho J(z, \ell)=(1-\beta) q(\ell) \ell(b+v(\ell))^{1-\frac{1}{z}} \bar{S}_{0}(z) \quad ; \quad \bar{S}_{0}(z) \equiv B^{\frac{1}{z}} \overline{\mathcal{S}}(z) \quad ; \quad \overline{\mathcal{S}}(z)=\frac{z}{1-z} \frac{\tau z}{\tau z+1} \quad ; \quad B \equiv \rho Y / \underline{y}_{0}$.

Expressing $b+v(\ell)=\frac{\underline{w}(\ell)}{1-\beta+\beta \underline{y}_{0} / \rho}$, I obtain

$$
\rho J(z, \ell)=\frac{1-\beta}{1-\beta+\beta \underline{y}_{0} / \rho} q(\ell) \ell \underline{w}(\ell)^{1-\frac{1}{z}}\left(1-\beta+\beta \underline{y}_{0} / \rho\right)^{1 / z} \bar{S}_{0}(z) .
$$

Define

$$
\bar{S}(z)=\bar{S}_{0}(z)\left(1-\beta+\beta \underline{y}_{0} / \rho\right)^{1 / z}=\left(Y / \underline{w}_{0}\right)^{\frac{1}{z}} \frac{z}{1-z} \frac{\tau z}{\tau z+1} .
$$

Finally, substitute the definition of $\bar{S}(z)$ into (33) and raise to a power $\frac{z}{1-z}$ to deliver (14).

\section{B.4.2 Workers' value of employment}

Before turning to the proof of Propostion 2, it is useful to derive an equilibrium expression for the value of future employment opportunities to unemployed workers $v(\ell)$. In what follows, I denote $\overline{\mathcal{S}}(\zeta)=\overline{\mathcal{S}}(1 / \zeta)$ where $\zeta=1 / z$.

Using Lemma 1 together with the surplus-sharing rule (8), I obtain

$$
\begin{aligned}
v(\ell) \ell & =\rho^{-1} \beta f(\ell) \ell(b+v(\ell))\left(\frac{B}{b+v(\ell)}\right)^{\zeta(\ell)} \overline{\mathcal{S}}(\zeta(\ell)) \\
& =\rho^{-1} \beta m^{\frac{1}{\alpha}} \ell q(\ell)^{-\frac{1-\alpha}{\alpha}}(b+v(\ell))\left(\frac{B}{b+v(\ell)}\right)^{\zeta(\ell)} \overline{\mathcal{S}}(\zeta(\ell)) .
\end{aligned}
$$

Therefore,

$$
q(\ell)^{\frac{1-\alpha}{\alpha}}=\rho^{-1} \beta m^{\frac{1}{\alpha}} v(\ell)^{-1}(b+v(\ell))^{1-\zeta(\ell)} B^{\zeta(\ell)} \overline{\mathcal{S}}(\zeta(\ell))
$$

\section{B.4.3 Separation threshold}

Equation (34) implies $b+v(\ell)=\frac{b}{1-\rho^{-1} \beta f_{R}(\ell) \overline{\mathcal{S}}(\zeta(\ell))}$. Using Lemma 1, $\underline{y}(\ell)=\frac{1+\tau}{\tau} \frac{1}{\rho+\delta-\sigma^{2} / 2} \frac{b}{1-\rho^{-1} \beta f_{R}(\ell) \overline{\mathcal{S}}(\zeta(\ell))}$, which is decreasing in $\rho$ and increasing in $f_{R}(\ell)$ since $\tau$ is increasing in $\rho$. Cross-derivatives capture the discounting effect. The cross-derivative in $(\rho, z(\ell)=1 / \zeta(\ell))$ is positive, and the cross-derivative in $\left(f_{R}(\ell), z(\ell)\right)$ is negative. 


\section{B.4.4 Proof of Propostion 2}

The proof of Proposition 2 is structured in four steps. First, re-write the location choice problem (14) into a simpler, equivalent form. Second, show that this assignment problem admits a support that is an interval. Third, show that there is positive assortative matching conditional on workers' values. Fourth, show that there is positive assortative matching when workers' values are determined in general equilibrium.

Step 1: equivalent location choice problem. To make notation lighter, denote $\zeta=1 / z$. Using again the reservation wage equation $b+v(\ell)=\frac{\underline{w}(\ell)}{1-\beta+\beta \underline{y}_{0} / \rho}$ to replace reservation wages by $b+v$ in (14), I obtain that new jobs $\zeta$ solve the equivalent assignment problem:

$$
\ell^{*}(\zeta)=\underset{\ell}{\operatorname{argmax}}[\zeta-1] \log \frac{1}{b+v(\ell)}+\log (\ell q(\ell)) .
$$

This is a non-standard assignment problem, where labor costs $v(\ell)$ enter both in the return to a location and as part of the endogenous price that adjusts to mediate the matching. Using (35) to substitute for $q(\ell)$, I obtain

$\ell^{*}(\zeta)=\underset{\ell}{\operatorname{argmax}}(\zeta-1) \log \frac{1}{b+v(\ell)}+\log \ell+\frac{\alpha}{1-\alpha}\left\{\log \frac{b+v(\ell)}{v(\ell)}+\zeta^{*}(\ell) \log \frac{B}{b+v(\ell)}+\log \bar{S}\left(\zeta^{*}(\ell)\right)\right\}$.

Since the complementarity arises between $\zeta$ and the endogenous value of search $v$, it is useful to consider the inverse function $\ell(v)$ rather than $v(\ell)$, and view the problem as

$$
v^{*}(\zeta)=\underset{v}{\operatorname{argmax}}(\zeta-1) \log \frac{1}{b+v}+\underbrace{\log \ell(v)+\frac{\alpha}{1-\alpha}\left\{\log \frac{b+v}{v}+\zeta^{*}(v) \log \frac{B}{b+v}+\log \bar{S}\left(\zeta^{*}(v)\right\}\right.}_{\equiv P(v), \text { endogenous "price" sustaining the assignment }} .
$$

Step 2: interval property. To use first-order conditions (FOC) to characterize the assignment in problem (38), I first show that the equilibrium results in a single interval of $v$ 's.

Now suppose for a contradiction that the function $v(\ell)$ is discontinuous, and that there is a jump at $\ell_{0}$. Denote $v_{1}=v\left(\ell_{0}^{-}\right) \neq v_{2}=v\left(\ell_{0}^{+}\right)$the lim-sup before the jump and the lim-inf after the jump. The objective function in (36) is continuous and decreasing in $v(\ell)$. Thus, the jump in $v(\ell)$ at $\ell_{0}$ results in a jump in the objective function for a positive measure of employers $\zeta{ }^{57}$ Thus, almost no employer would find it optimal to locate on the side of $\ell_{0}$ that has the lowest $v$. Thus, locations to side of $\ell_{0}$ that deliver the lowest $v$ do not have any employers. But now recall that in the trembling-hand refinement, due to Inada conditions of the matching function, these locations have some (vanishing fraction) of workers. Thus, locating there for a single deviating employer would have infinite returns. This argument delivers the required contraction, and $v(\ell)$ must be a continuous function.

Step 3: sorting conditional on workers' values. Having shown that $v$ is a continuous function, I can consider the location choice problem (38). I use standard results on monotone comparative statics-see e.g. Galichon (2016) — for problem (38), in which I temporarily consider the unknown function $v \mapsto P(v)$ as the equilibrium "price" that sustains the assignment. The supermodularity between $\zeta$ and $\log \frac{1}{b+v}$ implies

\footnotetext{
${ }^{57}$ Although $q(\ell)$ could also jump at $\ell_{0}$ and ensure continuity of the objective function for a particular $\zeta_{0}$, the term $\zeta \log \frac{1}{b+v(\ell)}$ ensures that the objective jumps for almost all $\zeta$ 's.
} 
that the equilibrium features a one-to-one assignment function between $\zeta$ and $v$. From the second-order condition, the assignment function that maps $\log \frac{1}{b+v}$ to $\zeta$ is increasing, and so the assignment function $\zeta(v)$ is decreasing: $\zeta^{\prime}(v)<0$.

Step 4: sorting in general equilibrium. In this last step, I characterize under which conditions the function $\ell \mapsto v(\ell)$ is increasing in equilibrium. Given the property $\zeta^{\prime}(v)<0$, increasing $v$ is equivalent to $\zeta^{\prime}(\ell)<0$. The FOC in problem (38) leads to

$$
(1-\alpha) \frac{v \ell^{\prime}(v)}{\ell(v)}=\alpha+\frac{v}{b+v}(\zeta(v)-1)+\alpha v \underbrace{\left(\frac{\overline{\mathcal{S}}^{\prime}(\zeta(v))}{\overline{\mathcal{S}}(\zeta(v))}+\log \frac{B}{b+v}\right)}_{<0} \cdot \underbrace{\left(-\zeta^{\prime}(v)\right)}_{>0} .
$$

When $\alpha=0$, the bracket on the left-hand-side is always positive. In this case, $\ell^{\prime}(v)>0$, which implies $z^{\prime}(\ell)>0$ : there is positive assortative matching (PAM). Therefore, there exists a region of the parameter space where $\alpha$ is small and positive assortative matching obtains. ${ }^{58}$ As a result, standard results - e.g. Galichon (2016) — apply and there exists a unique assignment, for which $z$ and $\underline{w}$ are increasing.

Substituting $v(\ell)$ into (39), I obtain

$$
\left[\alpha+\frac{v}{b+v(\ell)}(\zeta(v)-1)\right] v^{\prime}(\ell)=(1-\alpha) \frac{v(\ell)}{\ell}-\alpha v \underbrace{\left(\frac{\overline{\mathcal{S}}^{\prime}(\zeta(v(\ell)))}{\overline{\mathcal{S}}(\zeta(v(\ell)))}+\log \frac{B}{b+v(\ell)}\right)}_{<0} \cdot\left(-\zeta^{\prime}(\ell)\right)
$$

Thus, if $\zeta^{\prime}(\ell)<0$, then $v^{\prime}(\ell)>0$. This observation implies that there exists a unique assignment with increasing $z$ and $\underline{w}$ among all assignments with increasing $z$, regardless of the value of $\alpha$.

\section{B.5 Proof of Proposition 3}

The proof of Proposition 3 is structured in four steps. First, derive the system of ODEs that determine the equilibrium. Second, show existence of solutions to this system conditional on general equilibrium aggregates. Third, show existence of general equilibrium aggregates. Fourth, show uniqueness.

Step 1: ODE system. Impose Assumption 1 and consider dynamically stable steady-states. Then, PAM obtains. Denote again $\zeta=1 / z$. Because of PAM, labor market clearing in location $\ell$ implies

$$
\theta(\ell)=-\frac{M_{e} f_{\zeta}(\zeta(\ell)) \zeta^{\prime}(\ell)}{u(\ell) L(\ell) f_{\ell}(\ell)} \Longrightarrow M_{e} f_{\zeta}(\zeta(\ell)) \zeta^{\prime}(\ell)=-L(\ell) u(\ell) \theta(\ell) f_{\ell}(\ell)
$$

Using the expression of the finding rate in Proposition 1, re-express labor market tightness as a function of $v, \zeta$ :

$$
\theta(\ell)=\left[\frac{\rho}{\beta m} \frac{v(\ell)}{(b+v(\ell))\left(\frac{B}{b+v(\ell)}\right)^{\zeta(\ell)} \mathcal{\mathcal { S }}(\zeta(\ell))}\right]^{\frac{1}{1-\alpha}} \equiv \Theta(v(\ell), \zeta(\ell)) .
$$

\footnotetext{
${ }^{58}$ Formally, this statement anticipates that the general equilibrium conditions involve only continuously differentiable fixed point functionals.
} 
Define also notation for the local unemployment rate $u(v(\ell), \zeta(\ell))=\frac{\delta \zeta(\ell)}{\delta \zeta(\ell)+\Phi_{R}(v(\ell), \zeta(\ell))}$. Land market clearing writes in each location

$$
r(\ell)=\omega L(\ell) \ell[b u(v(\ell), \zeta(\ell))+(1-u(v(\ell), \zeta(\ell)))(b+v(\ell))((1-\beta)+\beta \mathcal{E}(\zeta(\ell))],
$$

where $\mathcal{E}(\zeta)=\underline{y}_{0} / \rho \frac{\kappa \zeta}{(\kappa-1)(\zeta-1)}$ is expected productivity under the invariant distribution from Lemma 2 . Substituting into workers' free mobility condition $\rho U=\frac{\ell(b+v(\ell))}{r(\ell)^{\omega}}$, one can express population as

$$
L(\ell)=U^{-\frac{1}{\omega}} \bar{L}(\ell, v(\ell), \zeta(\ell))
$$

with

$$
\bar{L}(\ell, v(\ell), \zeta(\ell))=\frac{1}{\omega \rho^{\frac{1}{\omega}}} \frac{\ell^{\frac{1}{\omega}-1}(b+v(\ell))^{\frac{1}{\omega}}}{b u(v(\ell), \zeta(\ell))+(1-u(v(\ell), \zeta(\ell)))(b+v(\ell))((1-\beta)+\beta \mathcal{E}(\zeta(\ell))} .
$$

Substitute back into labor market clearing:

$$
K \zeta^{\prime}(\ell)=-\frac{f_{\ell}(\ell) \tilde{L}(\ell, v(\ell), \zeta(\ell)) \Theta(v(\ell), \zeta(\ell))}{f_{\zeta}(\zeta(\ell))},
$$

where $K=U^{\frac{1}{\omega}} M_{e}$ is a combined general equilibrium constant. (41) defines a function $Z$ such that $\zeta^{\prime}(\ell)=Z(\ell, v(\ell), \zeta(\ell))$. In addition,

$$
\tilde{L}(\ell, v(\ell), \zeta(\ell))=\bar{L}(\ell, v(\ell), \zeta(\ell)) u(v(\ell), \zeta(\ell))=\frac{1}{\omega \rho^{\frac{1}{\omega}}} \frac{\ell^{\frac{1}{\omega}-1}(b+v(\ell))^{\frac{1}{\omega}}}{b+\frac{\rho v(\ell)}{\delta \beta \zeta(\ell) \mathcal{S}(\zeta(\ell))}((1-\beta)+\beta \mathcal{E}(\zeta(\ell))} .
$$

Substituting into the FOC for $v$ :

$$
\frac{v^{\prime}(\ell)}{v(\ell)}\left[\alpha+\frac{v(\ell)}{b+v(\ell)}(\zeta(\ell)-1)\right]=\frac{1-\alpha}{\ell}-\frac{1}{K} \times \alpha\left(\frac{\overline{\mathcal{S}}^{\prime}(\zeta(\ell))}{\overline{\mathcal{S}}(\zeta(\ell))}+\log \frac{B}{b+v(\ell)}\right) \frac{\tilde{L}(\ell, v(\ell), \zeta(\ell)) \Theta(v(\ell), \zeta(\ell))}{f_{\zeta}(\zeta(\ell))} .
$$

(42) defines a function $V$ such that $v^{\prime}(\ell)=V(\ell, v(\ell), \zeta(\ell))$. Given $K$, equations (41)-(42) define a coupled system of ODEs, with two boundary conditions: $\zeta(\underline{\ell})=\bar{\zeta}$ and $\zeta(\bar{\ell})=\underline{\zeta}$.

Inspection of (41)-(42) indicate that the system satisfies standard regularity conditions for a unique solution to obtain if it has two initial conditions. The present system, however, has one initial and one terminal condition.

Step 2: Existence of a solution to the ODE system given $K$. Denote $\underline{v}=v(\underline{\ell})$. Given $K$, inspection of (41)-(42) reveals that the system is Lipschitz continuous. Given $\underline{v}, \zeta$ and $K$, there thus exists a unique solution to (41)-(42). The idea is now to study how changes in $\underline{v}$ affect $\zeta(\bar{\ell})$ in the solution to that system. Lipschitz continuity ensures that $\zeta(\bar{\ell})$ is a continuous function of $\underline{v}$. Further inspection of (41)-(42) reveals that as $v \rightarrow 0$, so do $Z, V$. Similarly, as $\underline{v} \rightarrow+\infty$, so do $Z, V$. Therefore, the same conclusion holds when $\underline{v} \rightarrow 0$ or $\underline{v} \rightarrow+\infty$. Hence, there exists at least one $\underline{v}(K)$ such that $\zeta(\bar{\ell})=\underline{\zeta}$. 
Step 3: Existence of $K$. The equilibrium has a block-recursive structure. Free-entry alone is enough to determine $K$ without using population adding up. Given $K$ and thus the solution $(b, \zeta)$, population adding-up immediately determines $U$ as per (40). Thus, it suffices to show that free-entry implies existence of $K$. Free-entry can be re-written

$K \cdot c_{e}=J_{0} \int\left[B^{\zeta(\ell)}(b+v(\ell))^{1-\zeta(\ell)} v(\ell)^{-\alpha} \overline{\mathcal{S}}(\zeta(\ell))\right]^{\frac{1}{1-\alpha}} \cdot \ell \cdot \bar{L}(\ell) u(\ell) \theta(\ell) d \ell=J_{0}^{\prime} \int v(\ell) \ell \tilde{L}(\ell, v(\ell), \zeta(\ell)) d \ell$

As $K \rightarrow 0$, (41) together with the boundary conditions on $\zeta$ and an application of Rolle's theorem to $\zeta^{\prime}(\ell)$ implies $\underline{v}(K)^{\frac{1}{1-\alpha}} \sim K \rightarrow 0$. As $K \rightarrow+\infty$, a similar argument implies $\underline{v}(K)^{\frac{1}{\omega}-1+\zeta_{0}} \sim K \rightarrow+\infty$, where $\zeta_{0} \in[\underline{\zeta}, \bar{\zeta}]$. Thus, the right-hand-side integral of free-entry is of order $K^{1-\alpha}$ as $K \rightarrow 0$, and is of

order $K^{\frac{1}{\zeta_{0}+1-\omega}}$ as $K \rightarrow+\infty$. Since $\underline{\zeta}>1$ by assumption, $\frac{1}{\zeta_{0}+1-\omega}<1$. Therefore, there exists at least one solution $K$ to the free-entry condition.

Step 4: Uniqueness. Now suppose that the supports of $F_{\ell}, F_{z}$ are small enough. This assumption makes possible using a first-order approximation to the ODE system (41)-(42). In that case, to a first order,

$$
K \zeta^{\prime}(\ell) \approx-\frac{\tilde{L}(\ell, \underline{v}, \bar{\zeta}) \Theta(\underline{v}, \bar{\zeta})}{f_{\zeta}(\bar{\zeta})}=-L_{0} \frac{\underline{v}^{\frac{1}{1-\alpha}}}{1+L_{1} \underline{v}}(b+\underline{v})^{\frac{1}{\omega}+\frac{\bar{\zeta}-1}{1-\alpha}}
$$

where $L_{0}, L_{1}>0$ are transformations of parameters. Integrating (43),

$$
K=L_{0}^{\prime} \frac{\underline{v}^{\frac{1}{1-\alpha}}}{1+L_{1} \underline{v}}(b+\underline{v})^{\frac{1}{\omega}+\frac{\bar{\zeta}-1}{1-\alpha}}
$$

where $L_{0}^{\prime}=L_{0} \frac{\bar{\ell}-\underline{\ell}}{\bar{\zeta}-\underline{\zeta}}$ only depends on parameters. Similarly, free entry can be approximated to a first order by

$$
K=J_{0}^{\prime \prime} \frac{\underline{v}}{\underline{v}+1 / L_{1}}(b+\underline{v})^{\frac{1}{\omega}},
$$

where $J_{0}^{\prime \prime}, J_{1}$ depend only on parameters. Substituting (45) into (44), one obtains

$$
1=L_{0}^{\prime \prime} \underline{v}^{\frac{\alpha}{1-\alpha}}(b+\underline{v})^{\frac{\bar{\zeta}-1}{1-\alpha}},
$$

where $L_{0}^{\prime \prime}$ depends only on parameters. The right-hand-side of (46) is strictly increasing in $\underline{v}$, and so (46) uniquely pins down $\underline{v}$. Then (45) uniquely pins down $K$. Then $\int L(\ell) F_{\ell}(d \ell)$ uniquely pins down $U$.

\section{B.6 Proof of Corollary 1}

This limiting economy preserve a wide support for $F_{z}$ but considers the limit of a small support for $F_{\ell}$. In that case, it is more useful to index locations by their value of search $v$ rather than productivity $\ell$. Shrinking the support of $F_{\ell}$ implies $\ell^{\prime}(v)=0$. Thus, the FOC (39) implies

$$
\alpha+\frac{v}{b+v}(\zeta(v)-1)+\alpha v\left(\frac{\overline{\mathcal{S}}^{\prime}(\zeta(v))}{\overline{\mathcal{S}}(\zeta(v))}+\log \frac{B}{b+v}\right)\left(-\zeta^{\prime}(v)\right)=0
$$


which defines a non-degenerate assignment $\zeta(v)$ in the limit. Given the boundary conditions and $\omega>0$, it must be that there is an interval of $v$ 's in the limit. The assignment $\zeta(v)$ implies non-vanishing dispersion in job losing and unemployment rates. If instead $\omega=0$, the free-mobility condition (10) would equalize $v$ across locations.

\section{B.7 Model validation}

\section{B.7.1 Proof of Corollary 2}

Claim 1. In any small time interval $d t$, the probability that a match at productivity $y_{t}=e^{x_{t}}$ in location $\ell$ separates is $\mathbb{P}\left[x_{t+d t}<\underline{x}(\ell) \mid x_{t}\right]=\mathbb{P}\left[d x_{t}<\underline{x}(\ell)-x_{t}\right]=\mathbb{P}\left[\frac{d W_{t}}{\sqrt{d t}}<\frac{\underline{x}(\ell)-x_{t}+\delta d t}{\sigma \sqrt{d t}}\right]=\Phi\left(\frac{\underline{x}(\ell)-x_{t}+\delta d t}{\sigma \sqrt{d t}}\right)$, where $\Phi$ denotes the standard normal cumulative distribution function. This expression is decreasing in $x_{t}=\log y_{t}$.

Claim 2. Directly follows from the assumption $d x_{t}=-\delta t+\sigma d W_{t}$.

Claim 3. Using Lemma 2, average log labor productivity in location $\ell$ is $\mathbb{E}_{\ell}[x]=\int_{\underline{x}(\ell)}^{\infty} x g(x, \ell) d x=$ $\underline{x}(\ell)+z(\ell)+1 / \kappa$ which is increasing in $\ell$ and thus in $z(\ell)$ after re-indexing.

Claim 4. Omit location indices. Using Lemma 2, the c.d.f. of $\log$ labor productivity is $G(x)=$ $\int_{\underline{x}}^{x} g(t) d t=1+\frac{\kappa}{\kappa z-1}\left[\kappa^{-1} e^{-\kappa(x-\underline{x})}-z e^{-(x-\underline{x}) / z}\right] .\left[\kappa^{-1} e^{-\kappa(x-\underline{x})}-z e^{-(x-\underline{x}) / z}\right]<0$ since $G(x)<1$. From Proposition 2, it suffices to show that $\frac{\partial G(x)}{\partial \underline{x}}, \frac{\partial G(x)}{\partial z}<0$ to obtain the FOSD result. Now, $\frac{\partial G(x)}{\partial \underline{x}}=$ $\frac{\kappa(x-\underline{x})}{\kappa z-1}\left[e^{-(x-\underline{x}) / z}-e^{-\kappa(x-\underline{x})}\right]=-(x-\underline{x}) g(x)<0$. In addition,

$\frac{\partial G(x)}{\partial z}=-\frac{\kappa}{(\kappa z-1)^{2}}\left[e^{-\kappa(x-\underline{x})}-e^{-(x-\underline{x}) / z}+(\kappa z-1) \frac{x-\underline{x}}{z} e^{-(x-\underline{x}) / z}\right] \equiv-\frac{\kappa}{(\kappa z-1)^{2}} H(u)$ with $\zeta=1 / z, u=x-\underline{x}$ and $H(u)=e^{-\kappa u}+e^{-\zeta u}((\kappa-\zeta) u-1)$. Thus, it suffices to show that $H(u)>0$ for all $u \geq 0$. But $H(u)=e^{-\kappa u}\left[1+e^{X}(X-1)\right] \geq 0$ because $e^{-X} \geq 1-X$ for all $X \in \mathbb{R}$, with $X=(\kappa-\zeta)(x-\underline{x})$.

Claim 5. Using the results from the proof of Claim 3, the c.d.f. of log labor productivity satisfies $1-G(x)=\frac{\kappa}{\kappa z-1}\left[\kappa^{-1} e^{-\kappa(x-\underline{x})}-z e^{-(x-\underline{x}) / z}\right]$. When $\kappa z<1$ and $x \rightarrow \infty, 1-G(x) \approx \frac{\kappa z}{1-\kappa z} e^{-(x-\underline{x}) / z}$ which defines a Pareto distribution with tail index $1 / z$.

Claim 6. Using Claim 4 , the ratio between tail indices in locations $\ell$ and $\ell^{\prime}$ are $z\left(\ell^{\prime}\right) / z(\ell)=s(\ell) / s\left(\ell^{\prime}\right)$.

\section{B.7.2 Empirical results}

Figure 14 zooms into the right tail of the productivity distribution by showing the log tail probability as a function of log labor productivity. In both groups of locations, the log tail probability is approximately linear, consistent with the third implication of a Pareto tail. The fourth implication of the model imposes a strong link between the local job losing rate and the shape of the right tail of the labor productivity distribution. I estimate the ratio between the tail indices in each group of locations to be 1.79. It is close to the ratio of group averages of job losing rates, which is 1.77. Together, these results support the Pareto assumption.

Table 7 reports the results from linear regressions of labor productivity for incumbent and entrant establishments on local job losing rates, as well as of annual labor productivity growth on local job losing rates. 
Figure 14: Tail labor productivity distribution across French commuting zones.

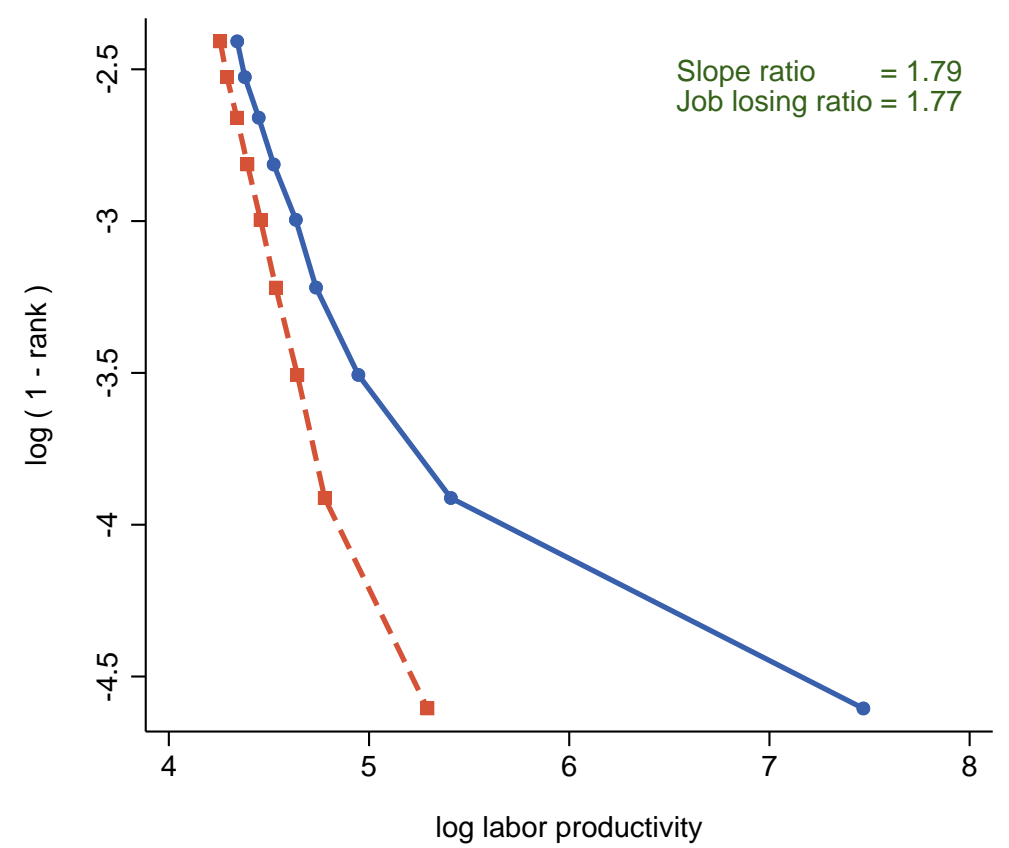

Note: Figure 14 plots the log inverse cumulative distribution function for bottom and top quartiles of commuting zones, ranked by job losing rates

\section{Estimation}

\section{C.1 Time-dependent KFE}

The first step for the estimation is to compute an explicit solution to the time-dependent KFE in logs: $g_{t}=L_{x}^{*} g-(\Delta+\mu) g$ where $t$ denotes tenure at a job, and subscripts denote partial derivatives. Define $g(t, y)=e^{-(\Delta+\mu) t} h(t, y)$. Then $g_{t}=e^{-(\Delta+\mu) t}\left(h_{t}-(\Delta+\mu) h\right)$ so that $h_{t}=L_{x}^{*} h$. The solution to this PDE is known. In $\operatorname{logs}, x=\log y$, define

$$
\Gamma(t, x)=\frac{1}{\sigma \sqrt{2 \pi t}} e^{-\frac{(x+\delta t)^{2}}{2 \sigma^{2} t}} \quad ; \quad G(t, x, y)=\Gamma(t, x-y)-e^{\frac{2 \delta}{\sigma^{2}}(y-\underline{x})} \cdot \Gamma(t, x+y-2 \underline{x}) .
$$

Then it is straightforward to check that $h(t, x)=\int_{\underline{x}}^{\infty} G(t, x, y) h_{0}(y) d y$ is the solution with initial distribution $h_{0}$. See Luttmer (2007) and references therein for a similar result. The details of the derivation are available upon request. Then, in logs,

$$
\begin{aligned}
g(t, x) & =e^{-(\Delta+\mu) t} \int_{\underline{x}}^{\infty} G(t, x, y) g_{0}(y) d y \\
& =\frac{\zeta}{2} e^{-\left(D+\delta \zeta-\frac{\sigma^{2} \zeta^{2}}{2}\right) t-\zeta x}\left(1+\operatorname{Erf}\left[\frac{x+t\left(\delta-\zeta \sigma^{2}\right)}{\sqrt{2 t} \sigma}\right]-e^{2\left(\zeta-\frac{2 \delta}{\sigma^{2}}\right) x} \operatorname{Erfc}\left[\frac{x-t\left(\delta-\zeta \sigma^{2}\right)}{\sqrt{2 t} \sigma}\right]\right)
\end{aligned}
$$

is the time-dependent distribution of log productivity across employed workers in a location with log threshold $\underline{x}$ given a starting distribution $g_{0}$. The second equality imposes $g_{0}\left(x_{0}\right)=\zeta e^{-\zeta\left(x_{0}-\underline{x}\right)} . D=\Delta+\mu$, and Erf denotes the error function, a transformation of the Gaussian cumulative function. 
Table 7: Plant-level regressions: growth rate of log labor productivity.

\begin{tabular}{lcc}
\hline & $(1)$ & $(2)$ \\
\hline Separation rate & 0.001 & -0.000 \\
& $(0.006)$ & $(0.006)$ \\
& & \\
Controls & & \\
$\quad$ Year & $\checkmark$ & $\checkmark$ \\
2-digit industry & $\checkmark$ & $\checkmark$ \\
Skill mix & & $\checkmark$ \\
\hline Obs. & 31373 & 31373 \\
$R^{2}$ & 0.012 & 0.013 \\
W.- $R^{2}$ & 0.000 & 0.001 \\
\hline
\end{tabular}

Note: Standard errors in parenthesis, clustered by city and 2-digit industry. $\quad+p<0.10,{ }^{*} p<$ $0.05,{ }^{* *} p<0.01,{ }^{* * *} p<0.001$. Annual frequency, 1997-2006. Entrant defined as less than two year old. Employment-unweighted regressions.

\section{C.2 Tenure profile of job loss}

Now fix a location $\ell$ and omit $\ell$ indices for simplicity. Normalize $\underline{x} \equiv 0$ without loss of generality. Recall that the flow of workers into local unemployment is Endog. Sep. $(t)=\frac{\sigma^{2}}{2} \frac{\partial g}{\partial x}(t, \underline{x})$, which can be calculated at all times using the explicit solution (48). It can be shown that

Endog. Sep. $(t)=e^{-(\mu+\Delta) t}\left[\frac{(s / \hat{\delta})}{\sqrt{t}} \varphi(\hat{\delta} \sqrt{t})+\frac{(s / \hat{\delta})^{2}}{2} e^{\frac{(s / \hat{\delta})^{2} t}{2}}\left\{e^{s t} \Phi(-(\hat{\delta}+s / \hat{\delta}) \sqrt{t})-e^{-s t} \Phi((\hat{\delta}-s / \hat{\delta}) \sqrt{t})\right\}\right]$

where $s=\delta \zeta$ is the local average job losing rate into local unemployment, and $\hat{\delta}=\delta / \sigma$. To get the time-aggregated job losing rate in the first year, denoted $s_{1}(s, \hat{\delta}, D)$, integrate between 0 and 1 against $g$. I obtain

$$
\begin{aligned}
s_{1}(s, \hat{\delta}, D)=\frac{(s / \hat{\delta})}{4}\{ & \frac{e^{-\left(D+s-(s / \hat{\delta})^{2} / 2\right)}}{D+s-(s / \hat{\delta})^{2} / 2}(s / \hat{\delta})+4 \frac{\operatorname{Erf}\left[\frac{\sqrt{2 D+\hat{\delta}^{2}}}{\sqrt{2}}\right]}{\sqrt{2 D+\hat{\delta}^{2}}} \\
& +\frac{s / \hat{\delta}}{D+s-(s / \hat{\delta})^{2} / 2}\left(-1-\frac{\hat{\delta}-s / \hat{\delta}}{\sqrt{2 D+\hat{\delta}^{2}}} \operatorname{Erf}\left[\frac{\sqrt{2 D+\hat{\delta}^{2}}}{\sqrt{2}}\right]+e^{-\left(D+s-(s / \hat{\delta})^{2} / 2\right)} \operatorname{Erf}\left[\frac{\hat{\delta}-(s / \hat{\delta})}{\sqrt{2}}\right]\right) \\
& +\frac{(s / \hat{\delta})}{D-s-(s / \hat{\delta})^{2} / 2}\left(-1+\frac{\hat{\delta}+s / \hat{\delta}}{\sqrt{2 D+\hat{\delta}^{2}}} \operatorname{Erf}\left[\frac{\sqrt{2 D+\hat{\delta}^{2}}}{\sqrt{2}}\right]+e^{-D+s+(s / \hat{\delta})^{2} / 2} \operatorname{Erfc}\left[\frac{\hat{\delta}+(s / \hat{\delta})}{\sqrt{2}}\right]\right) .
\end{aligned}
$$

In the limit of a small $D$, it can be checked that $s_{1}$ is a decreasing function of $\hat{\delta}$.

\section{C.3 Tenure profile of wages}

In the model, the wage of individual $i$ in employment spell $p$, location $c$, at calendar time $\tau$ and tenure $t$, is given by $w_{i p c \tau t}=w_{0 c} \times\left(A+B e^{x_{i p c t}}\right) k_{i p c \tau t}$, with $A=1-\beta$ and $B=\beta \frac{y_{0}}{\hat{\rho}}$, and $w_{0 c}$ is a location shifter. $k_{i p c \tau t}$ is the worker's human capital and is correlated with tenure. Calendar time and tenure are 
collinear: $\tau_{i p 0}+t_{i p}=\tau$ where $\tau_{i p 0}$ is the calendar time at which individual $i$ started employment spell $p$. Therefore, $k_{i p c \tau t}=k_{\tau_{i p 0}} e^{\lambda\left(\tau-\tau_{i p 0}\right)}$. Mean level wages in the economy grow at rate $\lambda$, and so $\bar{W}_{\tau}=\bar{W}_{0} e^{\lambda \tau}$. In particular, evaluating at the starting time of the spell, $\bar{W}_{\tau_{i p 0}}=\bar{W}_{0} e^{\lambda \tau_{i p 0}}$. Therefore, taking wages relative to aggregate wages at the starting time of the spell.

$$
\hat{w}_{i p c \tau t} \equiv \frac{w_{i p c \tau t}}{\bar{W}_{\tau}}=\tilde{w}_{0 c} \times\left(A+B e^{x_{i p c t}}\right) \times \varepsilon_{\tau_{i p 0}} ; \quad \tilde{w}_{0 c}=\frac{w_{0 c}}{\bar{W}_{0}} ; \varepsilon_{\tau_{i p 0}}=k_{\tau_{i p 0}} e^{-\lambda \tau_{i p 0}}
$$

$\varepsilon_{\tau_{i p 0}}$ plays the role of a individual-spell fixed effect. Take rescaled wage growth relative to initial rescaled wages at the spell: $\omega_{i p c \tau t} \equiv \frac{\hat{w}_{i p c \tau t}}{\hat{w}_{i p c, \tau_{i p 0}, 0}}=\frac{A+B e^{x_{i p c t}}}{A+B e^{x} 0}$. Recall that $x_{i p c t}$ and $x_{0}$ are correlated by definition.

Inspection of (48) reveals that $y=x / \delta$ has a distribution that is independent from $\delta$ at all timesincluding time 0 - conditional on $s, \hat{d}$. Anticipating a small estimate of $\delta$, I obtain $\omega_{i p c \tau t}=\frac{\hat{w}_{i p c \tau t}}{\hat{w}_{i p c, \tau_{i p 0}, 0}}=$ $\frac{A+B e^{\delta y_{t}}}{A+B e^{\delta y_{0}}} \approx_{\delta \rightarrow 0} 1+\frac{\delta B}{A+B}\left(y_{t}-y_{0}\right)$. To a first order, when $\delta$ is small relative to $\rho$, it can be shown that $\frac{B}{A+B} \approx \frac{\beta}{(1-\beta) \hat{\rho}+\beta}$. Therefore, $\omega_{i p c \tau t} \approx 1+\frac{\delta \beta}{(1-\beta) \hat{\rho}+\beta}\left(y_{t}-y_{0}\right)$. Then compute

$$
\mathbb{E}\left[\omega_{i p c \tau t} \mid t, c\right]=1+\frac{\delta}{(1-\beta) \hat{\rho}+\beta} R(t)
$$

where $R(t)=\frac{\int h_{0}\left(y_{0}\right) d y_{0} \int G^{y}\left(t, y, y_{0}\right)\left(y-y_{0}\right) d y}{\int h_{0}\left(y_{0}\right) d y_{0} \int G^{y}\left(t, y, y_{0}\right) d y} . G^{y}$ is the Green's function associated with (48) and the change of variables $y=x / \delta$. It is given by $G^{y}\left(t, y, y_{0}\right) d y=e^{-D t}\left(\gamma^{y}\left(t, y-y_{0}\right)-e^{2 \hat{\delta}^{2} y_{0}} \gamma^{y}\left(t, y+y_{0}\right)\right)$ with $\gamma^{y}(t, z)=\frac{\hat{\delta} \exp \left(-\frac{\hat{\delta}^{2}}{2 t}(z+t)^{2}\right)}{\sqrt{2 \pi t}}$. Mean rescaled wages in equation (49) are easily computed in the data, and can also be computed in the model at this stage of the estimation.

\section{C.4 Labor share}

From the bargaining solution, the labor share in location $\ell$ is

$$
\text { Labor Share }(\ell)=\frac{(1-\beta)\left(b+v(\ell)+\beta \underline{y}_{0} / \rho H(\ell)\right.}{E(\ell)},
$$

where $H(\ell)=\mathbb{E}_{\ell}[y / y \mid y \geq \underline{y}]$ is expected labor productivity in location $\ell$ under the invariant distribution. Using the solution to the KFE, one obtains

$$
H(\ell)=\frac{\kappa \zeta(\ell)}{(\kappa-1)(\zeta(\ell)-1)}=\frac{\kappa}{(\kappa-1)(1-z(\ell))} \equiv H(z(\ell))
$$

\section{C.5 Learning parameters}

Log real wages are proportional to $K_{t} R_{t}^{-\omega}$, where $t$ is caldendar time, $K_{t}$ the average knowledge of the economy and $R_{t}$ average house prices. In the data, economy-wide log real wages grow by 0.0015 each quarter. In the model, $K_{t} R_{t}^{-\omega} \propto K_{t}^{1-\omega-\psi}$ up to a constant. Thus, $\lambda=\frac{0.0015}{1-\omega-\psi}=0.0023$.

Then, notice that all workers who become unemployed in a given location have the same wage when they are laid off: the reservation wage. While they are unemployed, their human capital grows at rate $\lambda-\varphi$. When they find a new job, they draw a productivity from the local new job distribution, which is independent from their history. Therefore, equation (22) obtains. In empirical specifications, I follow 
Table 8: Unemployment scar estimation. Dependent variable: post-unemployment spell log wage.

\begin{tabular}{|c|c|c|c|c|c|c|}
\hline & \multicolumn{5}{|c|}{ Unemployed only } & \multirow{2}{*}{$\frac{\mathrm{DiD}}{(6)}$} \\
\hline & $(1)$ & $(2)$ & $(3)$ & $(4)$ & $(5)$ & \\
\hline Job loss $\times$ Duration & $\begin{array}{l}-0.02^{* * *} \\
(0.00)\end{array}$ & $\begin{array}{l}-0.01^{\text {*** }} \\
(0.00)\end{array}$ & $\begin{array}{l}-0.01^{* * *} \\
(0.00)\end{array}$ & $\begin{array}{l}-0.01^{* * *} \\
(0.00)\end{array}$ & $\begin{array}{l}-0.01 \\
(0.01)\end{array}$ & $\begin{array}{l}-0.01^{* *} \\
(0.00)\end{array}$ \\
\hline Job loss & & & & & & $\begin{array}{l}-0.10^{* *} \\
(0.04)\end{array}$ \\
\hline Duration & & & & & & $\begin{array}{l}0.00 \\
(0.00)\end{array}$ \\
\hline Pre log wage & & $\begin{array}{l}0.55^{* * *} \\
(0.02)\end{array}$ & $\begin{array}{l}0.44^{* * *} \\
(0.03)\end{array}$ & $\begin{array}{l}0.41^{* * *} \\
(0.03)\end{array}$ & $\begin{array}{l}-0.18^{*} \\
(0.07)\end{array}$ & $\begin{array}{l}-0.01 \\
(0.05)\end{array}$ \\
\hline Skill & & & $\begin{array}{l}0.00^{* * *} \\
(0.00)\end{array}$ & $\begin{array}{l}0.00^{* * *} \\
(0.00)\end{array}$ & & \\
\hline \multicolumn{7}{|l|}{ Fixed Effects } \\
\hline Year & $\checkmark$ & $\checkmark$ & $\checkmark$ & $\checkmark$ & $\checkmark$ & $\checkmark$ \\
\hline 2-digit Industry & & & & $\checkmark$ & $\checkmark$ & $\checkmark$ \\
\hline City & & & & $\checkmark$ & $\checkmark$ & $\checkmark$ \\
\hline Worker & & & & & $\checkmark$ & $\checkmark$ \\
\hline Obs. & 35021 & 35021 & 35021 & 35020 & 6100 & 76700 \\
\hline$R^{2}$ & 0.027 & 0.287 & 0.331 & 0.353 & 0.802 & 0.775 \\
\hline $\mathrm{W} .-R^{2}$ & 0.011 & 0.276 & 0.320 & 0.267 & 0.022 & 0.002 \\
\hline
\end{tabular}

Note: Standard errors in parenthesis, two-way clustered by city and 2-digit industry. ${ }^{+} p<$ $0.10,{ }^{*} p<0.05,{ }^{* *} p<0.01,{ }^{* * *} p<0.001$.

the literature and restrict the sample to workers that held a job for at least two years before becoming unemployed. This restriction ensures that the estimates are not driven by temporary jobs.

The model abstracts from additional mechanisms that could create a correlation between new productivity draws an workers' past unemployment or employment history, as in Jarosch (2021). Thus, in practice, equation equation (22) may deliver a biased estimate of the depreciation rate of human capital. To address such concerns, I run version of equation (22) with additional controls that account flexibly for workers' past employment history. I also control for worker-level unobserved heterogeneity. For completeness, I also propose a specification where I use employed workers as a control group in a difference-in-difference specification - although this control group introduces an additional endogeneity problem. Results for the estimate of $\lambda-\varphi$ are reported in the first row of Table 8. The point estimate remains stable across specifications. 


\section{C.6 Local wages}

Wages in location $\ell$ are given by

$$
\bar{w}(\ell)=W_{0} p \cdot\left(\frac{\Delta}{\Delta+\varphi u(\ell)}\right) r(\ell)^{-\psi} \underline{y}(\ell)\left[(1-\beta) \frac{\rho}{\underline{y}_{0}}+\beta H(\ell)\right],
$$

where $W_{0}$ is a general equilibrium constant.

\section{C.7 Housing elasticity}

Using (64) together with the solution for average wages in a location $W(\ell)$, housing prices become

$$
r(\ell)^{1+\eta}=\frac{\bar{w}(\ell)}{1-\beta+\beta \underline{y}_{0} / \hat{\rho} E(s(\ell))} \cdot L(\ell, a) G(s(\ell) / \delta, v(\ell)) .
$$

The right-hand-side defines $r_{0}$, and involves parameters that have been estimated or data.

\section{C.8 Migration elasticity}

To circumvent endogeneity in the OLS regression version of (24), I use changes in predicted local employment as an instrument. I break down the sample in two subperiods, and, in this section only, I use the notation $\Delta$ to refer to changes between these two periods. Specifically, I use predicted changes in local employment $\Delta E_{c}$ from Supplemental Material D.2. To understand this instrument within the model, assume that there is a set $\mathcal{J}=\{1, \ldots, J\}$ of industries. Employers in each industry draw from the same productivity distribution $F_{z}$. Locations $c$ differ in a set of industry-specific productivities $\left\{p_{j c}\right\}_{j}$. Consistent with larger cross-industry flows than cross-location worker flows, suppose that there is a single labor market for all industries within a location. Suppose further that the cross-industry variance in industry productivity $\operatorname{Var}_{c}\left(p_{j c}\right)$ is much smaller than the cross-location variance in city productivity $\operatorname{Var}_{j}\left(p_{j c}\right)$. This assumption implies that the industrial mix is not strongly predictive of the local unemployment rate, consistent with the data. Under this assumption, the single-industry model is also a close approximation to the multi-industry model.

Now consider a set of industry-wide shocks that change $p_{j c}$ to $p_{j c}^{\prime}=p_{j c} \hat{p}_{j}$. Vacancy creation reacts to changes $\hat{p}_{j}$, so that national employment in industry $j$ is positively correlated with $\hat{p}_{j}$. Similarly, employment shares $E_{j c, 0}$ in the first subperiod are correlated with $p_{j c}$. Suppose that $(1) \hat{p}_{j}$ are uncorrelated with $p_{j c},(2) \hat{p}_{j}$ are i.i.d. across industries. Then $\hat{p}_{j}$ are uncorrelated with changes in amenities $\Delta a_{c}$ in the population-weighted distribution of cities and industries, even if $\mathbb{E}_{c}\left[p_{j c}\right]$ are correlated with amenities. With a large number of industries and locations, the shift share $\Delta E_{c}$ is thus correlated with the average change in local productivity $\mathbb{E}_{c}\left[\Delta p_{j c}^{\prime}\right]$. In general equilibrium, employers relocate in each industry, and so $\Delta E_{c}$ is also correlated with $\mathbb{E}_{c}\left[\Delta \zeta_{j c}\right]$. If anything, this correlation makes the instrument stronger. The crucial exclusion restriction is that $\Delta E_{c}$ is uncorrelated with changes in amenities $\Delta a_{c}$. Therefore, it constitutes a valid instrument in this augmented model with small industry heterogeneity. 


\section{C.9 Productivity distribution}

To estimate $F_{z}$, I first recover firm quality in each location using (23). It is easier to work with the reciprocal of firm quality $z$, denoted $\zeta=1 / z$. Consider locations with profitability in $(\ell-d \ell, \ell]$. Because the job losing rate is strictly decreasing in $\ell$, they are exactly those with a job loss rate in $[s(\ell), s(\ell)+d s(\ell)]$. Due to the model's sorting implications, the measure of open jobs in those locations is proportional to $f_{\zeta}(\zeta(\ell)) d \zeta(\ell)=\delta^{-1} f_{\zeta}(\zeta(\ell)) d s(\ell)$.

For simulations, I estimate a a Beta distribution for $\zeta: f_{\zeta}(\zeta) \propto\left(\frac{\zeta-\underline{\zeta}}{\bar{\zeta}-\underline{\zeta}}\right)^{g_{2}}\left(\frac{\bar{\zeta}-\zeta}{\bar{\zeta}-\underline{\zeta}}\right)^{g_{1}}$ which is equivalent to a Beta distribution for $z$. I estimate the Beta distribution by minimizing the mean square error between the empirical density function (a histogram) and the Beta density.

\section{C.10 Matching function elasticity}

Start from $\theta(\ell)=\left(\frac{f_{\zeta}(\ell)\left|\zeta^{\prime}(\ell)\right|}{f_{\ell}(\ell) \mathcal{U}(\ell)}\right) J(\ell)^{\gamma}$. Note that $J(\ell)=q(\ell) \bar{J}(\ell) \propto \theta(\ell)^{-\alpha} \hat{J}(\ell)$, where $\hat{J}(\ell) \propto \bar{k}(u(\ell))^{\mathcal{Q}}$. $\ell(b+v(\ell))^{1-\psi \mathcal{P}} \cdot G(v(\ell), \zeta(\ell))^{\varepsilon \psi \mathcal{P}}\left(\frac{B}{b+v(\ell)}\right)^{\zeta(\ell)} \overline{\mathcal{S}}(\zeta(\ell))$. Therefore, $\theta(\ell)^{1+\alpha \gamma} \propto\left(\frac{f_{\zeta}(\ell)\left|\zeta^{\prime}(\ell)\right|}{f_{\ell}(\ell) \mathcal{U}(\ell)}\right) \bar{J}(\ell)^{\gamma}$, and so $f_{R}(\ell) /\left(\frac{B}{b+v(\ell)}\right)^{\zeta(\ell)} \propto\left(\frac{f_{\zeta}(\ell)\left|\zeta^{\prime}(\ell)\right|}{f_{\ell}(\ell) \mathcal{U}(\ell)}\right)^{\frac{1-\alpha}{1+\alpha \gamma}} \hat{J}(\ell)^{\frac{\gamma(1-\alpha)}{1+\alpha \gamma}}$. Taking logs delivers

$$
\log \left(\frac{f_{R}(\ell)}{\mathbb{P}_{\ell}[\text { Accept }]}\right)=\operatorname{cste}+\frac{1-\alpha}{1+\alpha \gamma} \log \frac{f_{z}(z(\ell)) z^{\prime}(\ell)}{f_{\ell}(\ell) \mathcal{U}(\ell)}+\frac{(1-\alpha) \gamma}{1+\alpha \gamma} \log \hat{J}(\ell, \underline{y}(\ell), z(\ell)),
$$

where recall that $\mathcal{U}(\ell)$ denotes the number of unemployed workers in location $\ell$, and $\hat{J}(\ell, \underline{y}(\ell), z(\ell))$ is now known. At this stage, both right-hand-side variables can be calculated. In the model, equation (52) can be estimated with OLS. It is not hard to add location-specific heterogeneity in the matching function efficiency or vacancy costs to the model. In that case a structural residual correlated with the right-hand-side variables arises. In contrast to the previous estimating equations, this structural residual leads to omitted variable bias in equation (52).

With OLS, $\alpha, \gamma$ are separately identified only through functional form differences between the righthand-side variables because both are functions of the same latent variable $\ell$. 2SLS also relies on functional form identification. Thus, I use the local shift-share shock and a non-linear transformation thereof as two instruments. Notice also that in the generalized model with omitted variable bias, the latter only affects the estimation of equation (52), and not the previous estimating equations. Indeed, the previous estimating equations condition on the observed job losing rate, which is enough to control for the omitted variables through local job quality $z(\ell)$.

I first-difference (52) between the two subperiods. I use as the first instruments the same shift-share shocks $\Delta E_{c}$. Under the same assumptions as in section C.8, it is a valid instrument. To obtain a second instrument, I de-mean $\Delta E_{c}$ and use $\mathbb{1}_{\Delta E_{c}>0}$. This is a nonlinear transformation of $\Delta E_{c}$. Strengthening the identification assumption to conditional independence makes it a valid instrument.

\section{C.11 Parameter estimates}

See Table 9. 
Table 9: Parameter estimates

\begin{tabular}{lllll} 
Parameter & Interpretation & Target & Estimator & Estimate \\
\hline & Discount rate & Annual interest rate & MDE & 0.008 \\
$\Delta$ & Labor force exit rate & Aggregate unemployment rate & MDE & 0.004 \\
$\omega$ & Housing share (workers) & Expenditures on housing & MDE & 0.23 \\
$\psi$ & Housing share (firms) & Expenditures on housing & MDE & 0.11 \\
$\delta$ & Drift of productivity & Job losing rate by tenure & NLLS & 0.001 \\
$\sigma$ & Volatility of productivity & Wage growth by tenure & NLLS & 0.004 \\
$\beta$ & Bargaining power & Labor share & MDE & 0.08 \\
$Y$ & Lower bound of init. prod. & Job acceptance probability & MDE & 0.93 \\
$\eta$ & Housing elasticity & Housing prices & OLS & 3.48 \\
$\mu$ & Migration rate & Migration rate & MDE & 0.002 \\
$1 / \varepsilon$ & Migration elasticity & Migration shares & 2 SLS & 4.72 \\
$\alpha$ & Matching function elasticity & Local job finding rates & 2 SLS & 0.30 \\
$\gamma$ & Vacancy cost elasticity & Local job finding rates & 2SLS & 1.44 \\
$\varphi$ & Learning rate & Unemployment scar & OLS & 0.01 \\
\hline & & & & \\
$\underline{z}$ & Lowest job quality & Local job losing rates & MDE & 0.03 \\
$\bar{z}$ & Highest job quality & Local job losing rates & MDE & 0.10 \\
$g_{1}$ & Shape of job quality distrib. & Local job losing rates & MDE & 1.36 \\
$g_{2}$ & Shape of job quality distrib. & Local job losing rates & MDE & 2.19 \\
$\sigma_{\ell}$ & St.d. of local productivity & Local wages & MDE & 0.14 \\
$\sigma_{a}$ & St.d. of local amenities & Local population & MDE & 0.21 \\
$c_{\ell, a}$ & Correlation prod.-amenities & Local wages and population & MDE & 0.38 \\
\hline & & & &
\end{tabular}

\section{C.12 Over-identification}

See Table 10.

Table 10: Correlation of estimated amenities with observables.

\begin{tabular}{|c|c|c|}
\hline Sun hours & $0.119^{*}$ & $(0.050)$ \\
\hline Basic public services & 0.072 & $(0.050)$ \\
\hline Education services & -0.012 & $(0.039)$ \\
\hline Health services & $0.067^{* *}$ & $(0.014)$ \\
\hline Commercial services & 0.046 & $(0.030)$ \\
\hline Obs. & 288 & \\
\hline$R^{2}$ & 0.457 & \\
\hline
\end{tabular}




\section{C.13 Additional results}

See Figures 15 and 16.

Figure 15: Labor market tightness against unemployment-employment ratios in model and data.

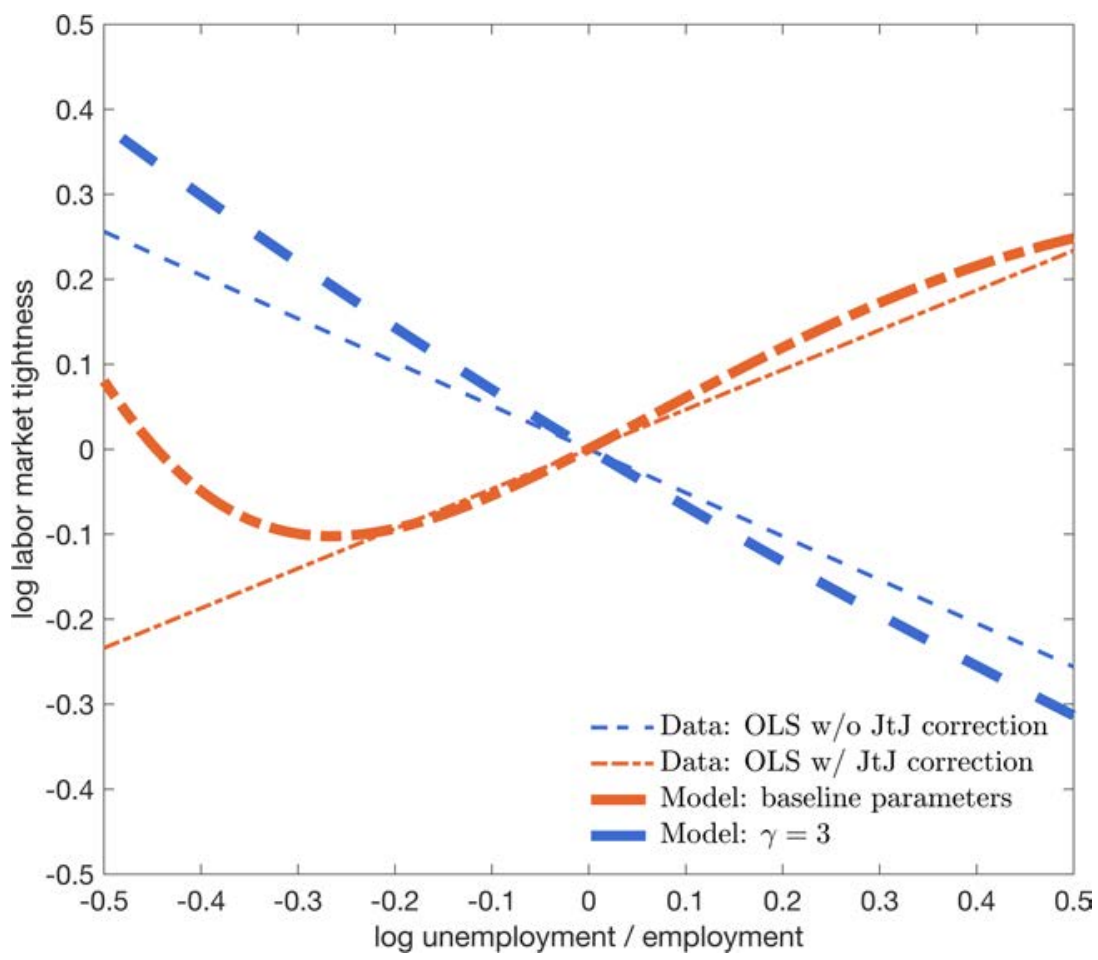

Note: Figure 15 plots the log of labor market tightness in the model at baseline parameters and when setting $\gamma=3$. It also plots regression lines from regressing labor market tightness onto the log unemployment-employment rate in the data, consistely with Figure 4(c). Figure 15 reports the regression lines with and without the job-to-job correction in the data.

Figure 16: Optimal policy: exact and approximation from Proposition 5.

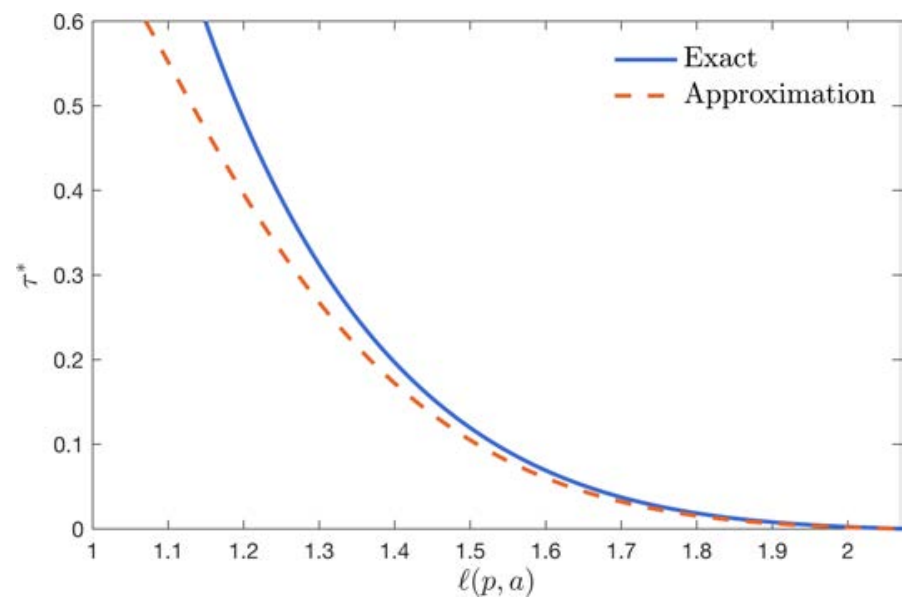

Note: Figure 16 plots two computations of the optimal gross profit subsidy across locations. The solid blue line represents the exact value. The dashed orange line represents the first-order approximation from Proposition 5. 